NBSIR 81-2450

\title{
Experimental Investigation of Transport of Discrete Solids With Surge Flows in $A$ 10.0 CM-Diameter Partially Filled Pipe
}

U.S. DEPARTMENT OF COMMERCE

National Bureau of Standards

National Engineering Laboratory

Center for Building Technology

Building Equipment Division

Washington, DC 20234

October 1981

Issued January 1982

Division of Energy, Building Technology and Standards

nffice of Policy Development and Research QCC partment of Housing and Urban Development sshington, DC 20410 



\section{EXPERIMENTAL INVESTIGATION OF}

TRANSPORT OF DISCRETE SOLIDS WITH

\section{SURGE FLOWS IN A}

10.0 CM-DIAMETER PARTIALLY

FILLED PIPE
MAR 41982

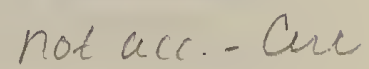

Bal M. Mahajan

U.S. DEPARTMENT OF COMMERCE

National Bureau of Standards

National Engineering Laboratory

Center for Building Technology

Building Equipment Division

Washington, DC 20234

October 1981

Issued January 1982

Division of Energy, Building Technology and Standards

Office of Policy Development and Research

Department of Housing and Urban Development

Washington, DC 20410

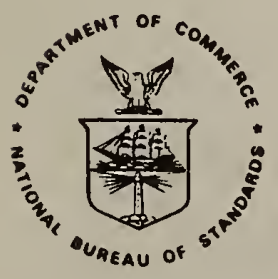

U.S. DEPARTMENT OF COMMERCE, Malcolm Baldrige, Secretary NATIONAL BUREAU OF STANDARDS, Ernest Ambler, Director 
-

4at a 350 and tristoth in

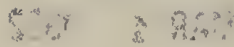




\section{ABSTRACT}

This report presents the results of a series of experiments on the transport of discrete solids with surge flows in a partially filled slightly pitched horizontal pipe. The experimental apparatus, instrumentation, and procedures are described.

The experiments were conducted, using a cylindrical solid in a 10.0-cm (4-in) diameter pipe. The water surge flows were obtained by discharging different volumes of water into the pipe from a falling head open container which simulated a water closet.

For each experiment, flow induced solid velocities and stream depth histories at various locations along the length of the pipe were measured. The effects of water volume used, pipe slope, and size of the solid, on the solid velocities were examined. Solid velocities were compared with the maximum water velocities estimated from the stream depth histories. Also, the distance traversed by the solids in the pipe were measured for those cases in which the solids did not clear the pipe.

The solid velocity increased with an increase in water volume used, a decrease in the size of the solid, and an increase in the pipe slope. The solid velocity in the initial reach of the pipe was less than the maximum water velocity; and the solid velocity approaches the maximum water velocity as the solid traveled downstream, except for some experiments with small water volumes.

The distance traversed by the solid increased with an increase in water volume, a decrease in the size of the solid, and an increase in the pipe slope.

The available data are too few to indicate any definitive conclusion, however, a comparison of data on solid transport in $7.6-\mathrm{cm}$ (reported in a prior publication) and $10.0-\mathrm{cm}$ pipe suggests that the $7.6-\mathrm{cm}$ pipe may be slightly better for transport of solids with small water volumes than the $10.0-\mathrm{cm}$ pipe. 


\section{PREFACE}

This report is one of a group documenting National Bureau of Standards (NBS) research and analysis efforts in developing water conservation test methods, analysis, economics, and strategies for implementation and acceptance. This work is sponsored by the Department of Housing and Urban Development/Office of Policy Development and Research, Division of Energy Building Technology and Standards, under HUD Interagency Agreement H-48-78. 


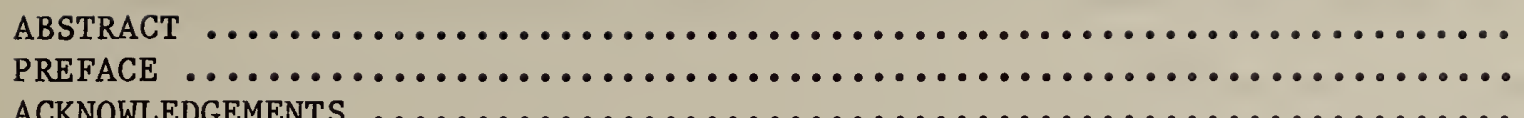

1. Introduction $\ldots \ldots \ldots \ldots \ldots \ldots \ldots \ldots \ldots \ldots \ldots \ldots \ldots \ldots \ldots \ldots \ldots \ldots \ldots \ldots \ldots \ldots$

2. Experimental Equipment and Procedures $\ldots \ldots \ldots \ldots \ldots \ldots \ldots \ldots \ldots \ldots \ldots \ldots$

2.1 Equipment $\ldots \ldots \ldots \ldots \ldots \ldots \ldots \ldots \ldots \ldots \ldots \ldots \ldots \ldots \ldots \ldots \ldots \ldots \ldots \ldots \ldots \ldots$

2.2 Procedures $\ldots \ldots \ldots \ldots \ldots \ldots \ldots \ldots \ldots \ldots \ldots \ldots \ldots \ldots \ldots \ldots \ldots \ldots \ldots \ldots \ldots$

3. Experimental Results and Discussion ....................... 6

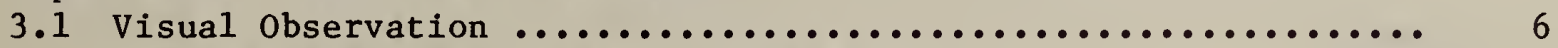

3.2 Maximum water Velocities in Surge Flows ................. 7

3.3 Solid Velocities ................................. 8

3.4 Distance Traversed by the Solids Within the Pipe .......... 11

3.5 Comparison of Solid Transport Data in 7.6 and $10.0 \mathrm{~cm}$ Diameter Pipes $\ldots \ldots \ldots \ldots \ldots \ldots \ldots \ldots \ldots \ldots \ldots \ldots \ldots \ldots \ldots \ldots \ldots \ldots$

4. Conclusions.$\ldots \ldots \ldots \ldots \ldots \ldots \ldots \ldots \ldots \ldots \ldots \ldots \ldots \ldots \ldots \ldots \ldots \ldots \ldots \ldots \ldots \ldots$

5. References ...................................... 13 
$\mathrm{A}_{\mathrm{W}}=$ portion of the pipe's cross-sectional area occupied by the water, or the flow cross-sectional area

$\mathrm{d}=$ diameter of the solid

$\mathrm{D}=$ diameter of the pipe

$h=$ depth of water stream

$\mathrm{L}=$ length of the solid

$\mathrm{n}=$ the Manning coefficient

$\mathrm{P}_{\mathrm{W}}=$ perimeter

$\mathrm{p}=$ pressure

$\mathrm{q}=$ volume flow rate

$\mathrm{R}=\mathrm{A} / \mathrm{P}_{\mathrm{W}}=$ hydraulic radius

$S=$ pipe slope $\sin \theta$

$\mathrm{S}_{\mathrm{f}}=$ energy gradient or slope of the energy line

$t=$ time

$\mathrm{T}=$ time period (or duration) of the surge flow through a cross-section (location) of the pipe

$\mathrm{U}_{\mathrm{S}}=$ solid velocity

$\mathrm{U}_{\mathrm{W}}=$ water velocity

$\mathrm{U}_{\mathrm{m}}=$ maximum value of water velocity

$\mathrm{V}_{\mathrm{W}}=$ total volume of water used in an experiment

$X=x$-axis or the axial distance along the length of the pipe

\section{Greek Symbols}

$\theta=$ pipe slope angle

$\lambda=h / D$

$\mu=\left(\sqrt{S_{f}}\right) / n$ 
Subscript

m refers to maximum value

$t$ refers to instantaneous values 



\section{INTRODUCTION}

Need for water conservation has drawn attention to the large quantities of water used in water closet (WC) operations and to a variety of means to curtail this use. Water closets consume about 195 liters [50 gallons] per person per day [1-4]*. This figure represent 40 percent of the total water consumed in a residence. It has been estimated that a reduction of 30 to 50 percent can be realized by replacing conventional WC's (19-26 liters per flush) with the currently available low-volume water-saving units (11-13 liters per flush), and a reduction of up to 90 percent of this water usage is possible if the conventional syphonic-flush WC's are replaced with innovative units [5].

Some researchers and plumbing professionals [5-8] however, have expressed concern about the use of low-volume WC's. These concerned professionals indicate that the use of low-volume WC's may reduce the wastewater flow in the horizontal branches of the gravity drainage system below levels necessary for the transport of waterborne solid waste, impairing the effectiveness of the drainage system.

To minimize the likelihood of drain clogging with reduced water usage, the drain pipes serving WC's should be properly designed. That is the selected pipe variables (diameter, length, and slope or pitch) should be such that the volume of water used in the WC's operation can adequately transport the solid waste through the drain. The theoretical and/or empirical relationships among the water volume used, drain pipe variables, hydraulic parameters of the flow in the pipe, and solid waste transport, however, are not well established.

The study presented in this report is part of a research program under way to investigate the transport mechanism of solids in slightly pitched horizontal drains and to develop the data base and establish correlations needed for selecting drain pipe design variables for effective solid waste transport with reduced water usage.

Data acquired earlier, during the exploratory experiments in a $76-\mathrm{mm}$ ( 3 in) diameter pipe has been presented in two separate reports $[9,10]$. The data of reference 9 indicated that the surge flow induced solid velocity and the distance traversed by the solid increased with: (a) an increase in the volume of water used; (b) an increase in the pipe slope; and (c) a decrease in the diameter and length of the solid.

The data of reference 10 indicated that: (a) the water stream depth at any given cross-section (or location) of the pipe rose rapidly to a peak value and then gradually fell off to zero; (b) the peak value of stream depth decreased with an increase in the distance from the pipe entrance for a given volume of water used; (c) at a given location the peak value of the stream depth increased with an increase in the volume of water used, a decrease in the pipe slope and with the presence of a solid in the pipe; and (d) the flow blockage produced by

* Numbers in brackets indicate references listed at the end of the report. 
a solid depended upon the size of the solid as well as its velocity relative to the local flow velocity.

The data acquired during the earlier experiments did not allow for a comparison of the flow-induced solid velocities $\left(U_{S}\right)$ with the maximum water velocities $\left(U_{m}\right)$. The solid velocities were measured in only 2 or 3 locations of the pipe, and the water depth data were not suitable for estimating the values of $U_{m}$. For this experiment the instrumentation was upgraded so that the data gathered would provide for a comparison of $\mathrm{U}_{\mathrm{S}}$ and $\mathrm{U}_{\mathrm{m}}$.

The objectives of the experimental study presented in this report were: (a) to measure the water flow-induced solid velocities at several locations along the length of the pipe; (b) to examine the effects of water volume used, size of the solid, and pipe slope on the solid velocity; (c) to estimate maximum velocity of water at various locations along the length of the pipe, and compare the solid velocity to the maximum water velocity; and (d) to measure the distance traversed by solids in the pipe for those cases in which the solid do not clear the pipe.

The data and results of the experimental studies will be utilized to validate and refine the mathematical models that are being developed for predicting the flow-induced motion of solids in pipes. Considerable work on modeling the partially filled pipe flows $[11,12,13]$, and motion of the solid in partially filled pipes [14] has already been completed. The mathematical models along with these data will provide a basis for establishing design recommendation for drain pipe diameter, length and slope for an effective waste transport with low water usage. 


\section{EXPERIMENTAL EQUIPMENT AND PROCEDURE}

\subsection{EQUIPMENT}

The apparatus used in the experiment is shown schematically in figure 1 . It is similar to the apparatus used in the earlier experimental work reported in references 1 and 2 . A right circular cylindrical tank containing a flush valve and down pipe is utilized to simulate a water closet; the flush valve is operated by a solenoid switch. The down pipe is connected by a 90-degree elbow to a 10.0-cm (4-in) diameter PVC pipe about $5 \mathrm{~m}$ (16.4 ft) long which simulates a pitched horizontal drain. At the drain inlet, a tee is provided adjacent to the elbow to permit insertion of the selected solid. The drain pipe is transparent, to facilitate visual observation of the transport phenomena. The pipe is mounted on several stands, which can be adjusted to establish the desired pitch or slope of the pipe. The exit end of the drain is about $4.8 \mathrm{~m}$ downstream of the solid starting line. The efflux from the drain is caught in a container for proper disposal. All pipes and fittings used to construct the apparatus are of standard plumbing sizes used in the United States.

Hollow right circular cylinders with flat ends were used as experimental solids. These cylinders were constructed from opaque and rigid plastic tubing. One end of the hollow cylinder is completely plugged; the plug on the other end contain a concentric threaded hole which can be closed with a threaded cap (figure 2 ). The end plugs and threaded caps were made from the same plastic material and were so constructed that the center of gravity of the closed cylinder coincide with its geometric center. The hollow cylinder with threaded cap permitted the specific gravity of the solids to be adjusted to unity. The length to diameter ratio of the cylindrical solids used in the experiments is given in table $A$.

Table A.

Length to Diameter Ratio of the Nine Cylindrical Solids Used in the Experiment

\begin{tabular}{llllllllll}
\multicolumn{1}{c}{ No. } & 1 & 2 & 3 & 4 & 5 & 6 & 7 & 8 & 9 \\
Length (cm) & 2.5 & 2.5 & 2.5 & 5.1 & 5.1 & 5.1 & 7.6 & 7.6 & 7.6 \\
Diameter (cm) & 2.5 & 3.2 & 3.8 & 2.5 & 3.2 & 3.8 & 2.5 & 3.2 & 3.8 \\
L/d & 1.00 & 0.80 & 0.67 & 2.00 & 1.60 & 1.33 & 3.00 & 2.40 & 2.00
\end{tabular}

Strain gauge pressure transducers are utilized to measure the depth of water in the tank (i.e., simulated WC) as well as in the pipe. The pressure transducers are connected to pressure taps, or small holes, situated at the bottom of the tank and at the lowest point of the pipe cross-section (see figure 1). The locations of the seven pressure transducers, numbers $P_{1}$ through $P_{7}$, used in the experimental study are shown in figure 1 . Pressure transducer $P_{1}$, located at the bottom of the tank, measures the water depth history of the water in the tank when the tank is being flushed. Pressure transducers $\mathrm{P}_{2}$ through $\mathrm{P}_{7}$, 
located at specific distances along the length of the pipe measure the water stream depth histories of the surge flow through the pipe.

The outputs of the pressure transducers are amplified and fed into an A/D converter of a micro-computer and subsequently recorded on a floppy disk. The computer is programmed to record the water depth data for each of the seven pressure transducers at 0.1 second intervals for a total of sixty seconds, starting with the activation of the flush valve.

Photodetectors, identical to those used in the earlier experimental work [1], are utilized for measuring the velocities of the solids in the pipe. However, a microcomputer was used for data acquisition instead of the automatic timers used in the earlier work. Also, the velocity of a solid is measured within six different sections of the pipe as compared to only three in the previous work.

Seven photodetectors, numbers $D_{1}$ through $D_{7}$, are situated at specific distances apart along the length of the pipe as indicated in figure 1. When a solid passes through the pipe cross-section containing the photodetector, the light to the photocell is interrupted and an electric signal is generated. The microcomputer records the time of the generated signals in miliseconds on a floppy disk. The velocity of the solid is computed from the time interval required for the solid to pass between two photodetectors located at known distance apart. The microcomputer is programed to calculate the average velocity of a solid within six different sections of the pipe: namely the sections between photodetectors $\mathrm{D}_{1}$ and $\mathrm{D}_{2}, \mathrm{D}_{2}$ and $\mathrm{D}_{3}, \mathrm{D}_{3}$ and $\mathrm{D}_{4}, \mathrm{D}_{4}$ and $\mathrm{D}_{5}, \mathrm{D}_{5}$ and $\mathrm{D}_{6}$, and $\mathrm{D}_{6}$ and $\mathrm{D}_{7}$.

\subsection{PROCEDURE}

The slope of the pipe was adjusted to the desired value. The data collection system (i.e., the computer, photodetectors, pressure transducers, amplifiers, etc.) was activated. The selected volume of water resting in the tank was released by the flush valve into the empty pipe. The depth histories of water flowing through the pipe cross-sections containing the pressure transducers was recorded. These data were later used to estimate the maximum velocity of water in surge flow at each location.

Next, a selected cylindrical solid was inserted through the tee opening, and placed on the lower wall of the empty pipe with its upstream end aligned with the solid starting line and its axis aligned with the drain axis as indicated in figure 1. With the solid at rest in the pipe, the selected volume of water was flushed from the tank into the pipe. The passage of the solid through the pipe cross-sections containing the photodetectors was timed by the microcomputer. From these data the average velocity of the solid within various pipe sections was calculated and stored on a floppy disk along with the solid passage time data.

Solid transport experiments were conducted with only one solid in the pipe at a time. Each experiment was run twice. The selected variables were: water volumes equal to $1.0,1.5,2.0,3.0,4.0,6.0$ and 8.0 liters; pipe slopes equal to $0.02,0.04$, and 0.06 ; no solid in the pipe; and with a single cylindrical solid in the pipe with dimensions shown in table $A$. 


\subsection{VISUAL OBSERVATIONS}

Observations of the surge flow and solid transport phenomenon revealed information identical to that observed previously during the earlier experimental work $[9,10]$. A summary of the observations is presented below.

The water flushed from the tank into the empty pipe streamed through the pipe unobstructed. The drain pipe was only partially filled and the depth of water stream was both nonuniform and unsteady. At a given pipe cross-section, stream depth rose rapidly to a peak value and then gradually fell off to zero. The peak value of depth decreased as the distance from the drain entrance increased.

When the water from the tank was flushed into the pipe containing a solid, the flow through the pipe basically displayed the above mentioned patterns with the following differences. The stationary solid partially blocked the flow, producing "backwater" effects on the flow (figure 3), and forcing the water to rush through the crescent shaped space between the solid and the pipe wall. The flow blockage produced by the solid appeared to be a function of the velocity of the solid relative to the local water velocity, because stationary solids and/or slow moving solids produced larger "backwater" effects than faster moving solids.

The stationary solid, in addition to its weight component, is also subjected to the following water flow induced forces in the downstream direction: a pressure force due to the unequal water depth and velocity on the opposite ends of the solid; and a shear force due to the streaming of water past the solid. In addition, the solid is also subjected to buoyancy force, equal in magnitude to the weight of water displaced by the solid, acting in an upward direction. These forces increase with the volume of water flow through the pipe.

When the forces acting on the solid in the downstream direction overcame the force of friction between the solid and the pipe wall, the solid started to move and accelerate. The motion of the solid within the pipe was greatly dependent upon the water volume used and the size of the solid. When water volumes equal to $1.0,1.5$ and 2.0 liters were used, the solid, regardless of its size, dragged on a thin film of water on the lower wall of the pipe; and when the water influx behind the solid declined, the solid started to decelerate. The decelerating solid during some experiments stopped within the pipe with some water still present in the pipe behind the solid. The remaining water then flowed through the crescent shaped space between the solid and the pipe. Smaller solids travelled farther in the pipe than the larger solids when equal volumes of water were used.

When water volumes equal to $3.0,4.0,6.0$ and 8.0 liters were used, the solid moved on a thick film of water between the solid and pipe wall; and the solid accelerated quickly to a maximum or terminal velocity. During all experiments with these water volumes, the solid cleared the pipe with a major portion of the water exiting the pipe after the solid. 


\subsection{MAXIMUM WATER VELOCITIES IN SURGE FLOWS}

Water velocity, $\mathrm{J}_{\mathrm{w}}$, and volume flow rate, $q$, of steady (uniform as well as gradually varied) water flows through partially filled pipes at any pipe crosssection are related to the depth of water through the hydraulic radius by the Manning equation [15]:

$$
\begin{aligned}
\mathrm{U}_{\mathrm{w}} & =\mathrm{R}^{2 / 3}\left(\sqrt{\mathrm{S}_{\mathrm{f}}}\right) / \mathrm{n} \\
\mathrm{q} & =\mathrm{A}_{\mathrm{w}} \mathrm{R}^{2 / 3}\left(\sqrt{\mathrm{S}_{\mathrm{f}}}\right) / \mathrm{n}=\mathrm{A}_{\mathrm{w}} \mathrm{U}_{\mathrm{w}}
\end{aligned}
$$

where various terms are defined in the nomenclature.

The Manning equation is not directly applicable to surge flows because the energy gradient, $S_{f}$, is variable. Nevertheless, approximate values of instantaneous velocity, $U_{t}$, may be computed from the stream depth history data by the use of the Manning equation as follows:

$$
\begin{aligned}
& \mathrm{U}_{t}=\mathrm{R}_{\mathrm{t}}^{2 / 3}\left[\left(\sqrt{\mathrm{s}_{\mathrm{f}}}\right) / \mathrm{n}\right]_{t}=\mathrm{R}_{\mathrm{t}}^{2 / 3} \mu_{t} \simeq \mathrm{R}_{\mathrm{t}}^{2 / 3} \bar{\mu} \\
& \mathrm{q}_{\mathrm{t}}=\mathrm{A}_{\mathrm{wt}} \mathrm{R}_{\mathrm{t}}^{2 / 3}\left[\left(\overline{\sqrt{\mathrm{s}_{f}}}\right) / \mathrm{n}\right]_{t} \simeq \mathrm{A}_{\mathrm{wt}} \mathrm{R}_{\mathrm{t}}^{2 / 3} \bar{\mu}
\end{aligned}
$$

where, $\mu=\left(\sqrt{\mathrm{S}_{f}}\right) / \mathrm{n}$; and $\bar{\mu}$ is the average value of $\mu$ at a given pipe location (cross-section) for a given surge flow.

The value of $\bar{\mu}$ at any pipe location for a given surge flow may be computed from the stream depth history data at that location, and the fact that the total volume of water flushed from the tank passes through the location during the time period of the surge duration, $\mathrm{T}$, at the location, or

$$
v_{w}=\int_{0}^{T} q_{t} d t=\Gamma_{0}^{T} q_{t} \Delta t
$$

or, substituting for $\mathrm{q}_{t}$ from equation (4) and rearranging

$$
\bar{\mu}=V_{W} /\left[\left(D^{2} / 4\right)(D / 4)^{2 / 3} \mathrm{~K}\right]
$$

where: $K=\int_{0}^{T} f\left(\lambda_{t}\right) \phi^{2 / 3}\left(\lambda_{t}\right) d t=\sum_{0}^{T} f\left(\lambda_{t}\right) \phi^{2 / 3}\left(\lambda_{t}\right) \Delta t$

$$
\begin{aligned}
f(\lambda) & =4 A_{w} / D^{2}=\left[\cos ^{-1}(1-2 \lambda)-2(1-2 \lambda) \sqrt{ }\left(\lambda-\lambda^{2}\right)\right] \\
\phi(\lambda) & =4 R / D=\left\{1-\left[2(1-2 \lambda) \sqrt{ }\left(\lambda-\lambda^{2}\right) / \cos ^{-1}(1-2 \lambda)\right]\right\} \\
\text { and } \lambda & =h / D
\end{aligned}
$$


During a surge flow the instantaneous water velocity will be maximum when $\phi\left(\lambda_{t}\right)$ is maximum, and $q_{t}$ will be maximum when the quantity $\left[f\left(\lambda_{t}\right) \phi^{2 / 3}(\lambda t)\right]$ is maxmum. For flow through circular pipes, $\phi(\lambda)$ initially increases as $\lambda$ is increased, attains the maximum value when $\lambda$ is about 0.81 , and then starts to decrease as $\lambda$ is further increased. The quantity $\left[f(\lambda) \phi^{2 / 3}(\lambda)\right]$ follows a trend similar to that for $\phi(\lambda)$, however, it attains the maximum value when $\lambda$ is about 0.94. For all the experimental surge flows in this study, the measured values of $\lambda$ (i.e., stream depth divided by the pipe diameter) were less than 0.5. Hence, for these flows the $U$ and $q$ will be maximum when $\lambda$ is maximum. Equations ( 3 ) may be rewritten for the maximum values of water velocity, $U_{m}$, in a surge flow as:

$$
\mathrm{J}_{\mathrm{m}}=\left[\left(4 \mathrm{~V}_{\mathrm{W}} / \mathrm{D}^{2}\right) \phi^{2 / 3}\left(\lambda_{\mathrm{m}}\right)\right](1 / \mathrm{K})
$$

The maximum water velocities in surge flows at different pipe locations, with no solid in the pipe, were computed numerically from the stream depth history data utilizing equation (11). The typical results of the computations are presented in figures 4 to 6 as the maximum water velocity versus nondimensional axial distance from the solid starting line or the pipe entrance (X/D). Figures 4,5 and 6 respectively are, for a pipe slope of $0.02,0.04$ and 0.06 , and each figure show data for several water volumes. The values of $\mathrm{U}_{\mathrm{wm}}$, for a given water volume, are also plotted as solid lines in figures 17 to 43 along with the solid velocity data for the purpose of comparison.

An examination of these figures indicates the followings: (1) The maximum water velocity at a given station increases as the value of $\mathrm{V}_{\mathrm{W}}$ increases; (2) Um, in general, increases as the $\mathrm{S}$ is increased except at pipe location $\mathrm{P}_{3}$ ( $\mathrm{i} . \mathrm{e}$, the pipe cross-section where pressure transducer $\mathrm{P}_{3}$ is situated); (3) $\mathrm{I}_{\mathrm{m}}$, in general, decrease as the distance from location $\mathrm{P}_{2}$ increases except for location $\mathrm{P}_{3}$; (4) It appears that depending upon the value of $V_{W}$ and $S$, the surge flows experience a "hydraulic drop" or a "hydraulic jump" in the vicinity of location $P_{3}$; and that the location $\mathrm{P}_{3}$ which is about 6 pipe diameters downstream of the solid starting line or about 9 pipe diameters from the elbow is within the transition zone where the swirls and/or eddies due to the change in the flow direction cause this odd behavior of the surge flow.

\subsection{SOLID VELOC.ITIES}

The velocity of the solid was measured in six different sections of the pipe The positions of. the photodetectors $D_{1}$ through $D_{7}$ are shown in figure 1 . The average values of the solid velocities within each respective section are denoted by Vel. 非 through Vel. \#6; and each velocity is considered to represent the solid velocity at an axial distance equal to the axial distance of the center of the respective section. Hence, referring to figure 1, the nondimensional axial distance $(X / D)$ from the solid starting position corresponding to velocities Vel. 非 1 to Vel. 非 6 respectively is about $2.3,3.8,5.3,14.5$, 31.8, and 42.2. The solid velocity data is presented in figure 7 to 43 .

Figures 7 to 16 show the data as solid velocity versus water volume. Each figure show only two of the six solid velocities, namely Vel. Figures 7,8 , and 9 respectively show the data for $2.5,5.1$ and $7.6 \mathrm{~cm}$ long 
solids for a pipe slope of 0.02 . Figures 10,11 , and 12 respectively show the data for $2.5,5.1$ and $7.6 \mathrm{~cm}$ long solids for a pipe slope of 0.04 . Figures 13, 14 , and 15 respectively show the data for $2.5,5.1$ and 7.6 long solids, for a pipe slope of 0.06 . Figure 16 show the data for a 3.5 by $5.1 \mathrm{~cm}$ solid for all three pipe slopes.

Figures 17 to 43 show the data as solid velocity versus $X / D$ (the nondimensional axial distance from the solid starting line). Each figure show average solid velocity data for: all three solid diameters; one value of solid length; one value of water volume, and one value of pipe slope. Each of these figures, also show the maximum water velocities as a line for the surge flow for the indicated values of water volume $\left(V_{W}\right)$ and pipe slope $(s)$ with no solid in the pipe. The maximum water velocity data are reproduced from figures 4 to 6 .

Effects of the experimental variables (i.e., water volume used, size of the solid, and the pipe slope) on the velocity attained by the solid are similar to those indicated by the data of earlier experiments conducted in a $7.6-\mathrm{cm}$. diameter pipe $[9,10]$. A discussion of these effects is presented below.

Variations of solid velocity with water volume used. An examination of these data, particularly of figures 7 to 15, indicates that the velocity of solid generally increases with an increase in $V_{W}$ (i.e., the water volume used). The data presented in these figures also suggest that the incremental increase in the solid velocity with an incremental increase in the water volume used is larger for small water volumes $\left(V_{W} \leq 3 l\right)$ than that for large water volumes $\left(V_{W}\right.$ $\geq 3 \mathrm{l}$ ). This pattern of incremental change in the water volume on the solid velocity may be interpreted as follows: when the depth of the water stream in the drain is relatively small and the solid is dragging on a very thin film of water between the solid and the pipe wall, a small increase in the amount of water volume used substantially increases the depth of water stream in the drain and the thickness of the water film between the solid and the pipe wall and reduces the friction; this pattern of solid-water movements was observed when small water volumes $\left(V_{\mathrm{W}} \leq 3 \ell\right)$ were used. With large water volumes $\left(V_{\mathrm{W}}>3 \ell\right)$ the depth of the water stream in the drain is relatively large and the solid is not dragging on a thin film of water but moving as a waterborne object, an increase in the stream depth due to further increase in water volume used has little or no effect on the friction; and any increase in solid velocity is primarily due to an increase in the water velocity. This pattern of solid-water movement was observed when large water volumes were used. This pattern of the solid velocities dependence on the water volume used suggests that the depth of water stream in the drain is a significant parameter for solid transport.

Variations of the velocity of solid with its size. An examination of these data indicates that the velocity attained by the solid generally decreases with an increase in the size of the solid, that is with an increase in the diameter and/or length of the solid.

In general, the incremental increase in the solid average velocity with incremental change in its size is larger for relatively small water volumes $\left(V_{\mathrm{W}} \leq 3 \ell\right)$ than that for relatively large water volumes $\left(V_{\mathrm{w}}>3 \ell\right)$. It appears that for small water volumes, since the solid drags on a thin film of water 
between the pipe and the solid, an increase in the solid size increases the force of friction significantly; and both the increase in the friction force and in the mass of the solid decrease the acceleration of the solid. For large water volume, since the solid moves as a waterborne object; an increase in the size of the solid has little or no effect on the friction force; and the decrease in the acceleration of the solid is primarily due to the increase in the mass of the solid.

Variation of solid velocity with the pipe slope. An examination of these data, particularly of figure 16, indicates that the velocity attained by a solid, in general, increase with an increase in the pipe slope (S), except with water volumes equal to 1.0 and 1.5 in the initial reach (length) of the pipe which represents the transition zone for the surge flow. For those water volumes, in the initial reach of the pipe the velocity of a solid was minimum for $S=$ 0.02 and maximum for $\mathrm{S}=0.04$. It was observed earlier, in section 3.2 , that in the transition zone the maximum water velocities for $S=0.04$ were larger than that for $S=0.06$. It appears, therefore, that velocity attained by a solid is strongly dependent upon the maximum value of local water velocity which in turn is a complex function of $S, V_{W}$ and axial distance from the pipe inlet.

Variations of solid velocity with the axial distance and its comparison with the local maximum water velocity. An examination of figures 17 to 43 indicates the following: Solid velocity first increases with an increase in the axial distance from the solid starting line, reaches a maximum value and then starts to decrease as the axial distance is further increased.

The magnitude of solid velocity, $\mathrm{U}_{S}$, is less than the magnitude of the local maximum water velocity, $U_{m}$, throughout the pipe for all experiments at a pipe slope of 0.02 and for experiments with water volumes less than 2 liters at pipe slopes of 0.04 and 0.06 . For all other experiments at pipe slopes of 0.04 and $0.06, U_{s}$ is less than $U_{m}$ only in the initial reach (initial length) of the pipe, and $U_{S}$ approaches $U_{m}$ as the solid travels downstream. For experiments with water volumes equal to or greater than 2 liters, $U_{s}$ approaches $U_{m}$ at an axial distance of about 14.5 and 5 pipes diameters for pipe slopes of 0.04 and 0.06 respectively.

The difference between $U_{m}$ and $U_{s}$ appears to be a function of water volume used, pipe slope, size of the solid, and the axial distance from the solid starting line, or

$\mathrm{U}_{\mathrm{m}}-\mathrm{U}_{\mathrm{S}}=\mathrm{U}_{\mathrm{x}}\left[\mathrm{V}_{\mathrm{w}}, \mathrm{S}, \mathrm{d}, \mathrm{L}\right.$, and $\left.\mathrm{x}\right]$

or

$$
\mathrm{U}_{\mathrm{S}}=\mathrm{U}_{\mathrm{m}}-\mathrm{U}_{\mathrm{x}}\left[\mathrm{V}_{\mathrm{W}}, \mathrm{S}, \mathrm{d}, \mathrm{L} \text {, and } \mathrm{x}\right]
$$

where, $\mathrm{U}_{\mathrm{X}}$ is a complex function of the experimental variables and axial distance from the solid starting line, and has the dimensions of velocity.

\subsection{DISTANCE TRAVERSED BY THE SOLID WITHIN THE PIPE}

It was noted previously in the discussion of visual observations that only during experiments with water volumes equal to $1.0,1.5$, and 2.01 iters some of 
the solids stopped within the pipe. All solids cleared the pipe during experiments with water volume equal to $3.0,4.0,6.0$, and 8.0 liters. Hence the data on the distance traversed by the solid within the pipe are limited. These data are summarized in table 1.

An examination of these data indicates that, in general, the distance traversed by the solid increases with: an increase in the water volume used; a decrease in solid diameter and length; and increase in the pipe slope. However, the number of data points are too small to obtain quantitative relationships.

\subsection{COMPARISON OF SOLID TRANSPORT DATA IN 7.6 AND 10.0 CM DIAMETER PIPES}

The data on the surge flow induced solid velocities and the distance traversed by the solid in a $7.6 \mathrm{~cm}$ diameter pipe has been reported earlier in reference 9. Similar solid transport data in a $10.0 \mathrm{~cm}$ diameter pipe are presented in this report. These data indicate the following:

1. The effects of the experimental variables (i.e., water volume, pipe slope, diameter and length of solid) on the solid velocity, and distance traversed by the solid are similar in both cases.

2. Measured values of average solid velocities at comparable pipe locations in the $7.6 \mathrm{~cm}$ pipe, in general, have a larger magnitude than those in the $10.0 \mathrm{~cm}$ pipe; and the difference is dependent upon the other experimental variables. The difference noted range between zero to about twenty percent.

3. The comparable solids which stopped in the pipe, in general, traversed a longer distance in the $7.6 \mathrm{~cm}$ pipe than that in the $10.0 \mathrm{~cm}$ pipe. The data for the distance traversed by the solids in the $7.6 \mathrm{~cm}$ pipe is reproduced and presented in table 2 for comparison.

\section{CONCLUSIONS}

The velocity attained by a solid increases with an increase in the water volume. The incremental increase in the average solid velocity with an incremental increase in the water volume is larger for small water volumes (1-3 liters) than for large water volumes (3-8 liters).

The average solid velocity decreases with an increase in the size of the solid (i.e., the diameter and/or length), and it increases with an increase in the pipe slope.

The average solid velocity at first increases, reaches a maximum value, and then starts to decrease as the axial distance from the starting reference increases. The magnitude of solid velocity is less than the maximum water velocity in the initial reach (initial length) of the pipe. The solid velocity approaches the maximum water velocity as the axial distance is further increased (or as the solid travels downstream), except for the experiments with $1.0,1.5$, and 2.0 liters of water. For these experiments the solid velocity is always less than the maximum water velocity; and in some cases the solid stopped within the pipe. 
The distance traversed by the solid within the pipe increases with an increase in the water volume used, an increase in pipe slope, and a decrease in the size of the solid.

The effects of the experimental variables on the solid velocity, and distance traversed by the solid, and stream depth history are similar to those found during the earlier experimental work with a $7.6-\mathrm{cm}$ diameter pipe.

Under comparable experimental conditions, the solid velocities in a $7.6-\mathrm{cm}$ pipe are somewhat larger $(0 \rightarrow 20$ percent $)$ than those in the $10.0-\mathrm{cm}$ pipe. The solid which stopped within the pipe, in general, traversed a slightly longer distance in the $7.6-\mathrm{cm}$ pipe than that in the $10.0-\mathrm{cm}$ pipe. The available data are too few to draw any definitive conclusions, however, these data suggest that smaller $7.6-\mathrm{cm}$ pipe may be slightly better for the transport of solids with small water volumes than the $10.0-\mathrm{cm}$ pipe.

\section{ACKNOWLEDGMENTS}

The author wishes to express his gratitude to Ms. Laura Sampson for her contribution to data acquisition and data processing, Mr. Michael J. McCall for his contribution to apparatus assembly, and $\mathrm{Mr}$. Paul A. Kopetka for contributing to apparatus assembly and data processing. 


\section{REFERENCES}

1. Bailey, J.R., et al., "A Study of Flow Reduction and Treatment of Waste Water from Households," Water Pollution Control Research Series 11050 FKE Cincinnati, Ohio: Advanced Waste Treatment Research Laboratory, 1967.

2. Konen, T.P., "A Review of the Hydraulic of Gravity Drainage, Waste and Vent Systems," Edward J. Zimmer Memorial Reference Course, Orlando, Florida, 1977.

3. Fowell, A.J., et al., "Water and Water Related Conservation in Buildings," Proceedings of International Symposium on Water Supply and Draiange, September 1976, NBS Special Publication 533.

4. Sharp, W.E., "Water Conservation with Water Savings Devices," Paper presented at the New Jersey Conference on Water Conservation, Rutgers University, New Jersey, 1976.

5. Cole, A.C., "Impact of Home Water Saving Devices on Collection Systems and Waste Treatment," Proceedings of Conference on Water Conservation and Sewage Flow Reduction with Water Savings Devices, Pennsylvania State University, University Park, Pennsylvania, April 1975.

6. Wyly, R.S., et al., "Hydraulics of Gravity Drainage," Proceedings of International Symposium on Water Supply and Drainage, September 1976, NBS Special Publication 533.

7. Wertz, R.J., "A Plumbing Manufacturer's Viewpoint on Water Savings Devices," Proceedings of the Conference on Water Conservation and Sewage Flow Reduction with Water Saving Devices, Pennsylvania State University, University Park, Pennsylvania.

8. Sampler, D.L., "Water Conservation: Prospects and Problems," Proceedings of National Conference on Water Conservation and Municpal Wastewater Flow Reduction, Chicago, Illinois, November 1978.

9. Mahajan, Bal M., "Experimental Investigation of Transport of Finite Solids in a $76 \mathrm{~mm}$ - Diameter Partially-Filled Pipe", NBS Report No., NBSIR 812266, April 1981.

10. Mahajan, Bal M., "Unsteady Water Depth Measurement in a Partially-Filled $7.6 \mathrm{~cm}$ Diameter Horizontal Pipe", NBS Report No., NBSIR 81-2249, April 1981 .

11. Swaffield, J. A., "Entry Transition Water Surface Profile Prediction in Supercritical Partially Fitted Pipe Flow", NBS Report No. NBSIR 91-2290, June 1981. 
12. Swaffield, J. A., "Prediction of the Hydraulic Jump Location Following a Change of Slope in Partially Filled Drainage Pipe", NBS Report No. NBSIR 81-2367, May 1981.

13. Swaffield, J. A., "An Initial Study of the Application of the Numerical Method of Characteristics to Unsteady Flow Analysis in Partially Filled Gravity Drainage Sized Pipes", NBS Report No. NBSIR 81-2308, July 1981.

14. Swaffield, J. A., "Dependence of Model Waste Solid Transport Characteristics in Drainage Systems on Solid Geometry, Mass and Pipe System Parameters", NBS Report No. NBSIR 81-2307, July 1981.

15. Chow, V.T., "Open-Channe1 Hydraulics," McGraw-Hil1 Book Company, New York, 1959. 



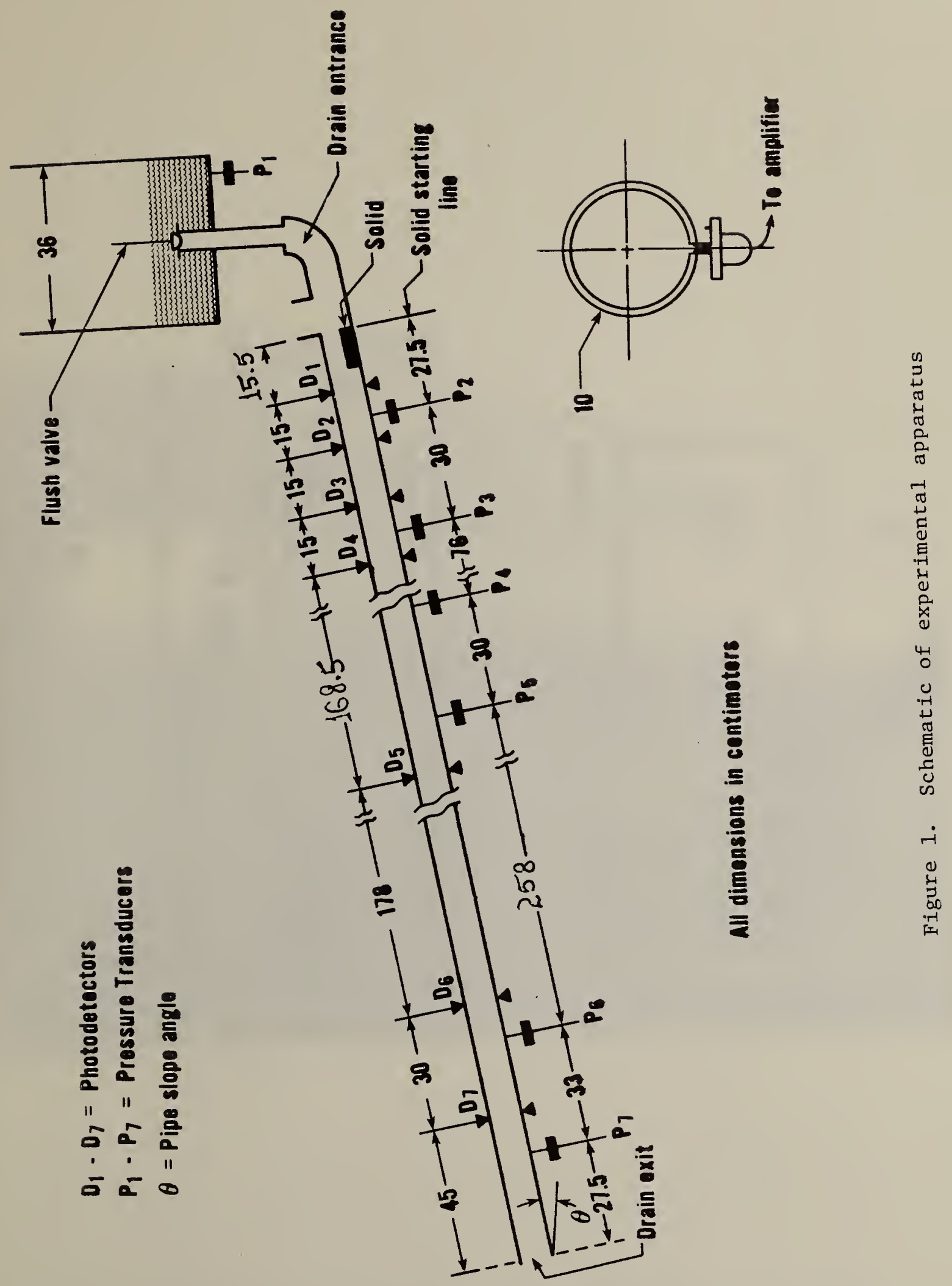



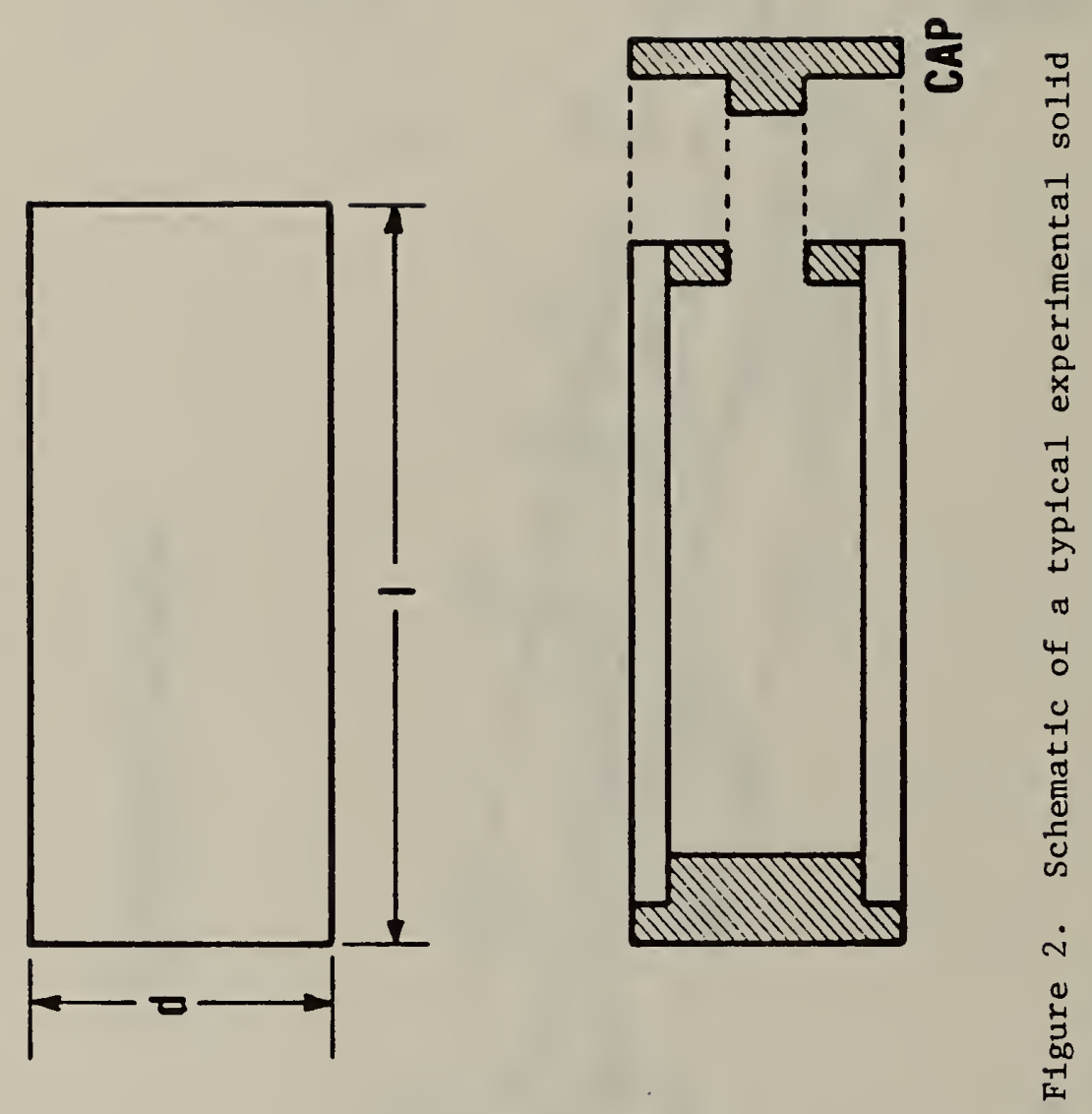


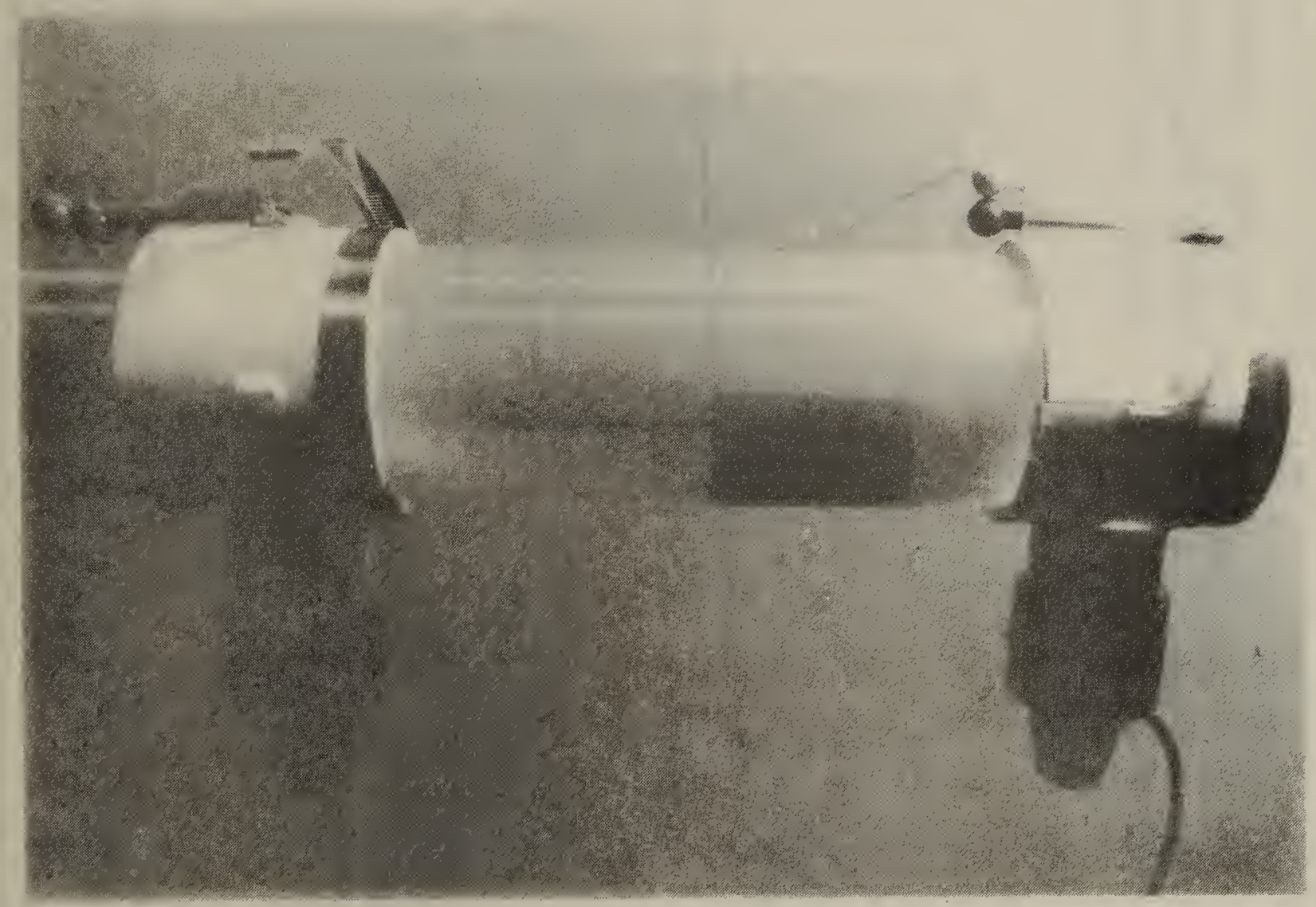

Figure 3. Photograph showing the "backwater effects" of a solid on the partially-filled pipe flow 


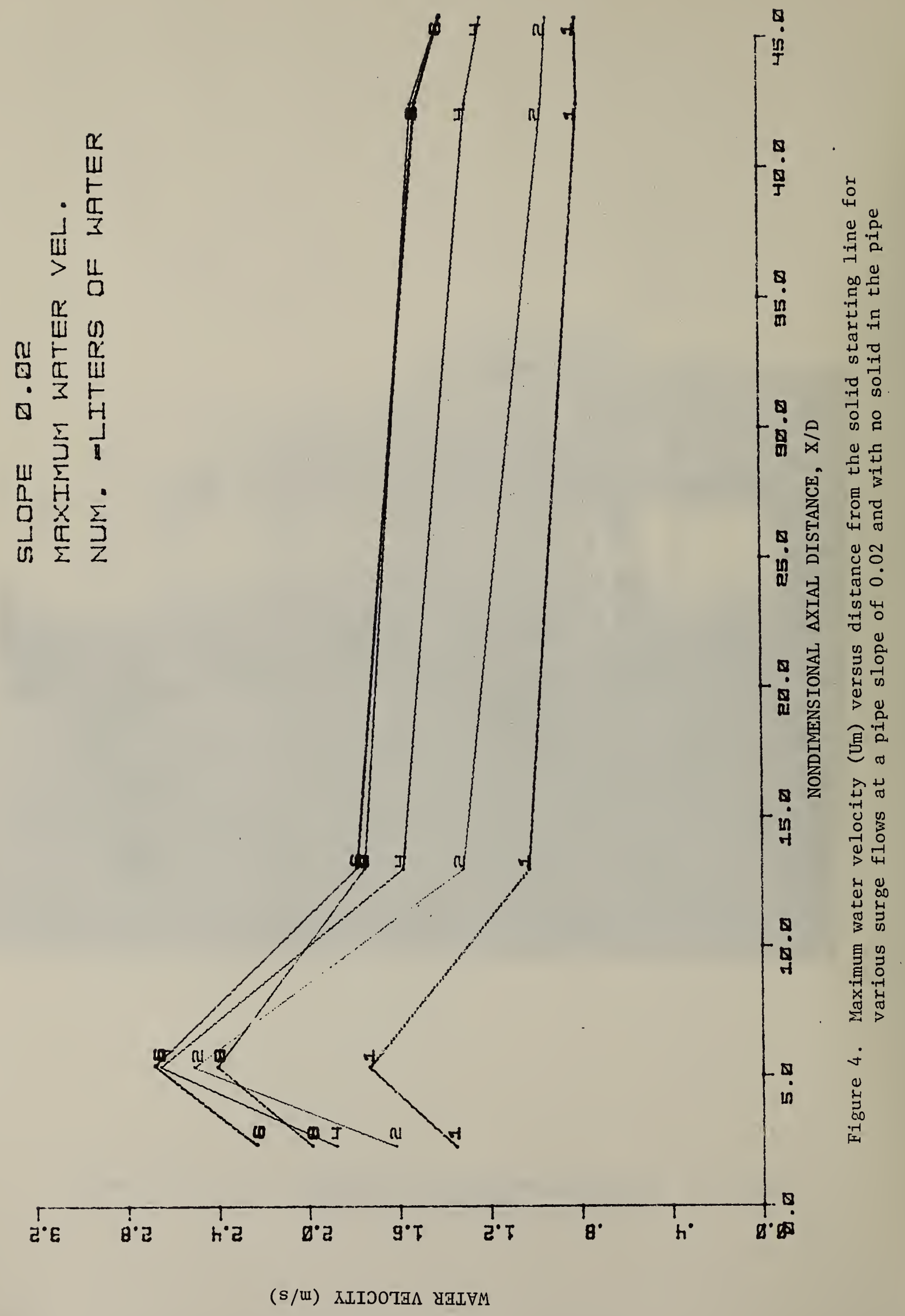




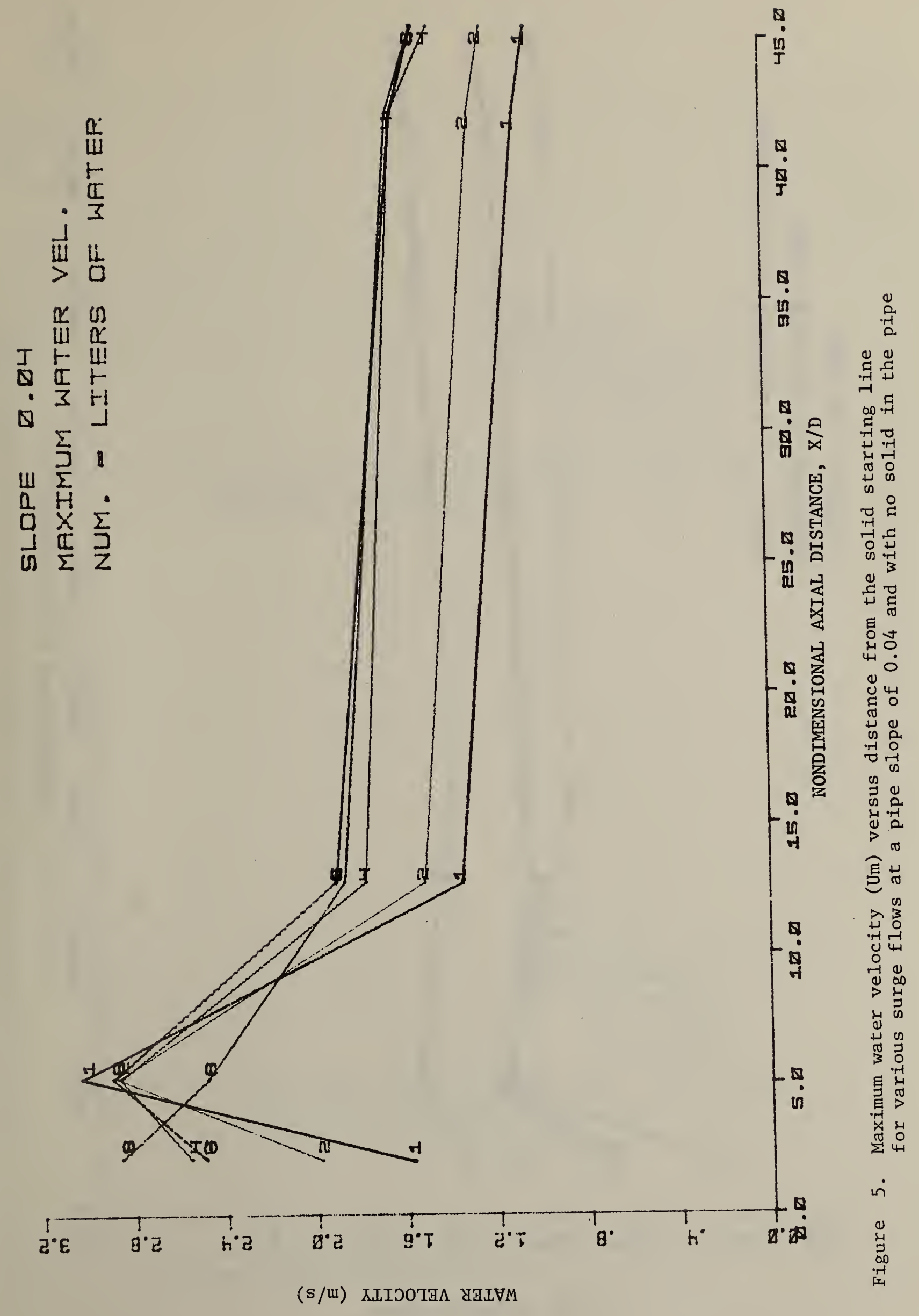




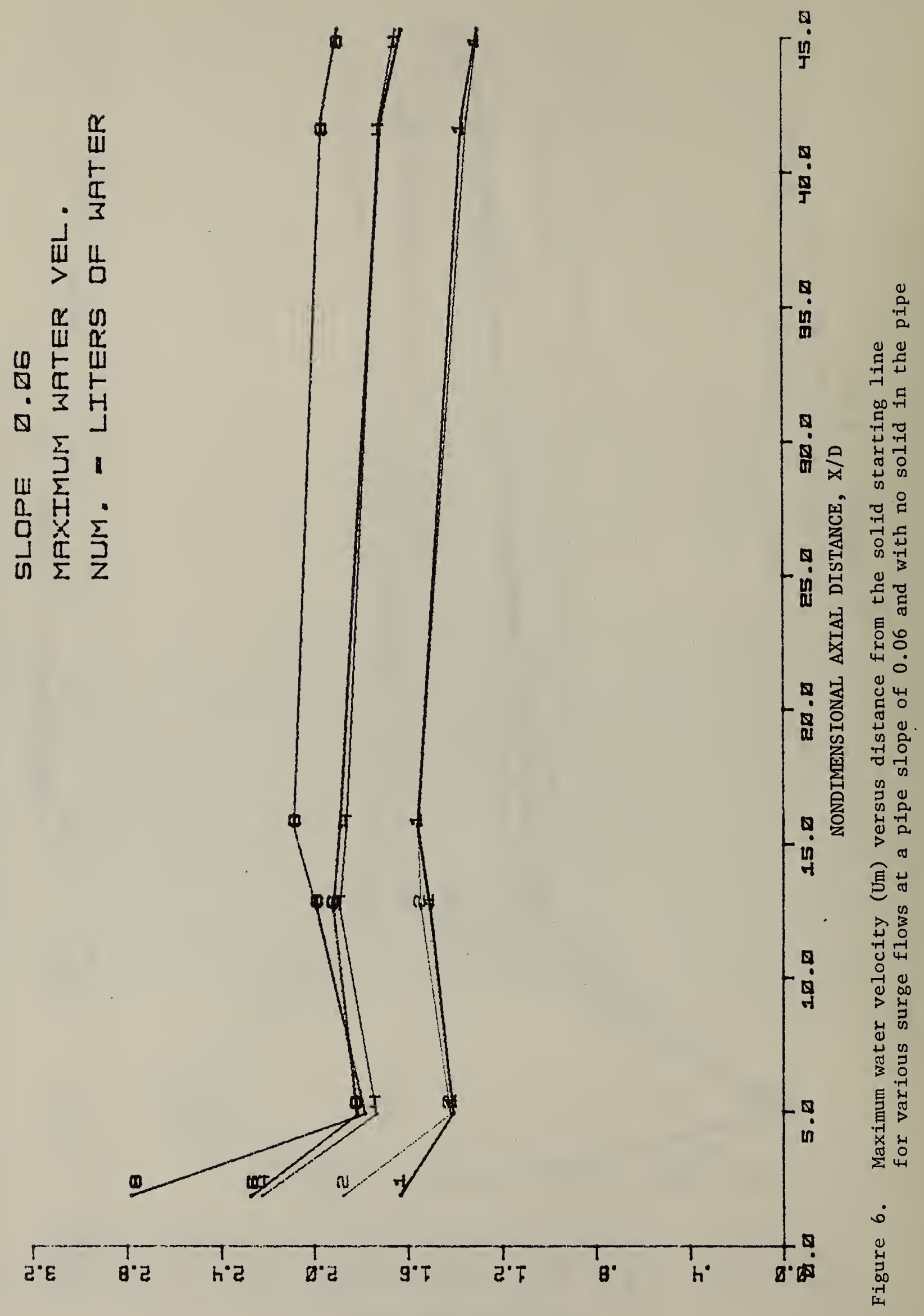

(s/u) ХІIวота ЧЈLVM 

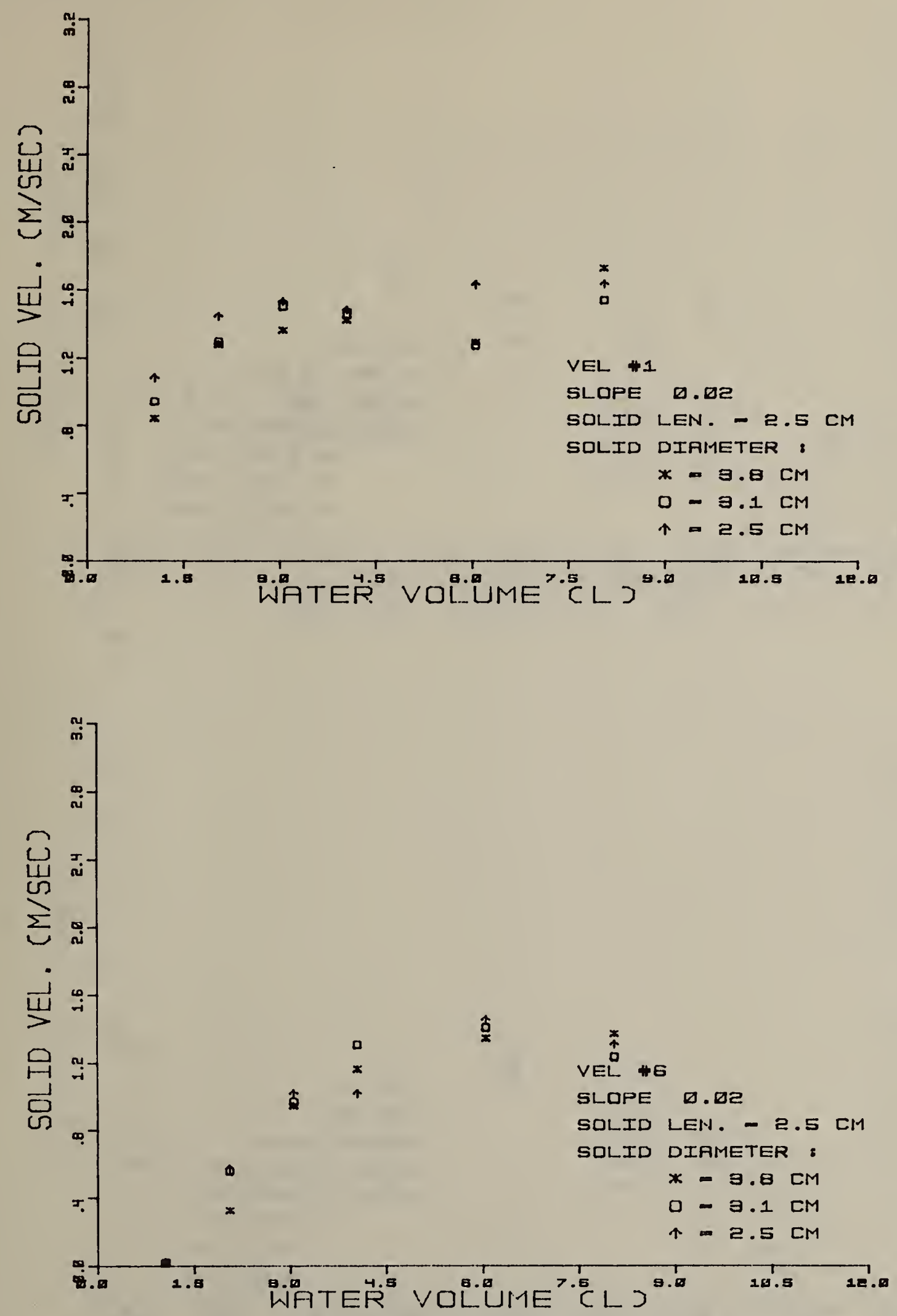

Figure 7. Solid velocity 1 1 and $\# 6$ versus water volume for $2.5 \mathrm{~cm}$ long solids at a pipe slope of 0.02 

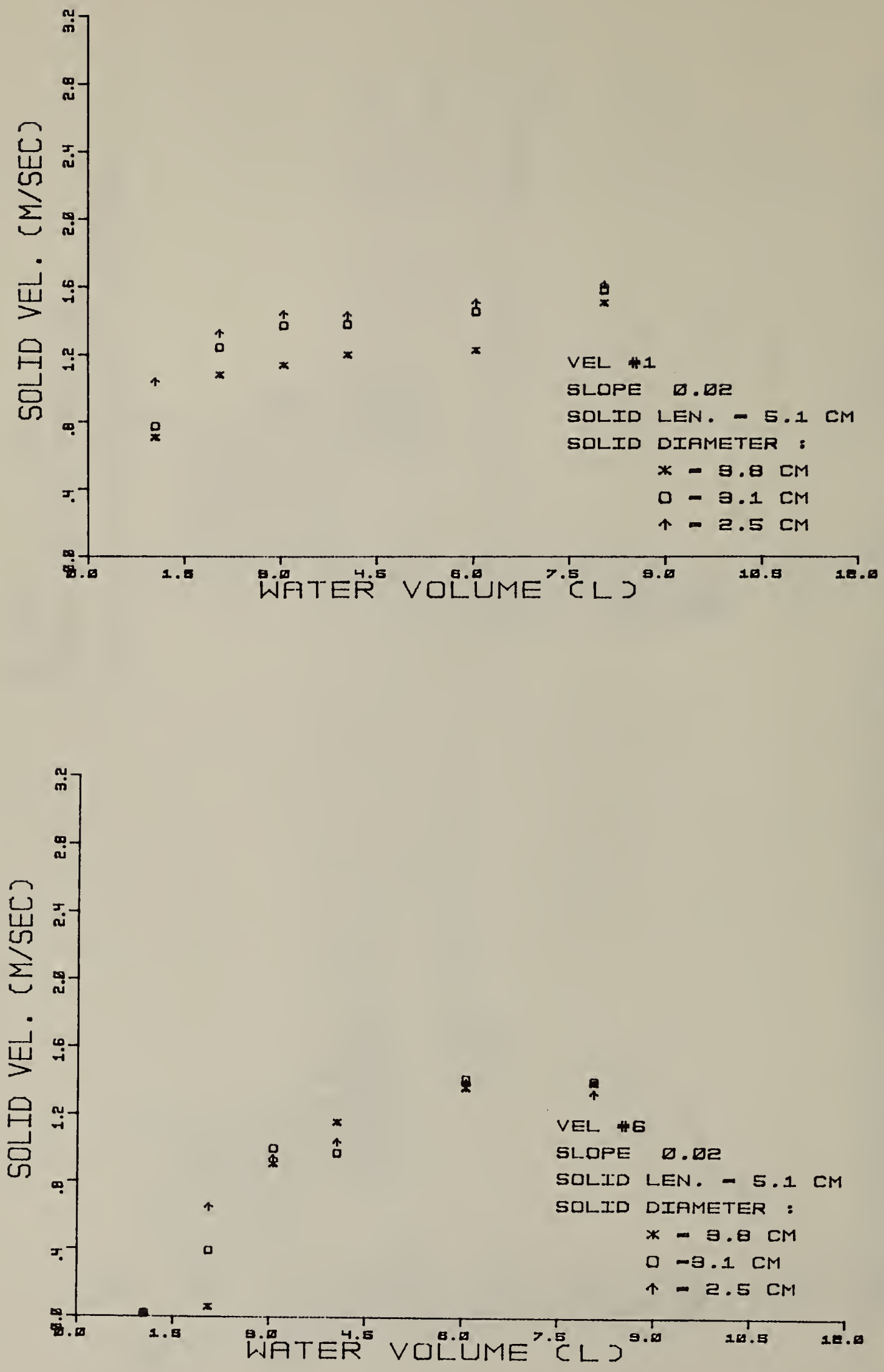

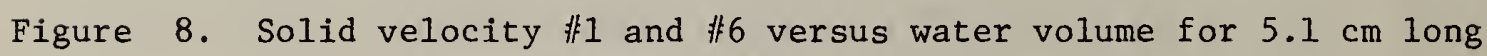
solids at a pipe slope of 0.02 

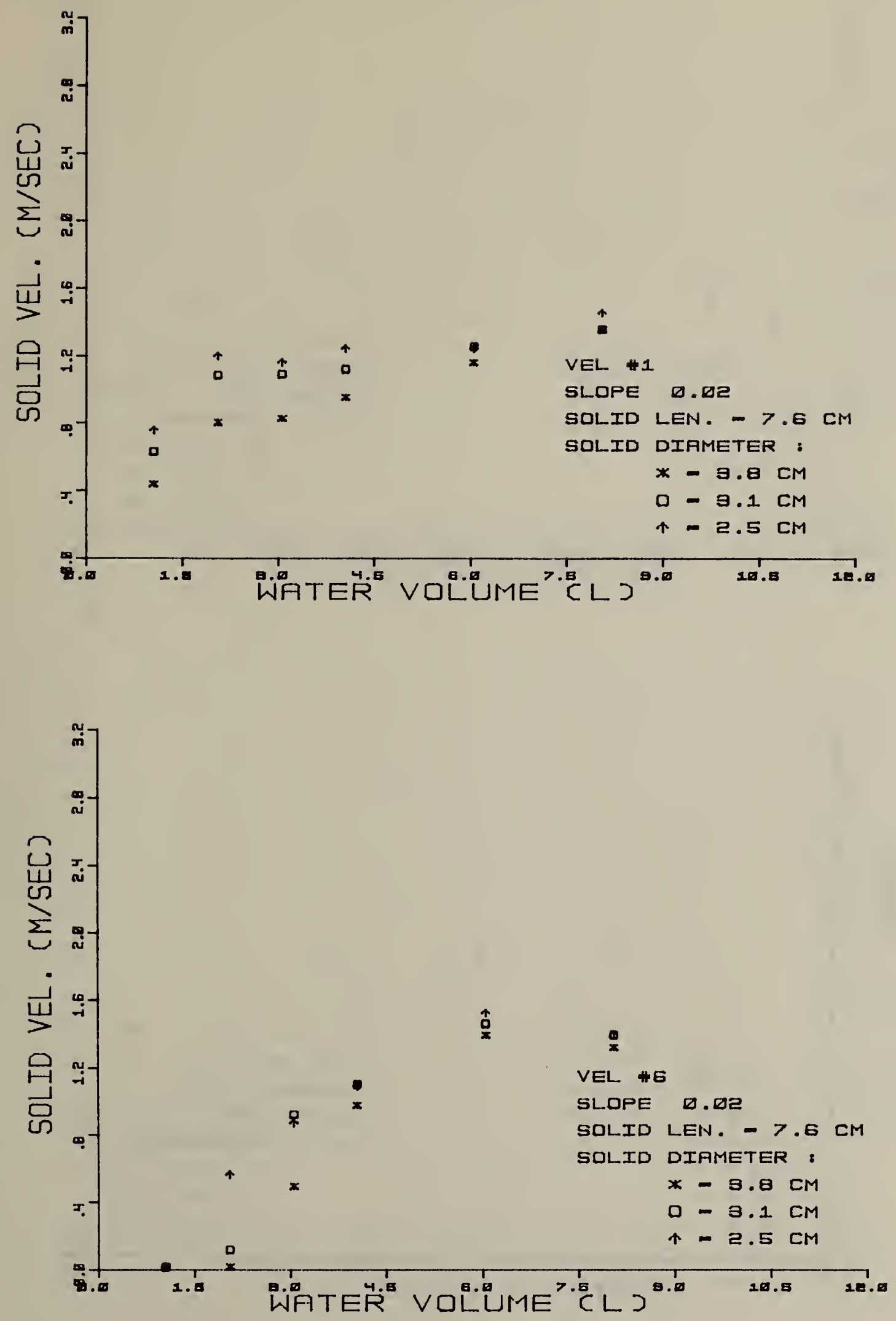

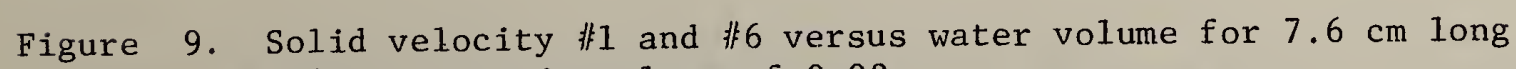
solids at a pipe slope of 0.02 

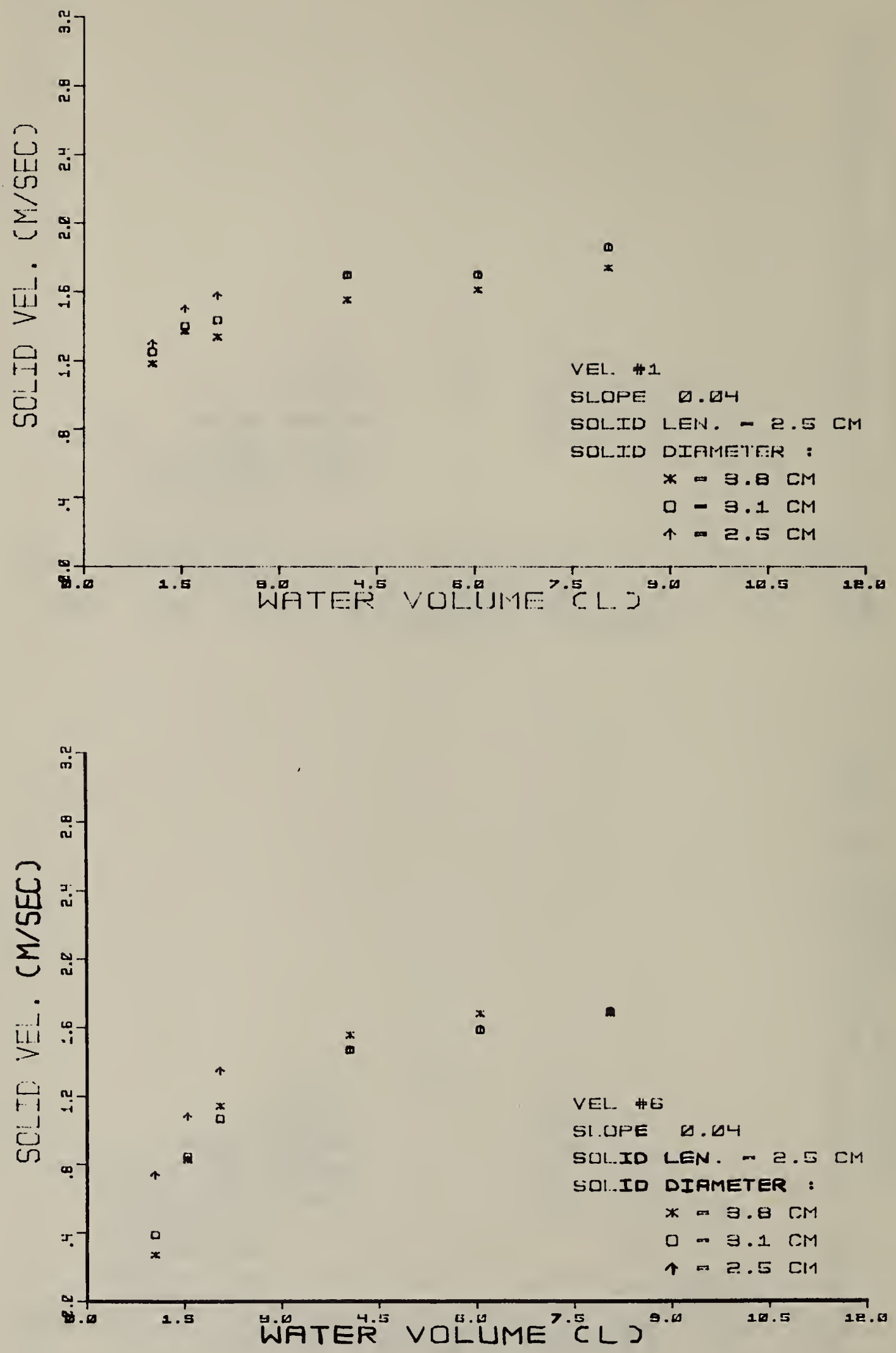

Figure 10. Solid velocity \#I and \#6 versus water volume for $2.5 \mathrm{~cm}$ long solids at a pipe slope of 0.04 

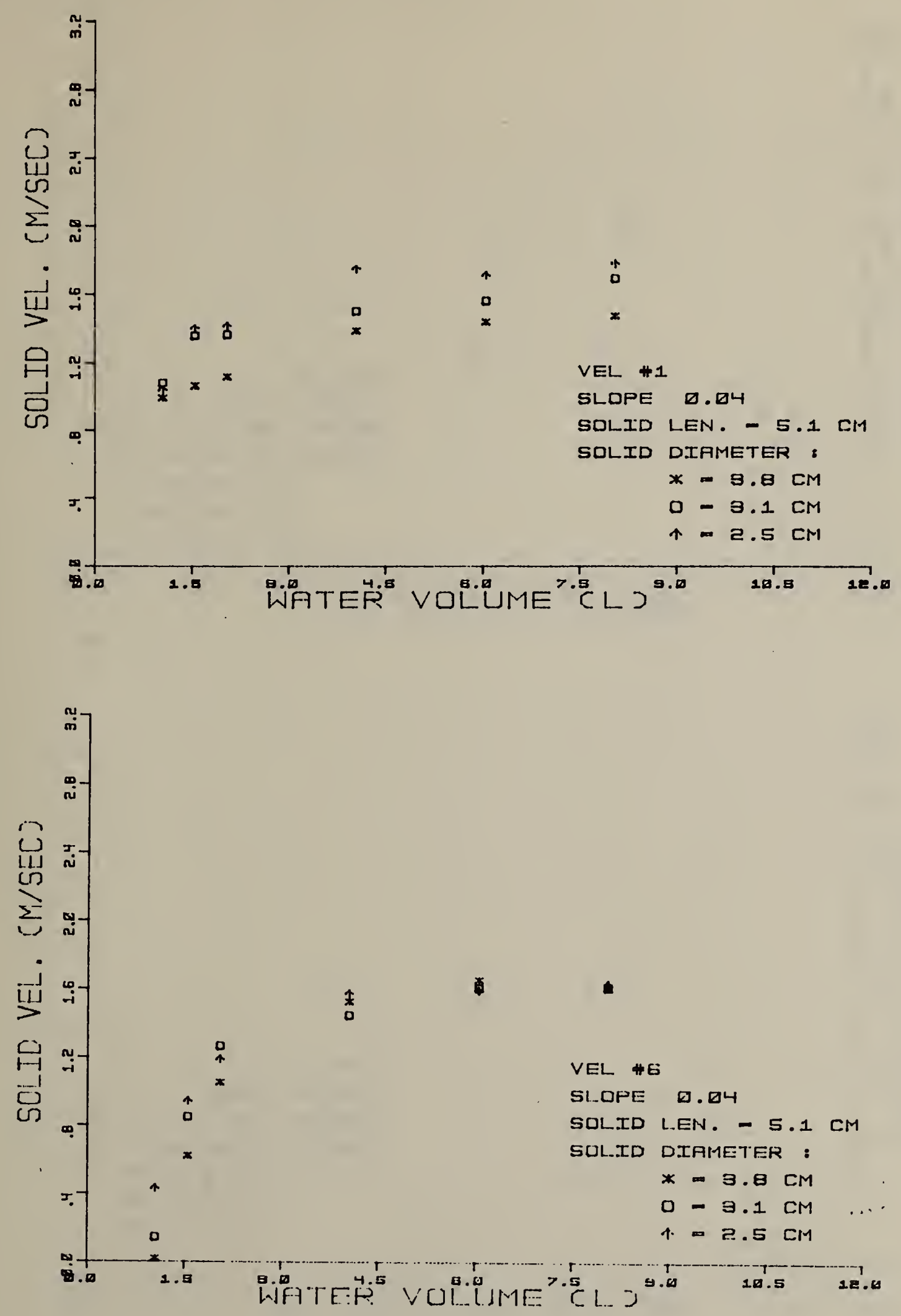

Figure 11. Solid velocity $\#_{1}$ and $\# 6$ versus water volume for $5.1 \mathrm{~cm}$ long solids at a pipe slope of 0.04 

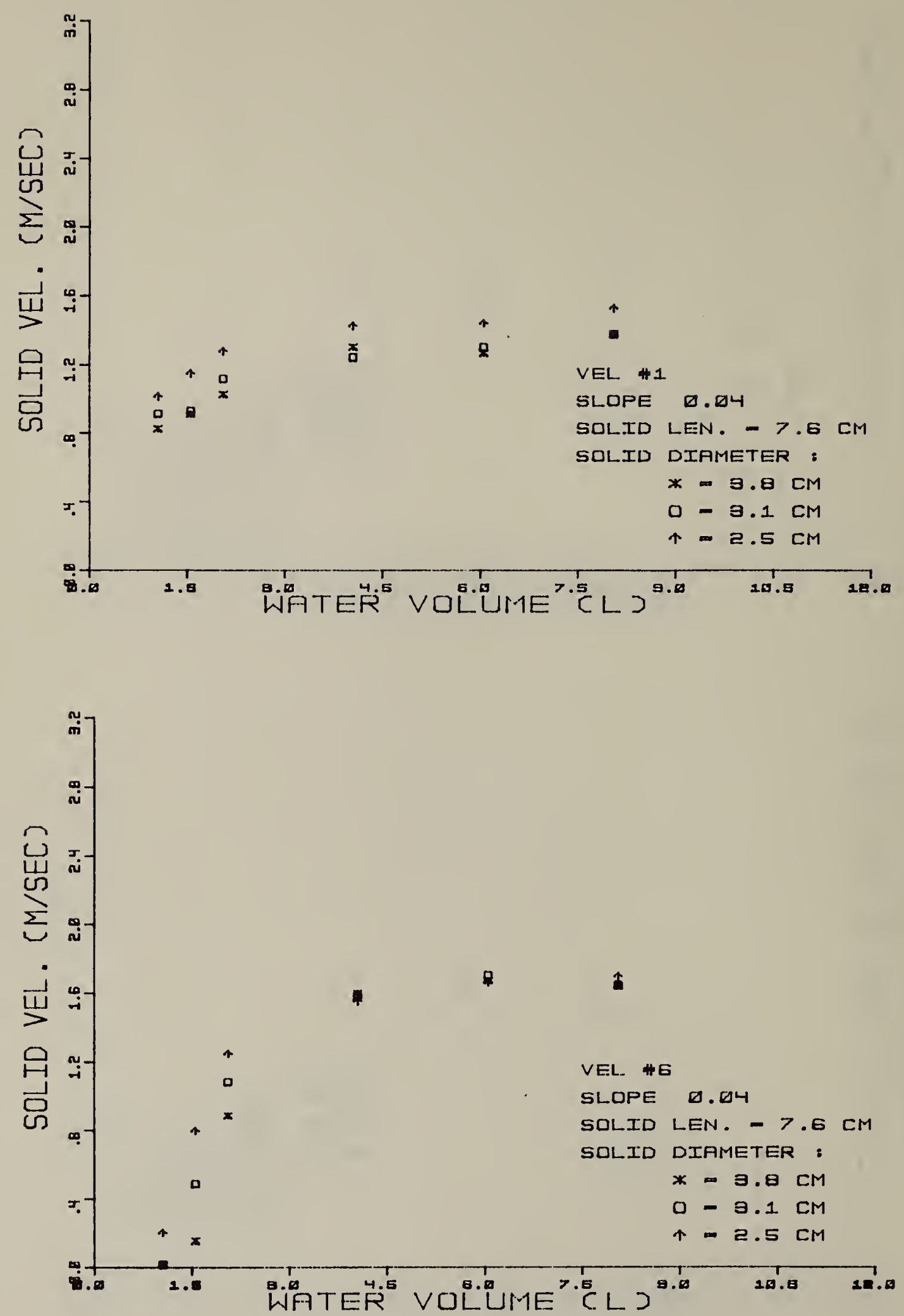

Figure 12. Solid velocity 非 and $\# 6$ versus water volume for $7.6 \mathrm{~cm}$ long solids at a pipe slope of 0.04 

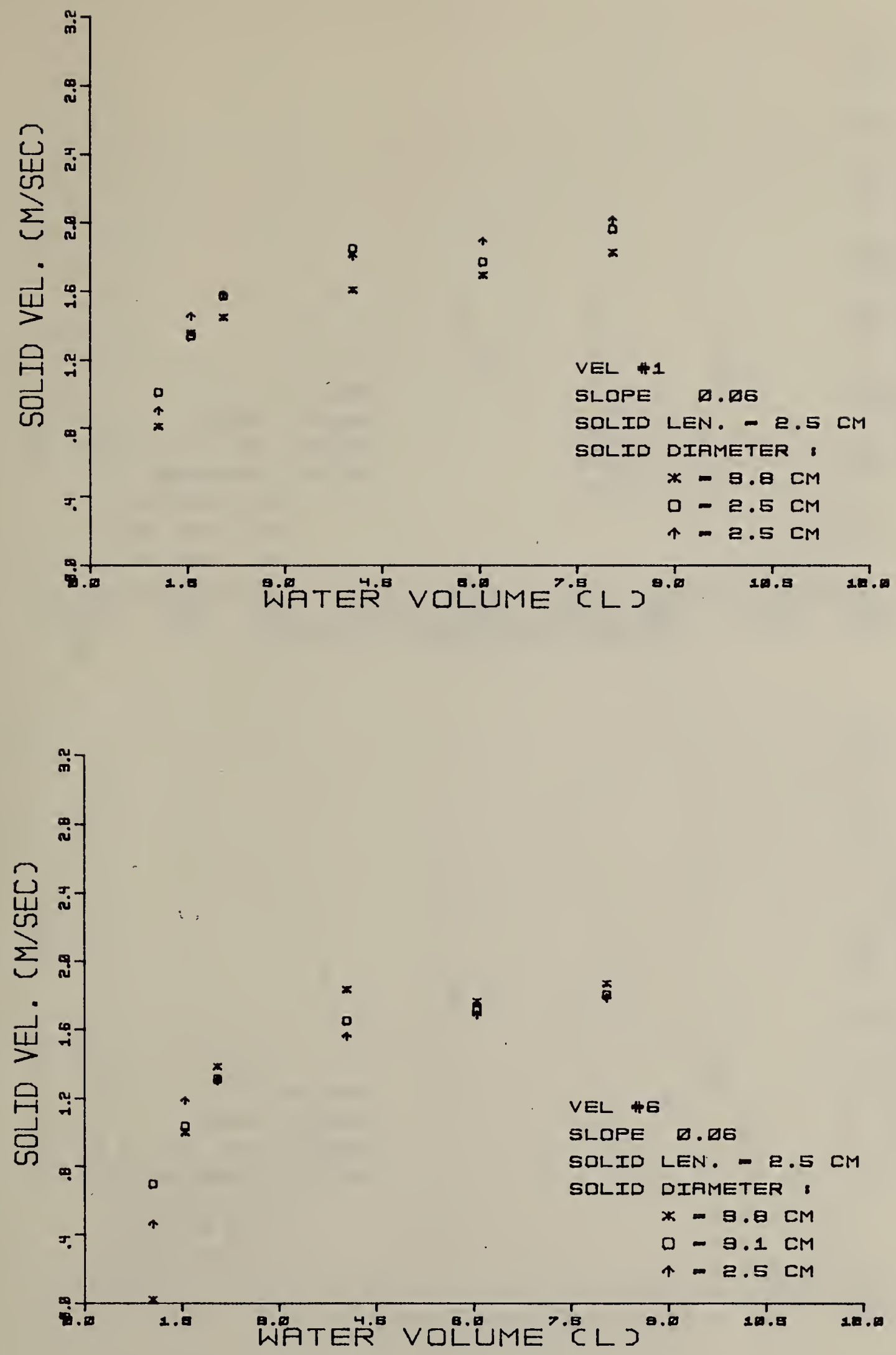

Figure 13. Solid velocity 1 1 and $\# 6$ versus water volume for $2.5 \mathrm{~cm}$ long solids at a pipe slope of 0.06 

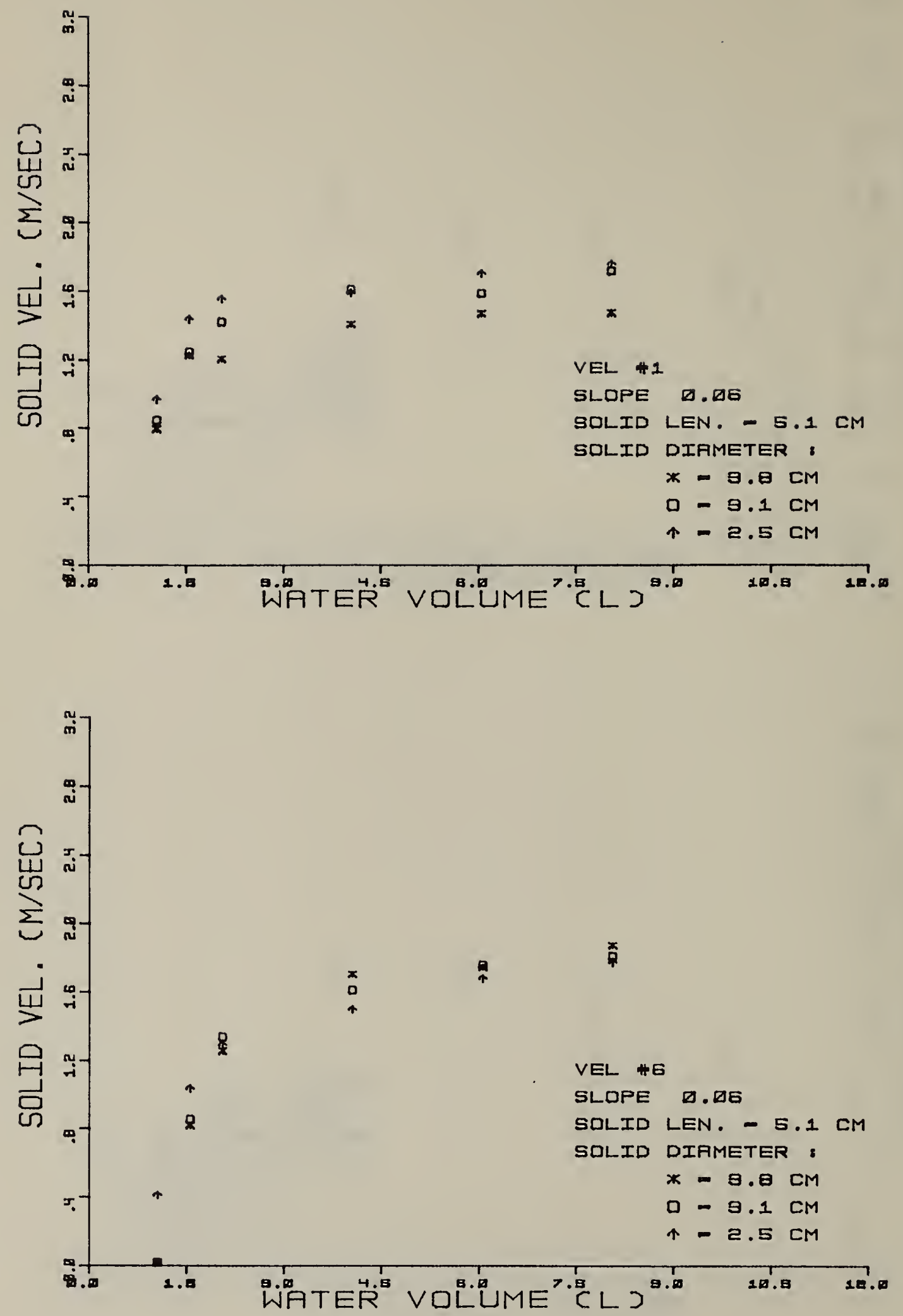

Figure 14. Solid velocity 非 1 and $\#^{6} 6$ versus water volume for $5.1 \mathrm{~cm}$ long solids at a pipe slope of 0.06 

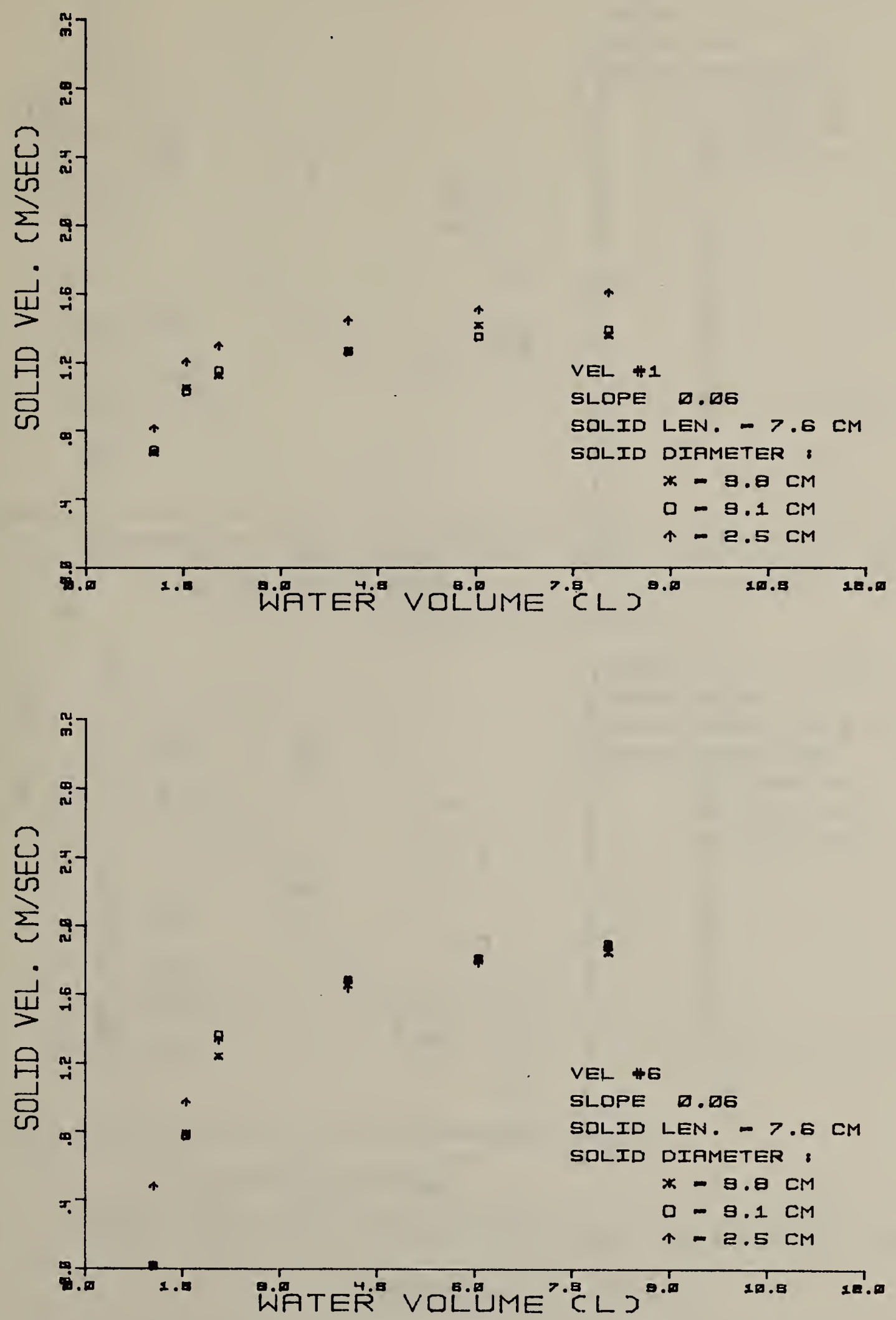

Figure 15. Solid velocity $\# 1$ and $\# 6$ versus water volume for $7.6 \mathrm{~cm}$ long solids at a pipe slope of 0.06 

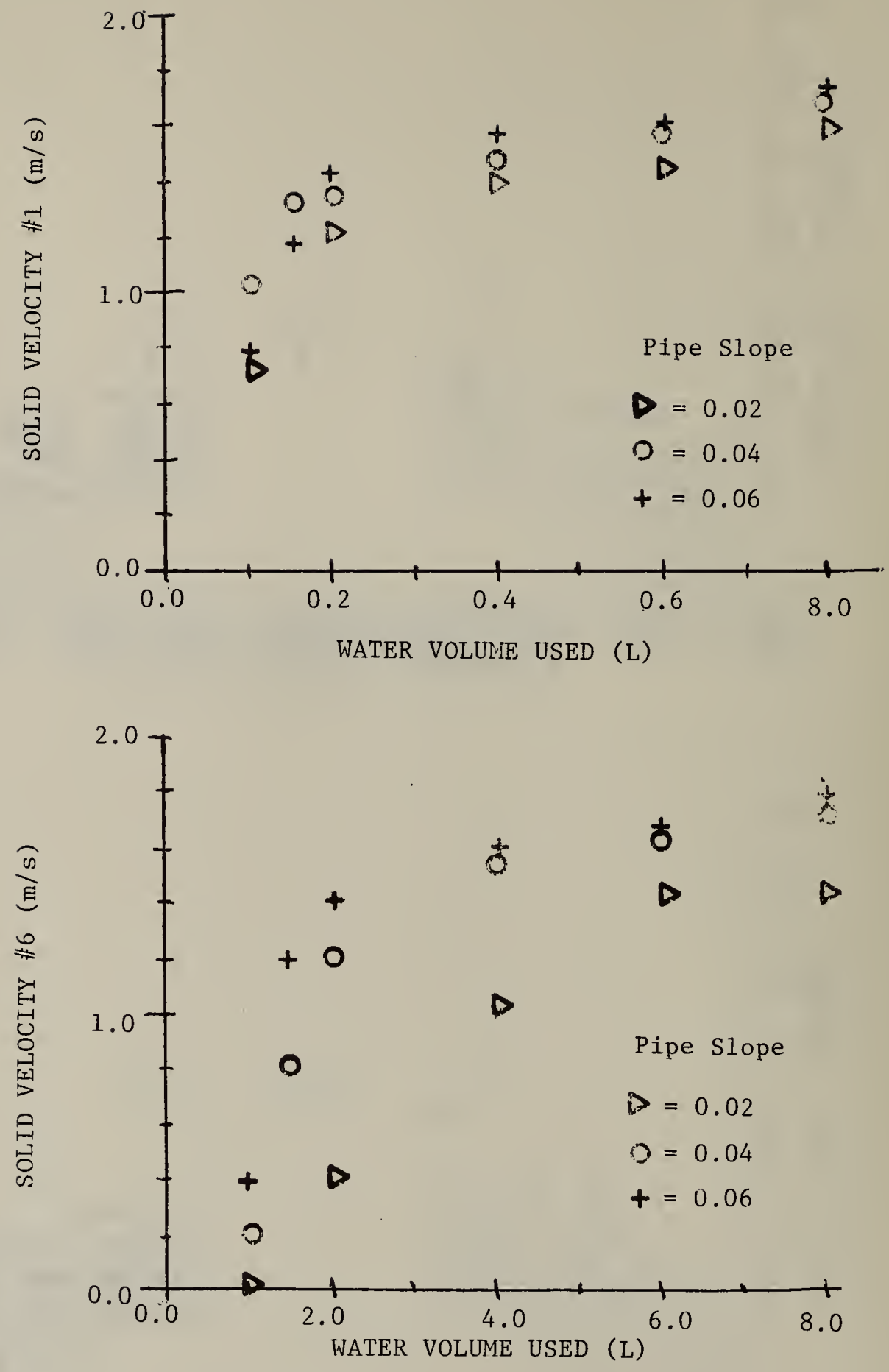

Figure 16. Solid velocity $\|_{1} 1$ and $\# 6$ versus water volume used for a 3.5 by $5.1 \mathrm{~cm}$ solid for all three pipe slopes 

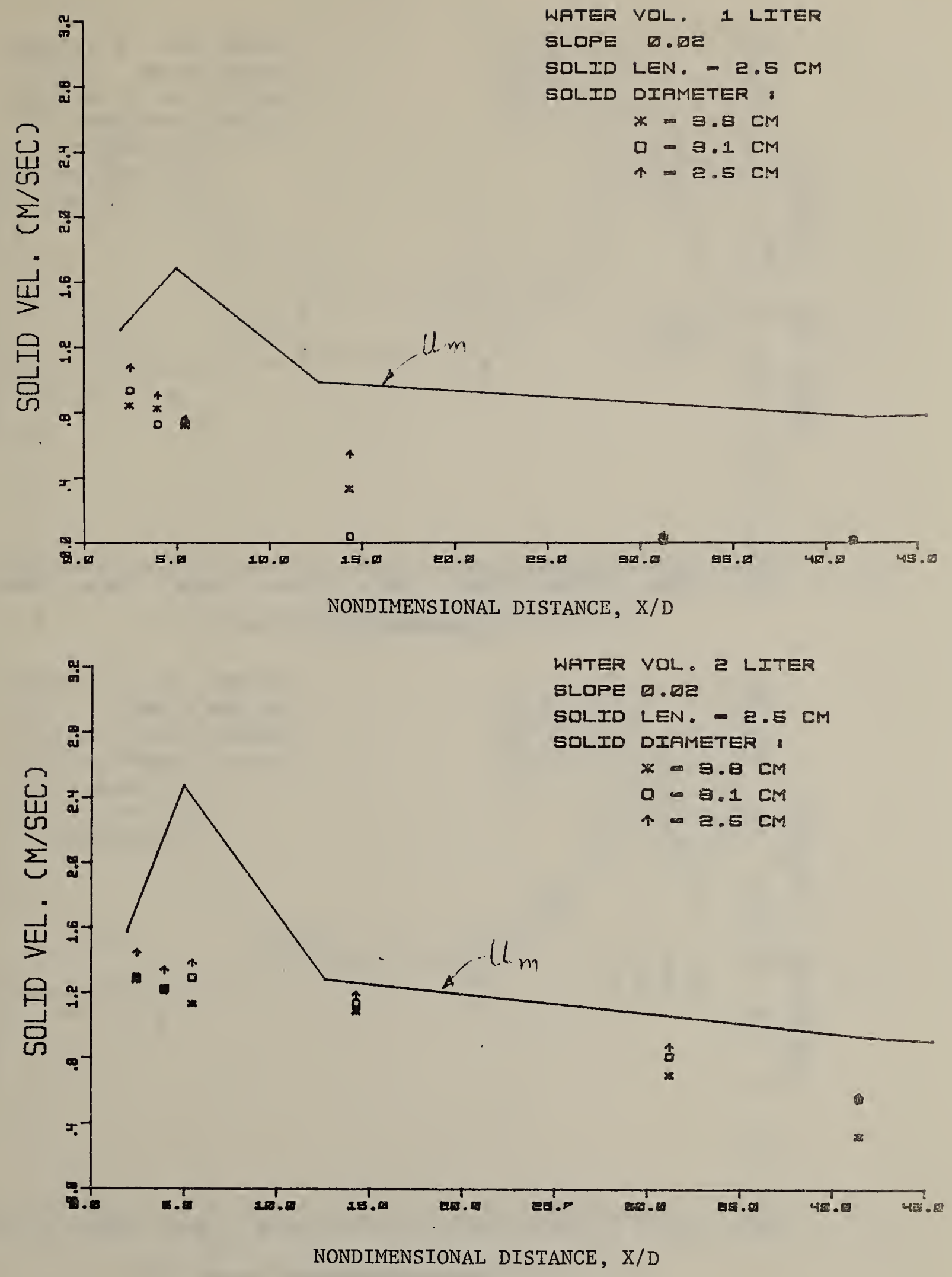

Figure 17. Solid velocity versus distance from the solid starting line for $2.5 \mathrm{~cm}$ long solids and for $\mathrm{V}_{\mathrm{w}}=1.0$ and $2.0 \mathrm{~L}$, at a pipe
slope of 0.02 


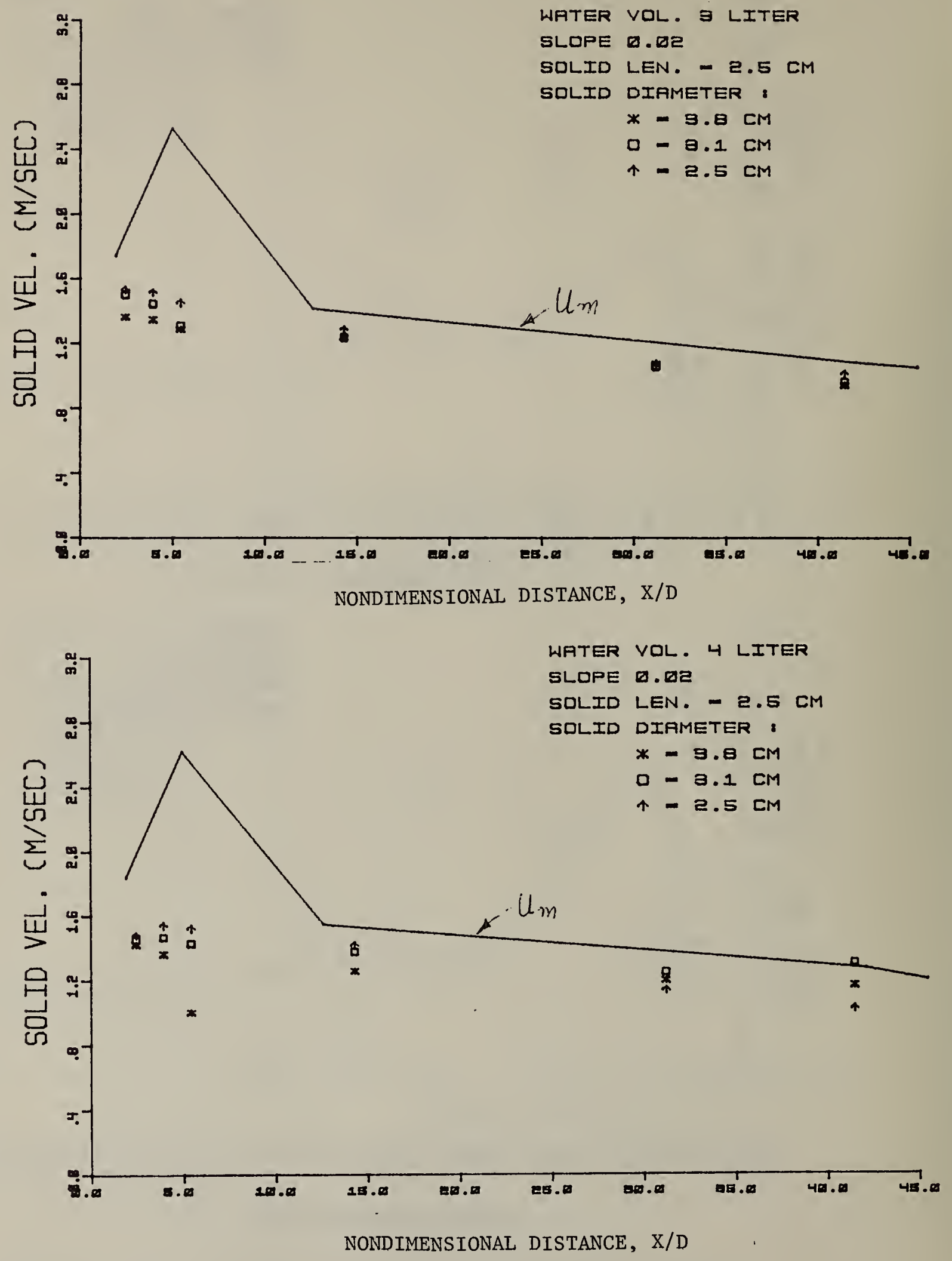

Figure 18. Solid velocity versus distance from the solid starting line for $5.1 \mathrm{~cm}$ long solids, and for $V_{\mathrm{W}}=3.0$ and $4.0 \mathrm{~L}$, at a pipe slope of 0.02 


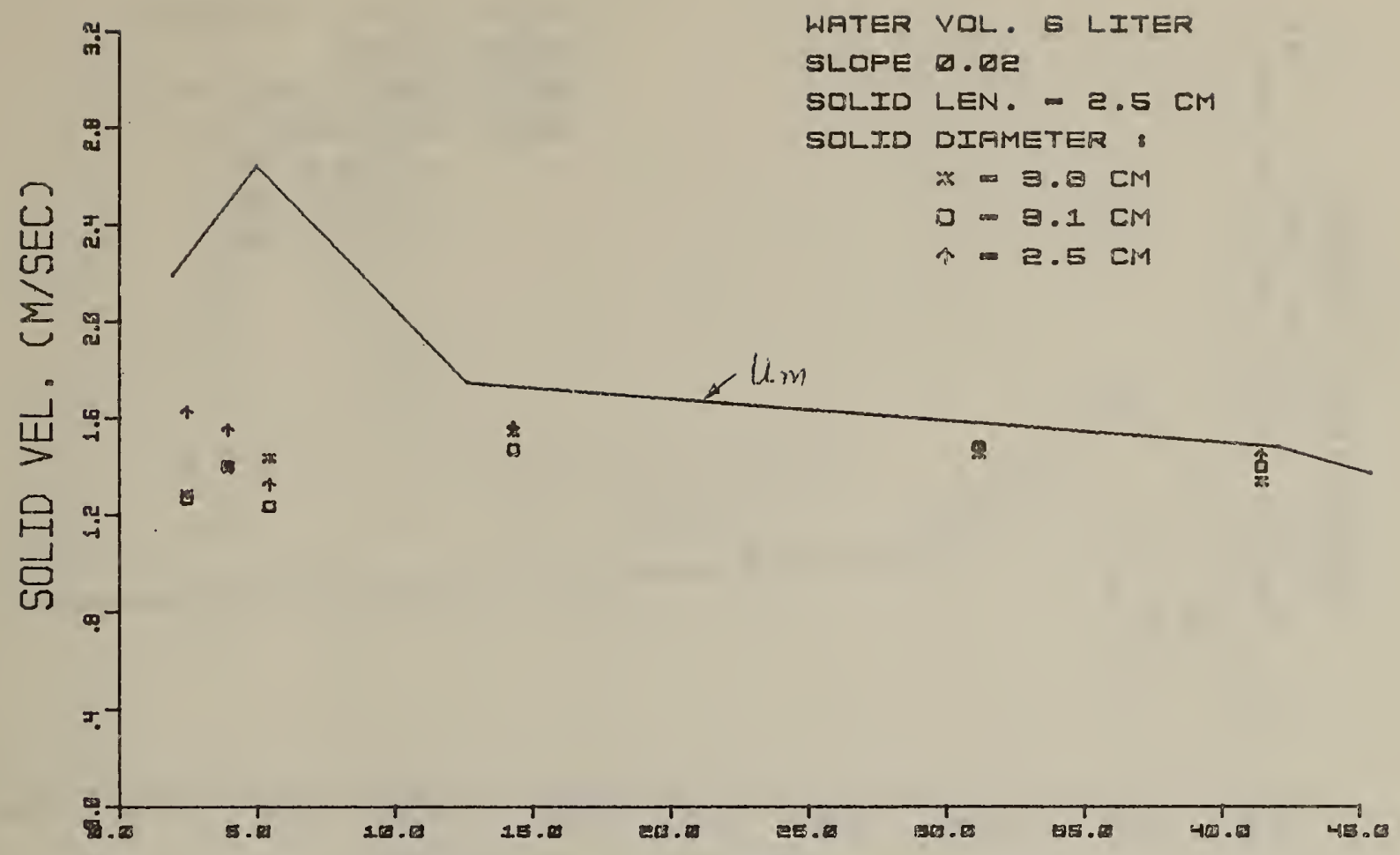

NOINDIMENSIONAL DISTANCE, X/D

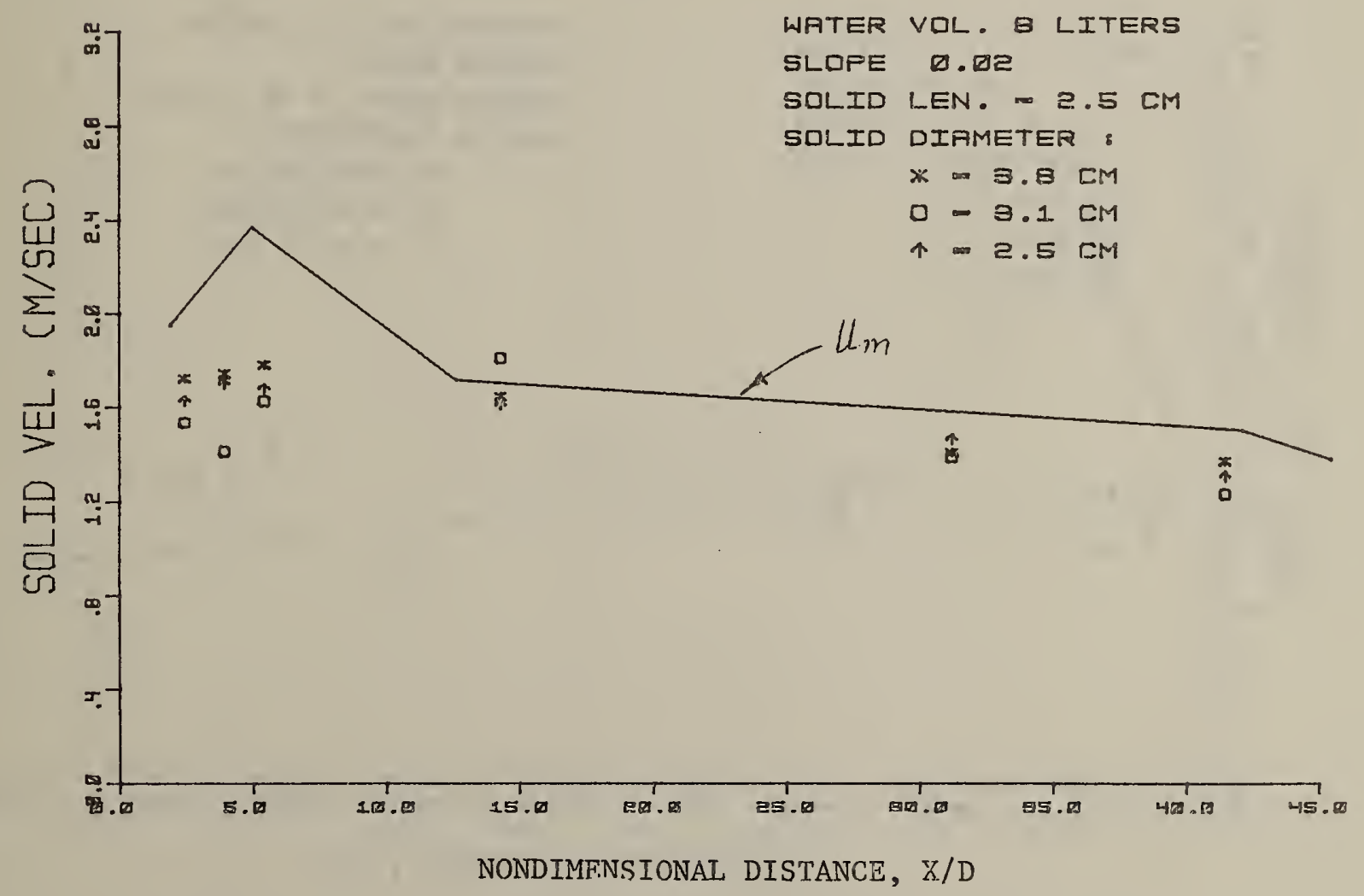

Figure 19. Solid velocity versus distance from the solid starting line for $5.1 \mathrm{~cm}$ long solids, and for $\mathrm{V}_{\mathrm{W}}=6.0$ and $8.0 \mathrm{~L}$, at a pipe slope of 0.02 

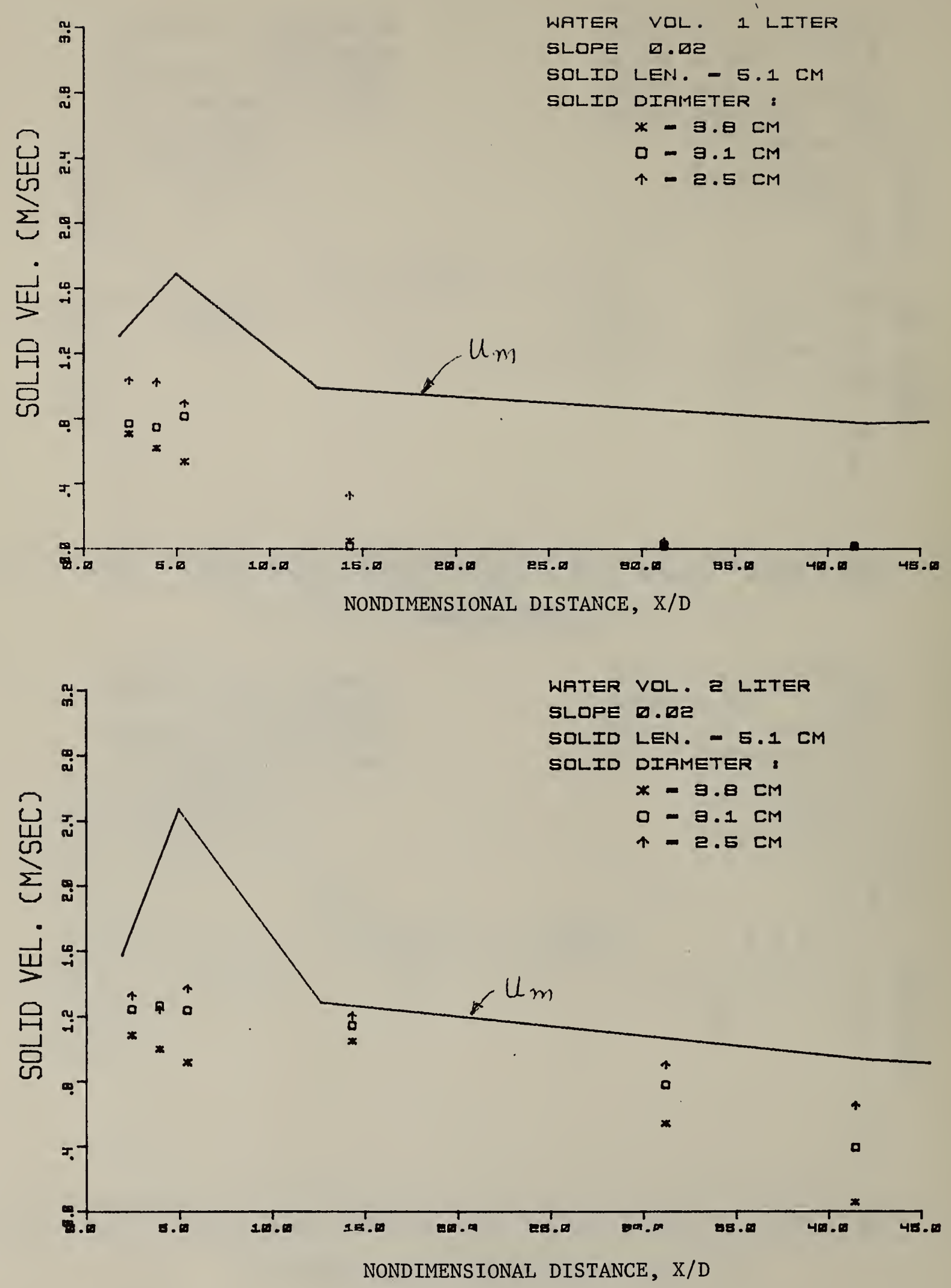

Figure 20. Solid velocity versus distance from the solid starting line for $5.1 \mathrm{~cm}$ long solids, and for $\mathrm{V}_{\mathrm{w}}=1.0$ and $2.0 \mathrm{~L}$, at a pipe slope of 0.02 


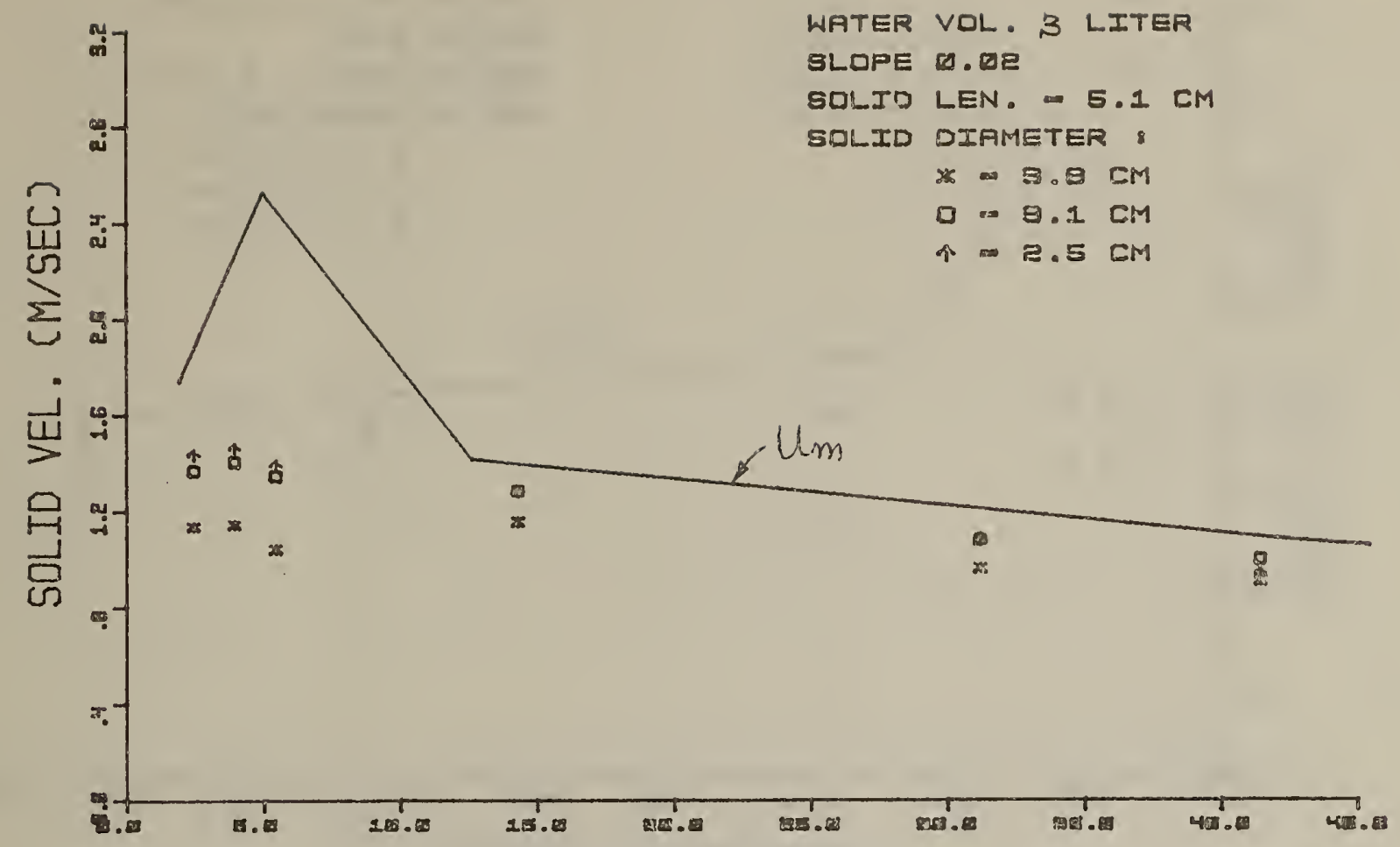

NONDIMENSIONAL DISTANCE, $\mathrm{X} / \mathrm{D}$

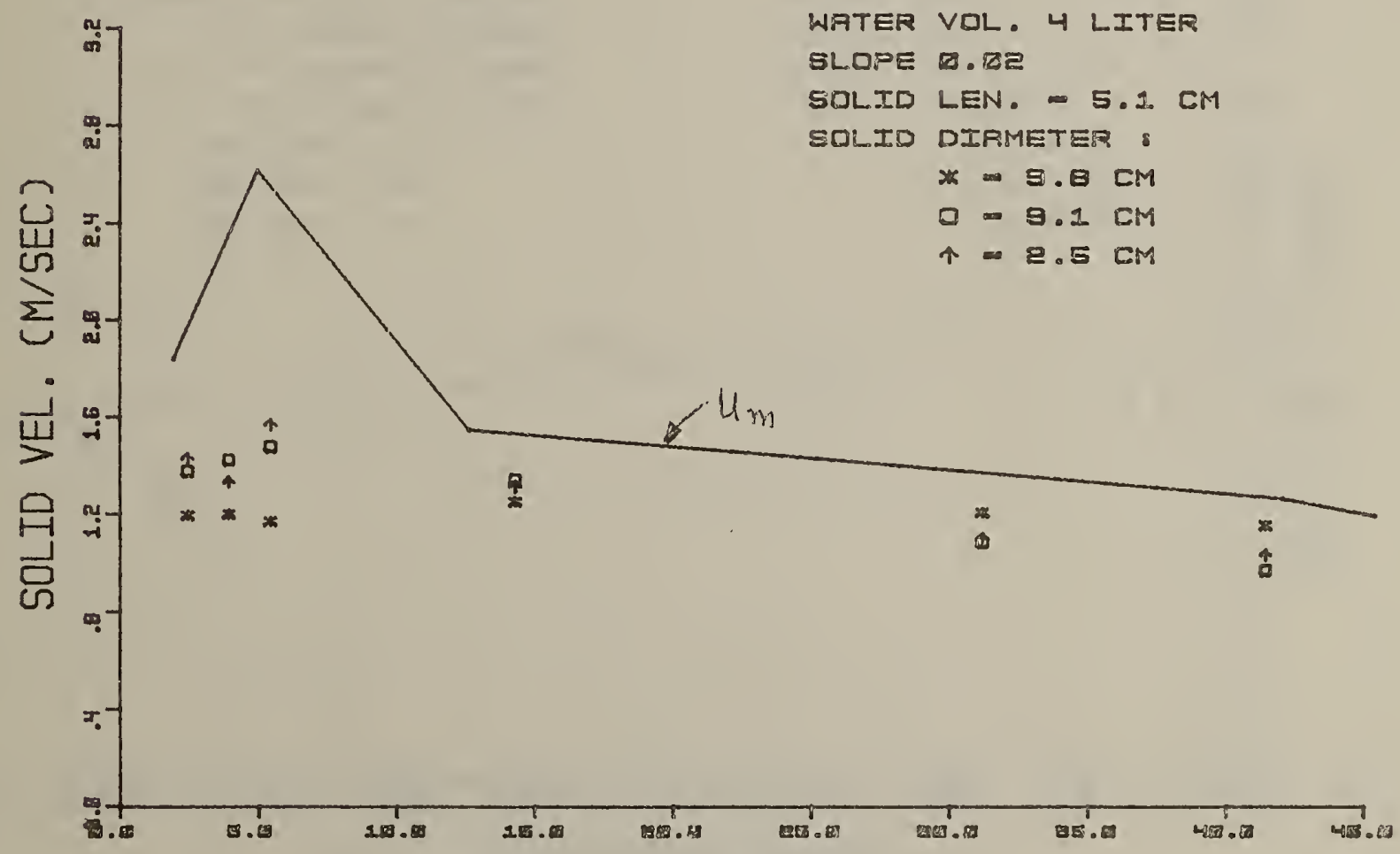

NONDIMENSIONAL DISTANCE, $\mathrm{x} / \mathrm{D}$

Figure 21. Solid velocity versus distance from the solid starting line for $5.1 \mathrm{~cm}$ long solids, and for $\mathrm{V}_{\mathrm{W}}=3.0$ and $4.0 \mathrm{~L}$, at a pipe slope of 0.02 

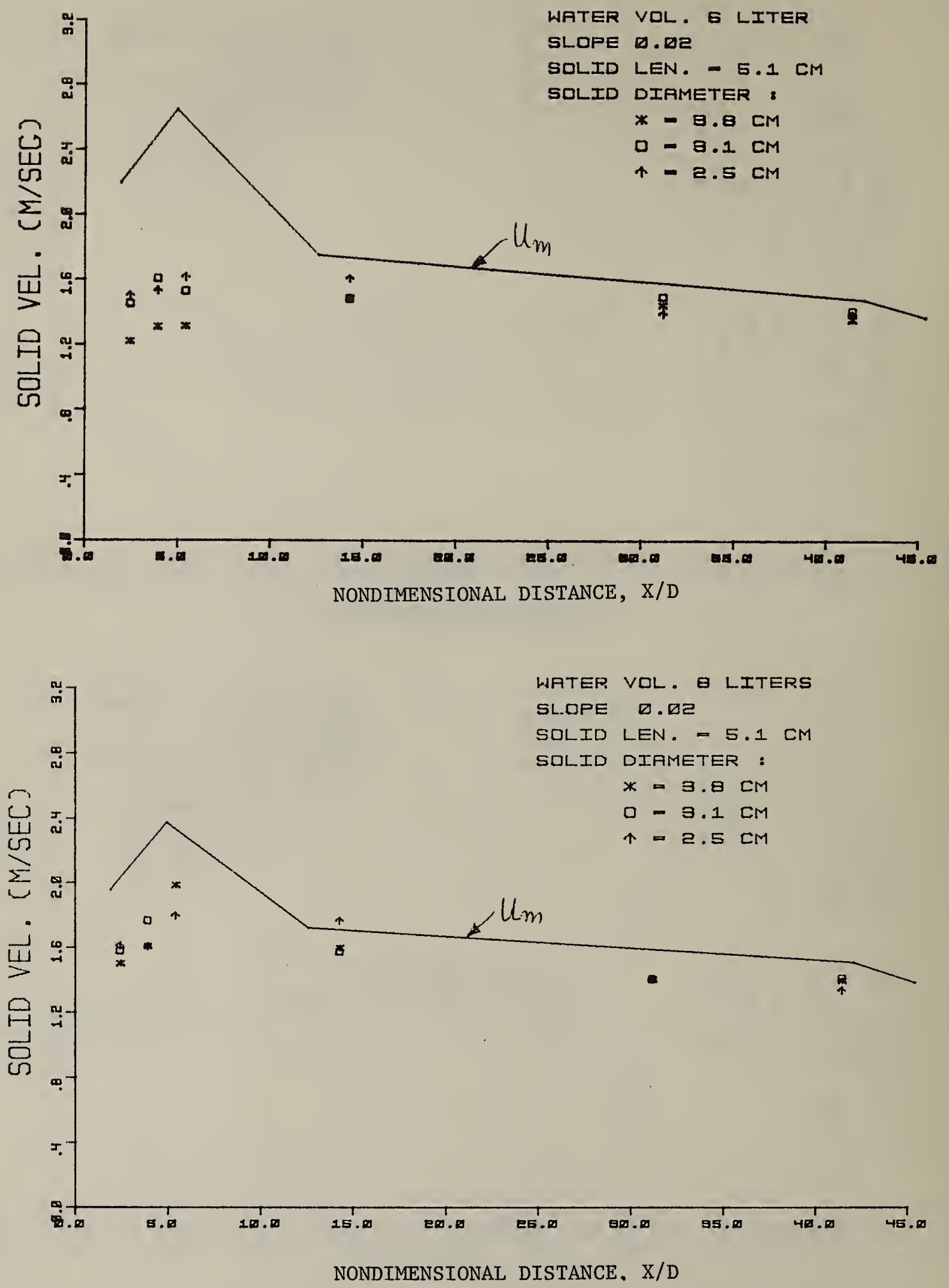

Figure 22. Solid velocity versus distance from the solid starting line for $5.1 \mathrm{~cm}$ long solids, and for $\mathrm{V}_{\mathrm{W}}=6.0$ and $8.0 \mathrm{~L}$, at a pipe slope of 0.02 

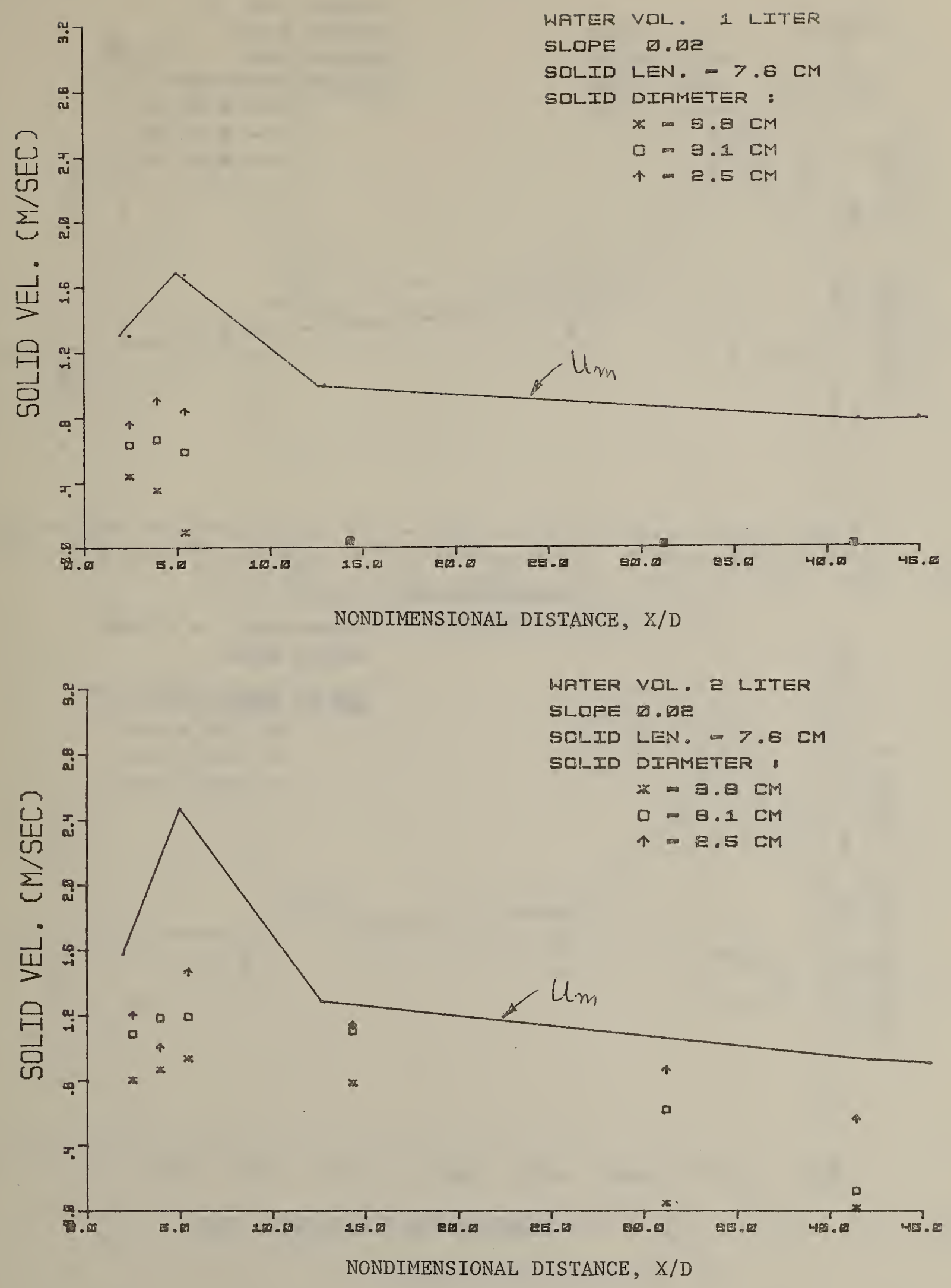

Figure 23. Solid velocity versus distance from the solid starting line for $7.6 \mathrm{~cm}$ long solids and for $\mathrm{V}_{\mathrm{W}}=1.0$ and $2.0 \mathrm{~L}$, at a pipe slope of 0.02 


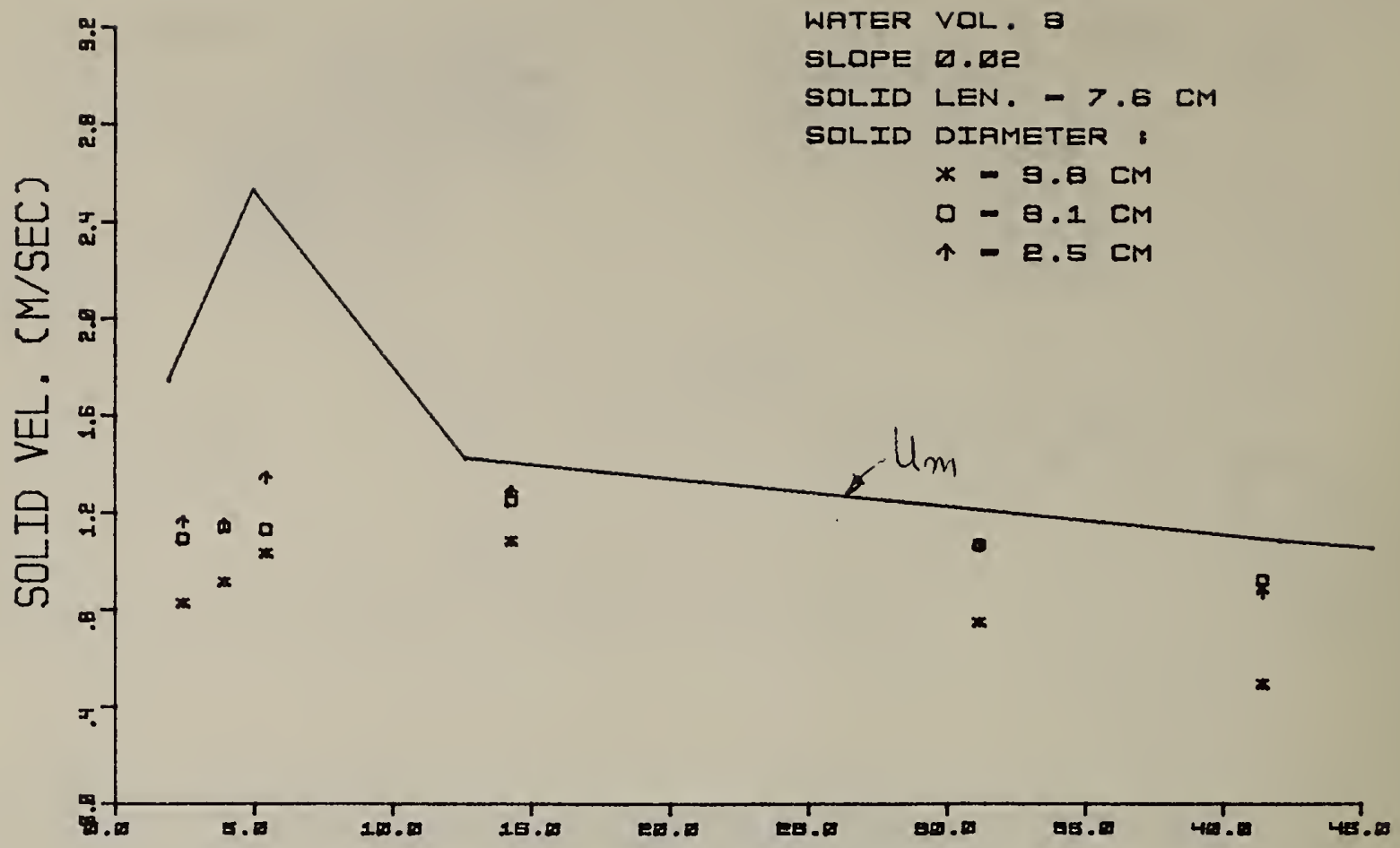

NONDIMENSTONAL DISTANCE, X/D

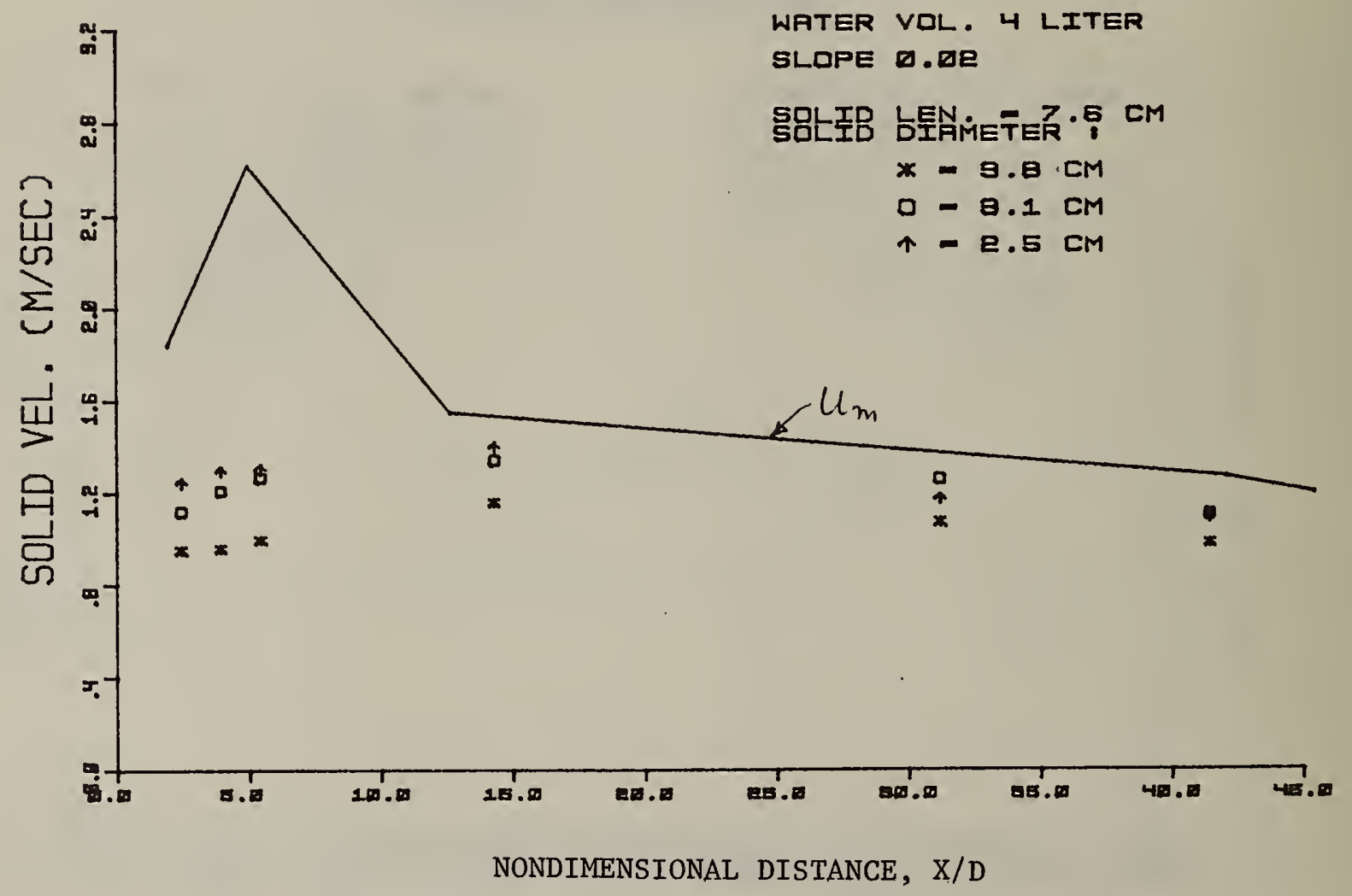

Figure 24. Solid velocity versus distance from the solid starting line for $7.6 \mathrm{~cm}$ long solids and for $\mathrm{V}_{\mathrm{W}}=3.0$ and $4.0 \mathrm{~L}$, at a pipe slope of 0.02 

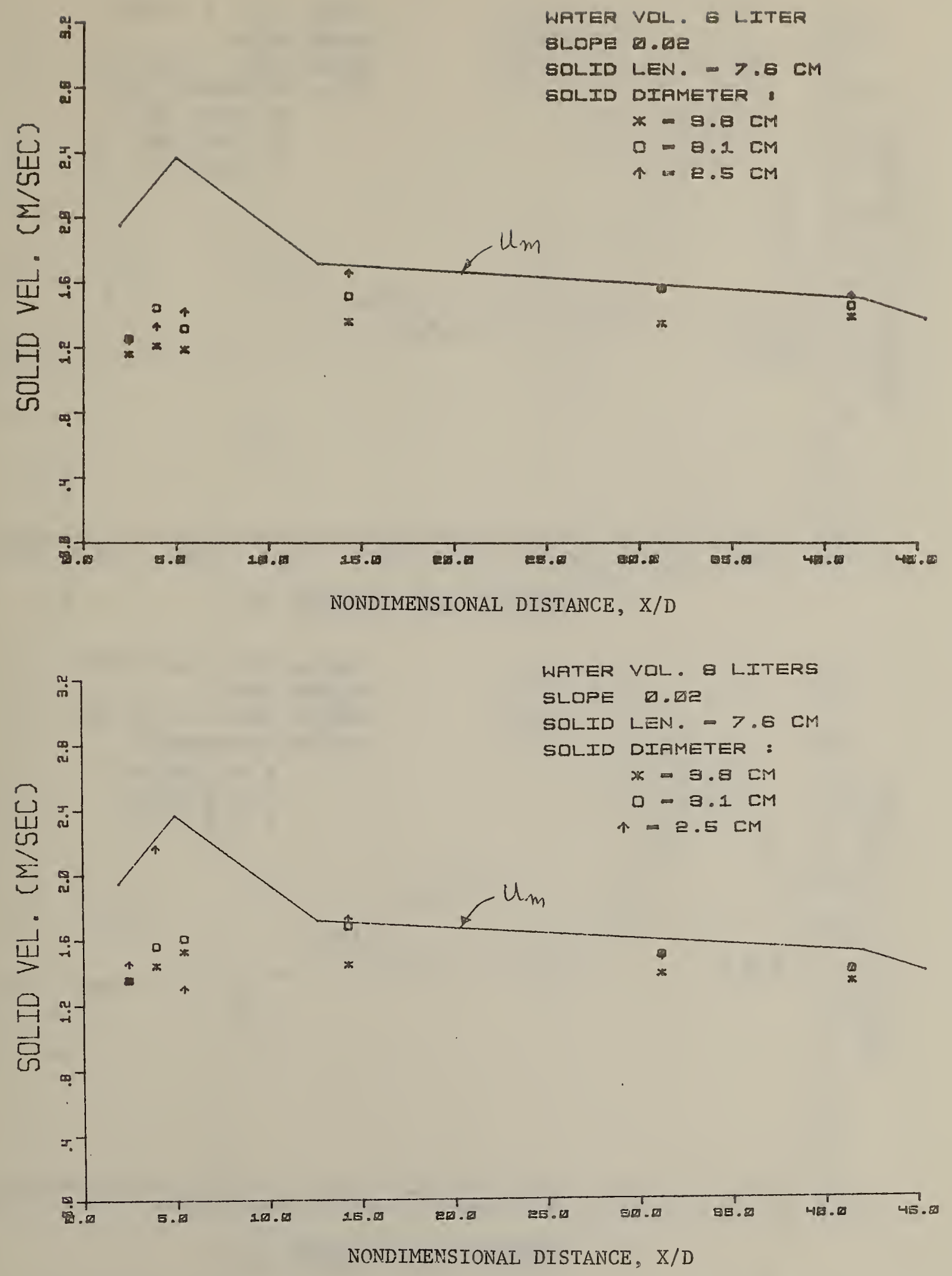

Figure 25. Solid velocity versus distance from the solid starting line for $7.6 \mathrm{~cm}$ long solids and for $\mathrm{V}_{\mathrm{w}}=6.0$ and $8.0 \mathrm{~L}$, at a pipe slope of 0.02 

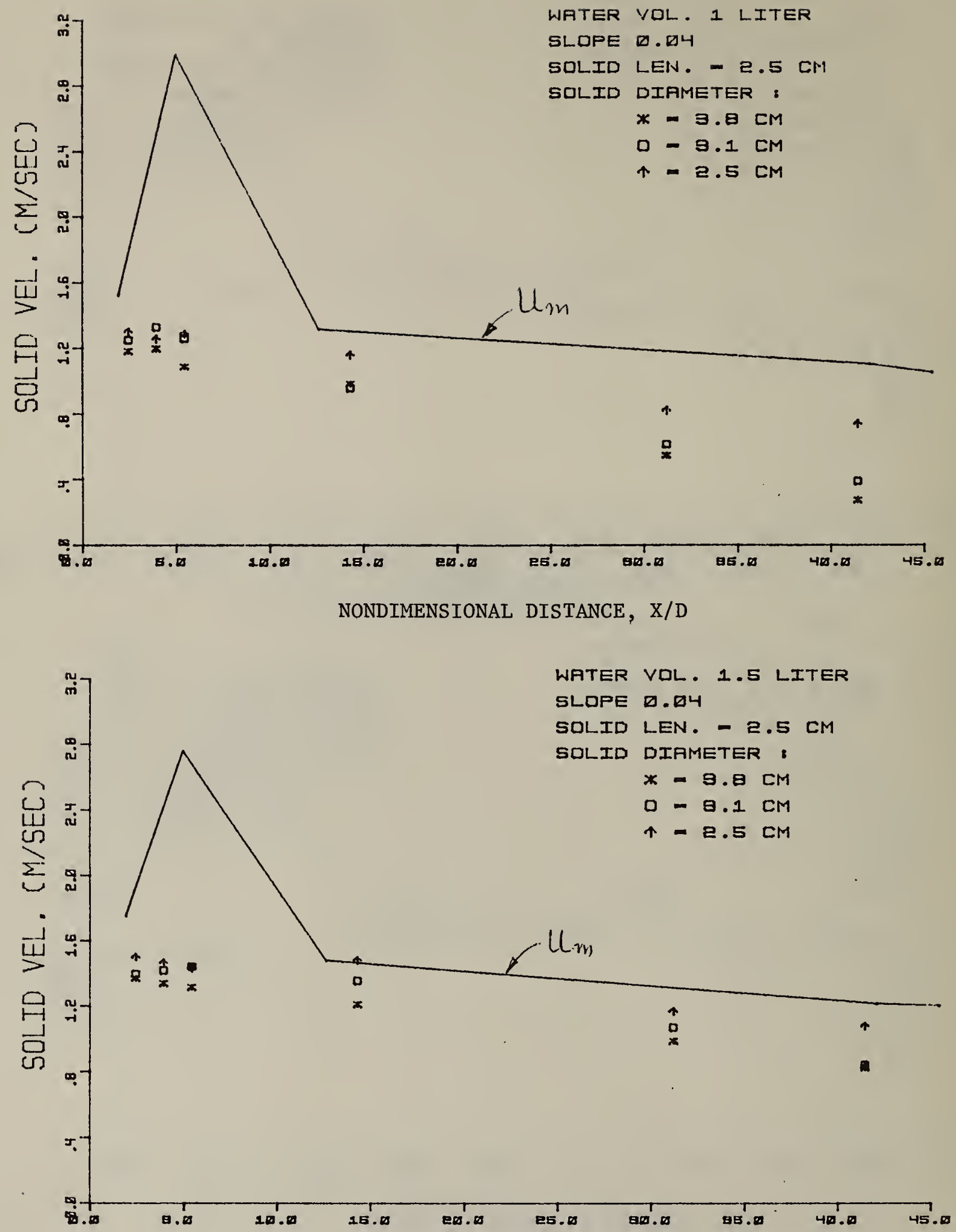

NONDIMENSIONAL DISTANCE, $\mathrm{X} / \mathrm{D}$

Figure 26. Solid velocity versus distance from the solid starting line for $2.5 \mathrm{~cm}$ long solids, and for $\mathrm{V}_{\mathrm{W}}=1.0$ and $1.5 \mathrm{~L}$, at a pipe slope of 0.04 

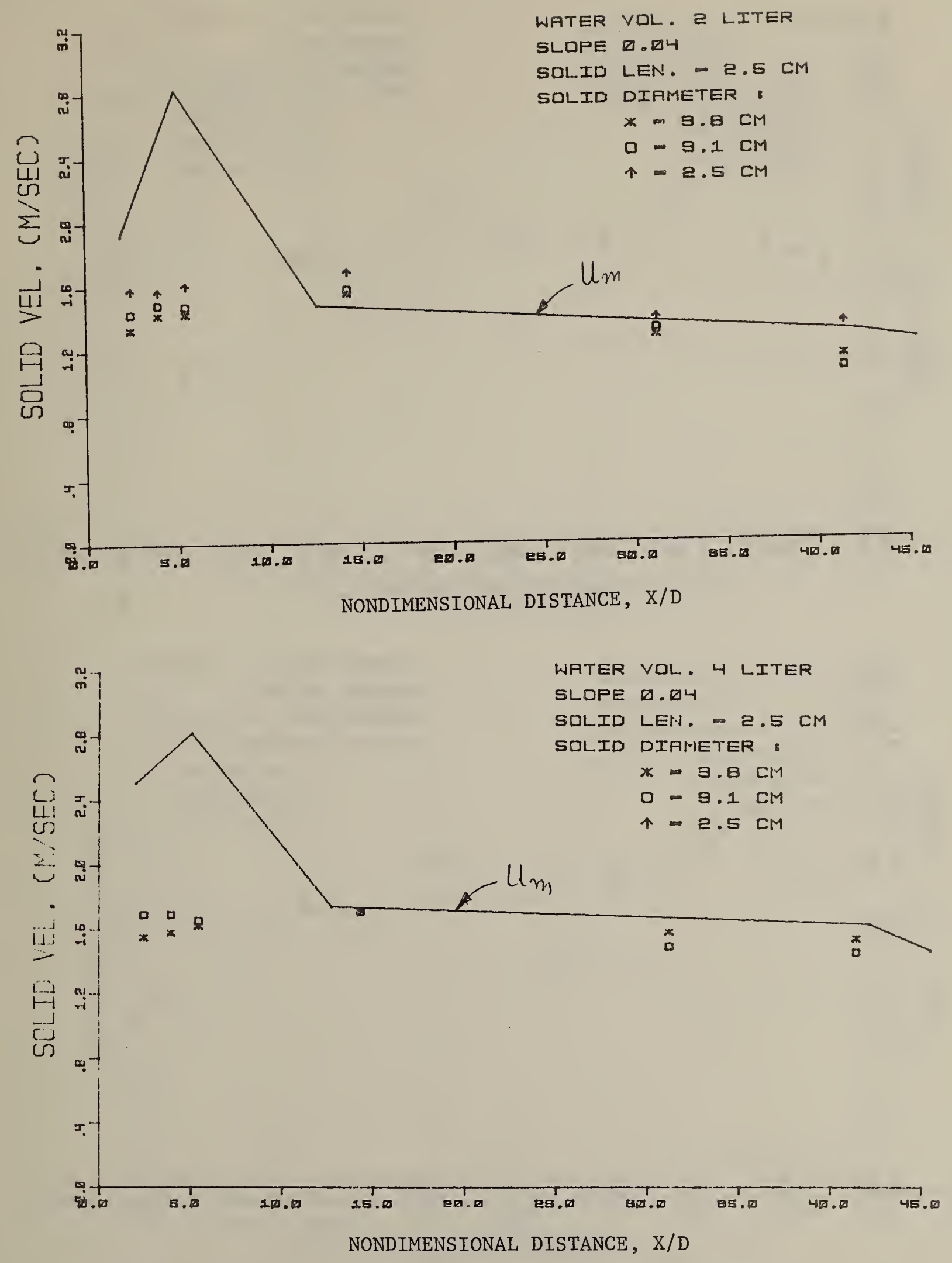

Figure 27. Solid velocity versus distance from the solid starting line for $2.5 \mathrm{~cm}$ long solids, and for $\mathrm{V}_{\mathrm{w}}=2.0$ and $4.0 \mathrm{~L}$, at a pipe slope of 0.04 

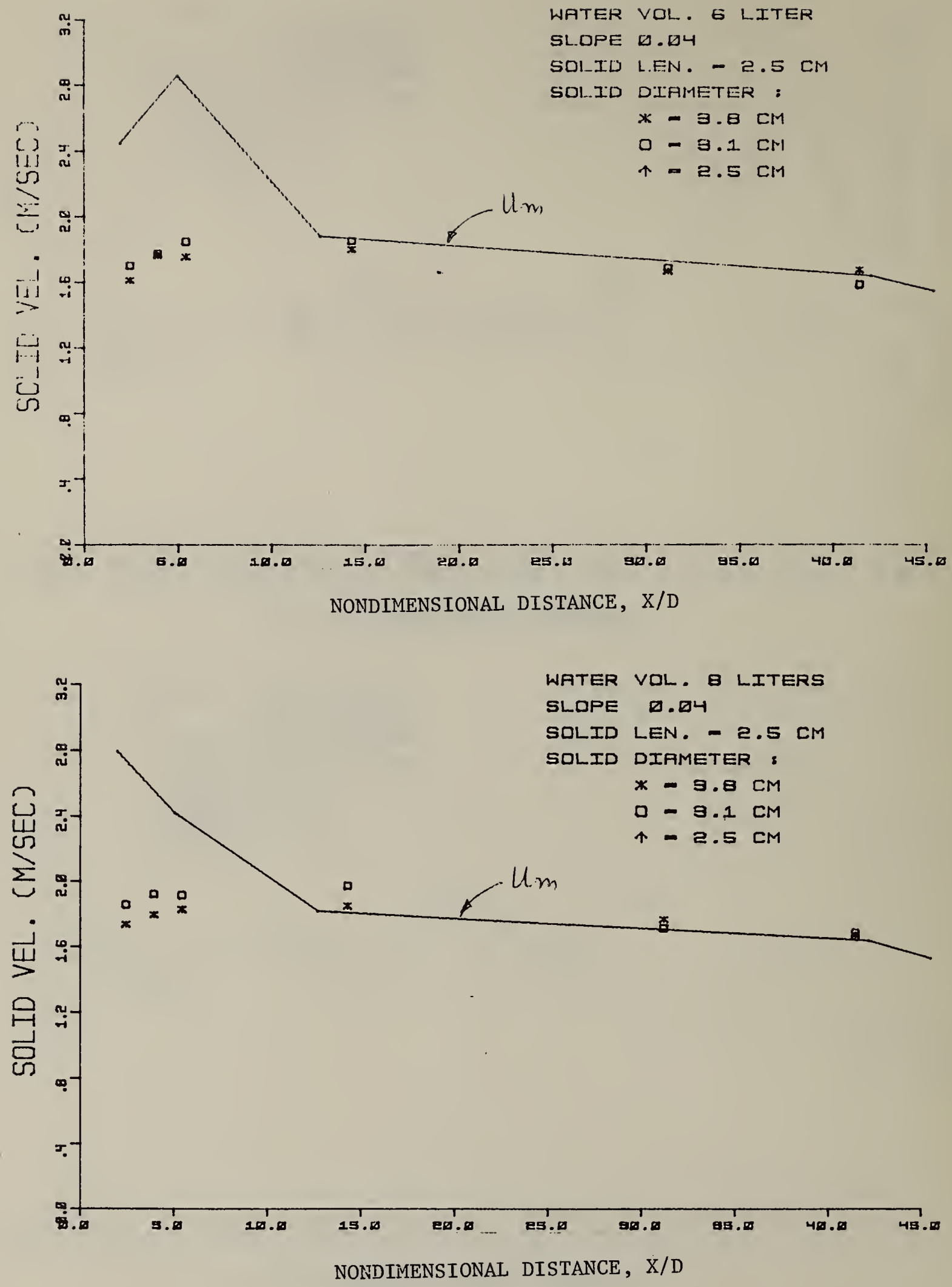

Figure 28. Solid velocity versus distance from the solid starting line for $2.5 \mathrm{~cm}$ long solids, and for $\mathrm{V}_{\mathrm{w}}=6.0$ and $8.0 \mathrm{~L}$, at a pipe slope of 0.04 

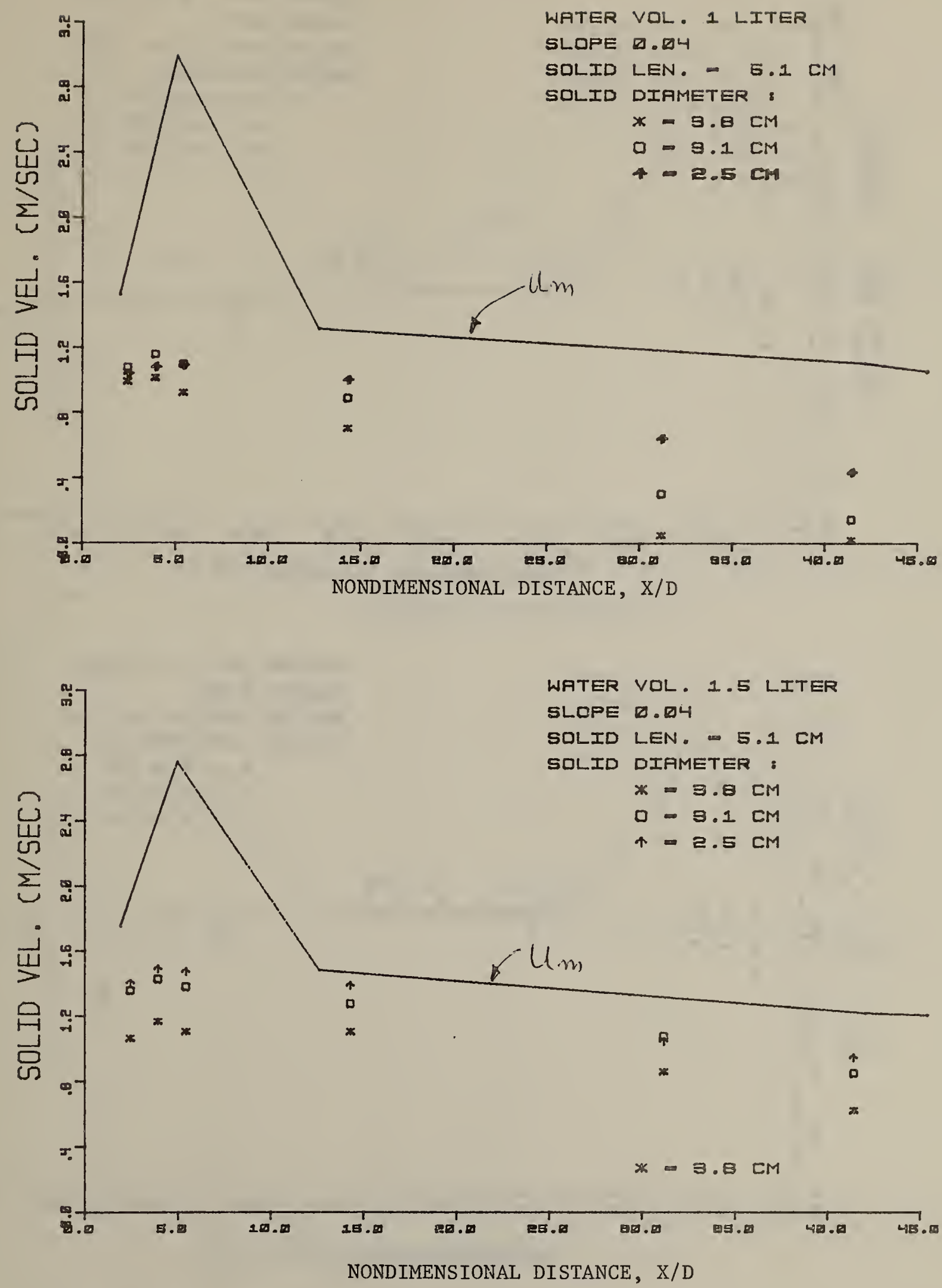

Figure 29. Solid velocity versus distance from the solid starting line for $5.1 \mathrm{~cm}$ long solid, and for $\mathrm{V}_{\mathrm{W}}=1.0$ and $1.5 \mathrm{~L}$, at a pipe 

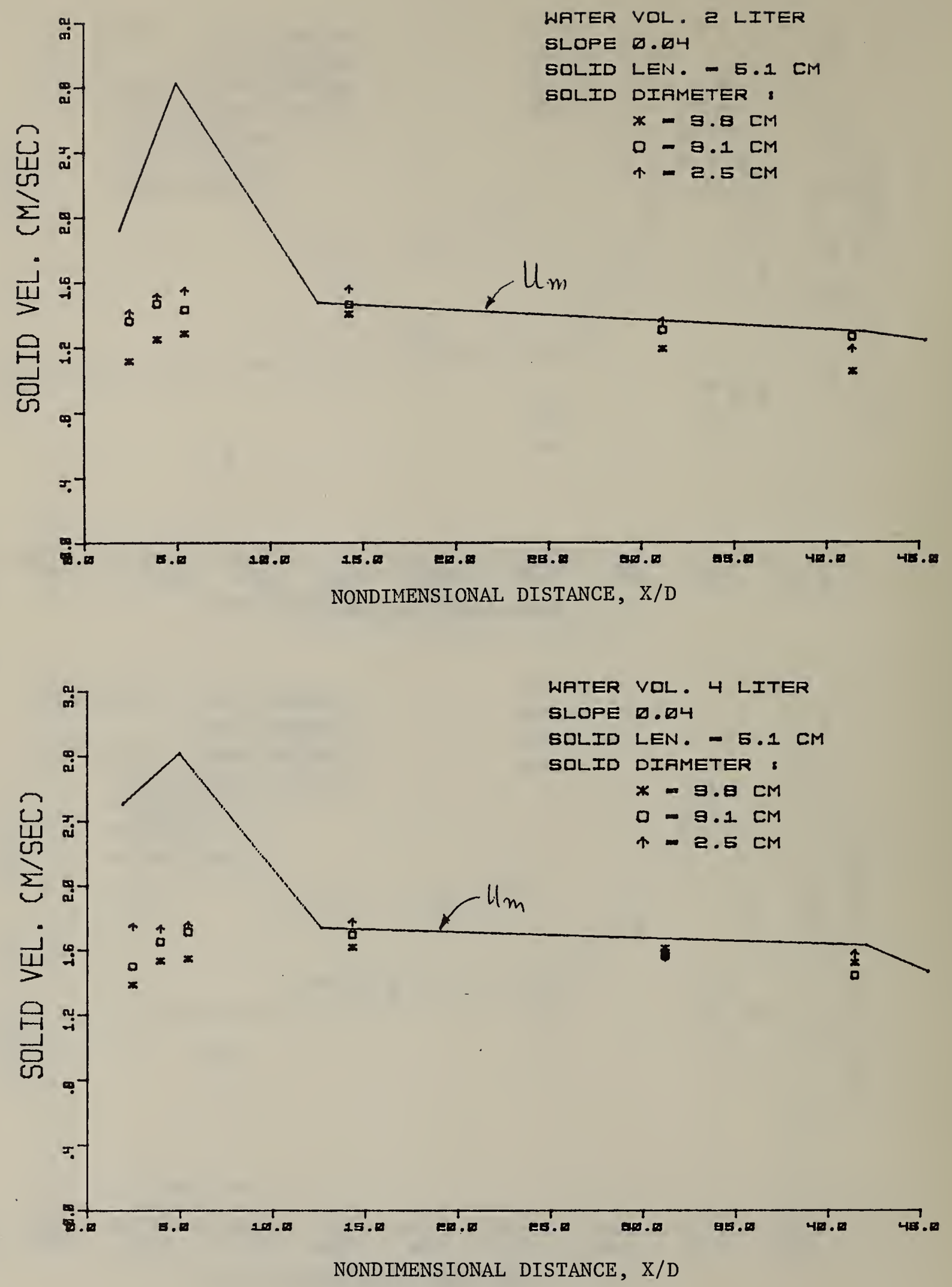

Figure 30. Solid velocity versus distance from the solid starting line for $5.1 \mathrm{~cm}$ long solid, and for $\mathrm{V}_{\mathrm{W}}=2.0$ and $4.0 \mathrm{~L}$, at a pipe slope of 0.04 


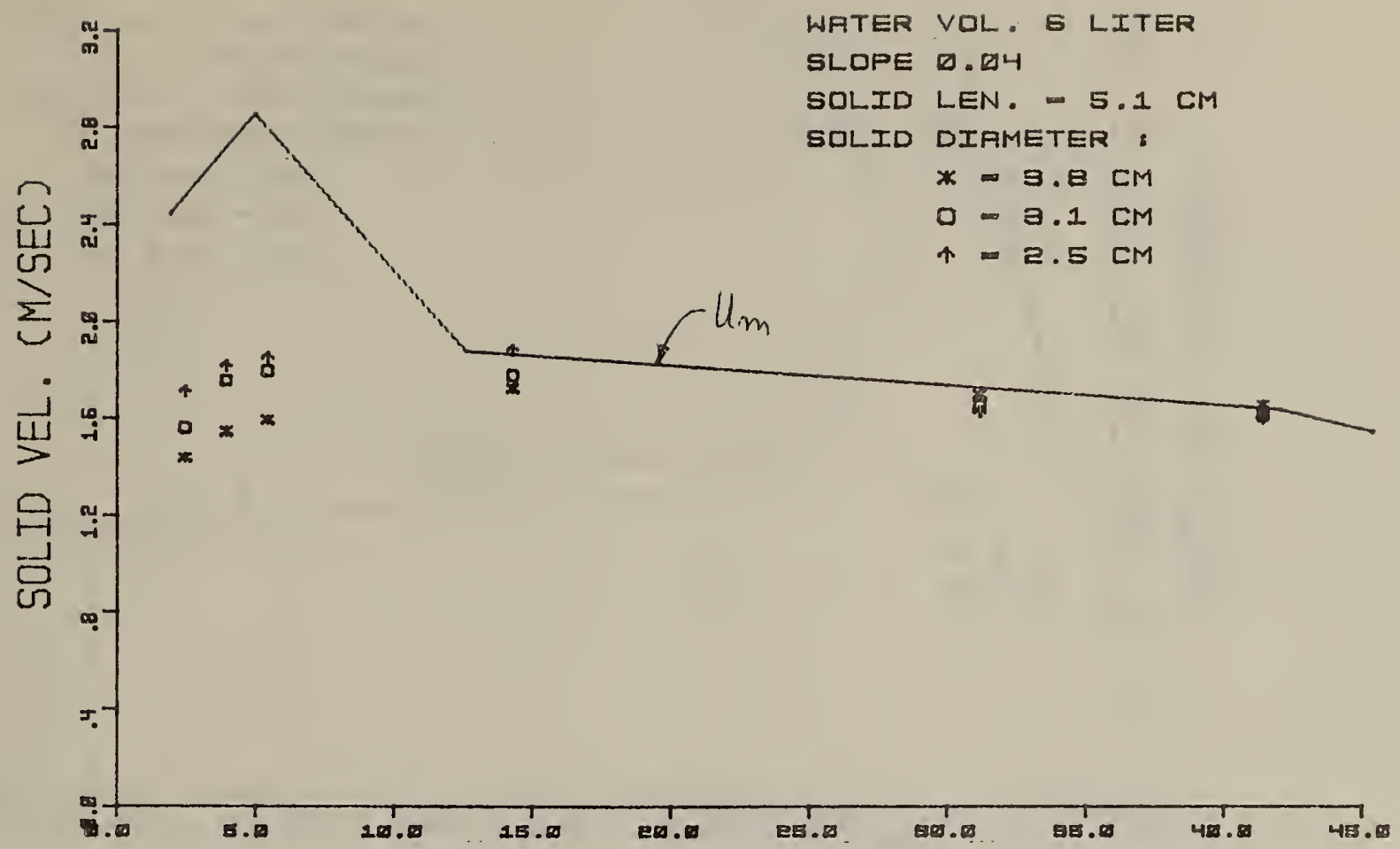

NONDIMENSIONAL DISTANCE, X/D

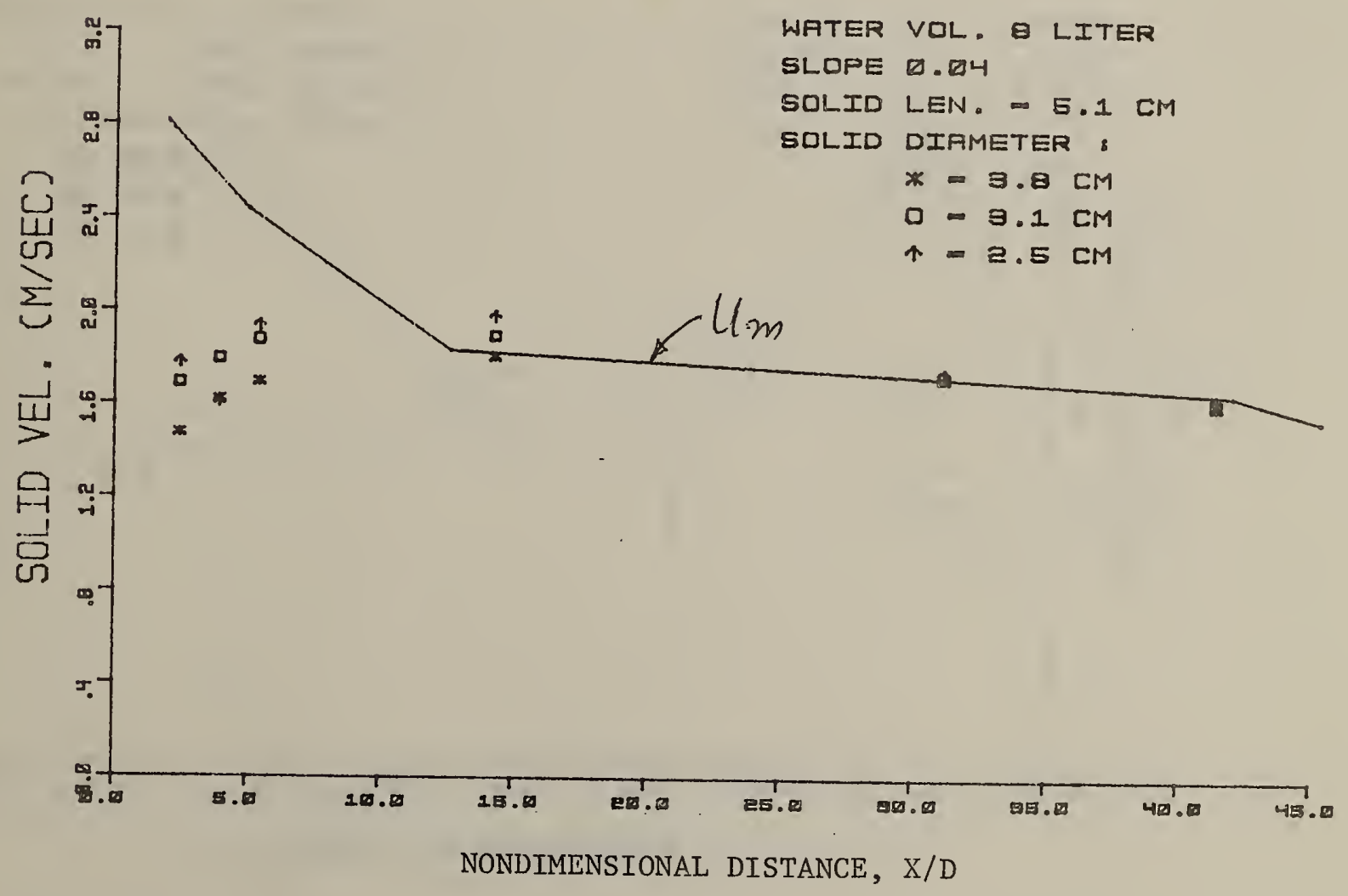

Figure 31. Solid velocity versus distance from the solid starting line for $5.1 \mathrm{~cm}$ long solid, and for $\mathrm{V}_{\mathrm{w}}=6.0$ and $8.0 \mathrm{~L}$, at a pipe slope of 0.04 

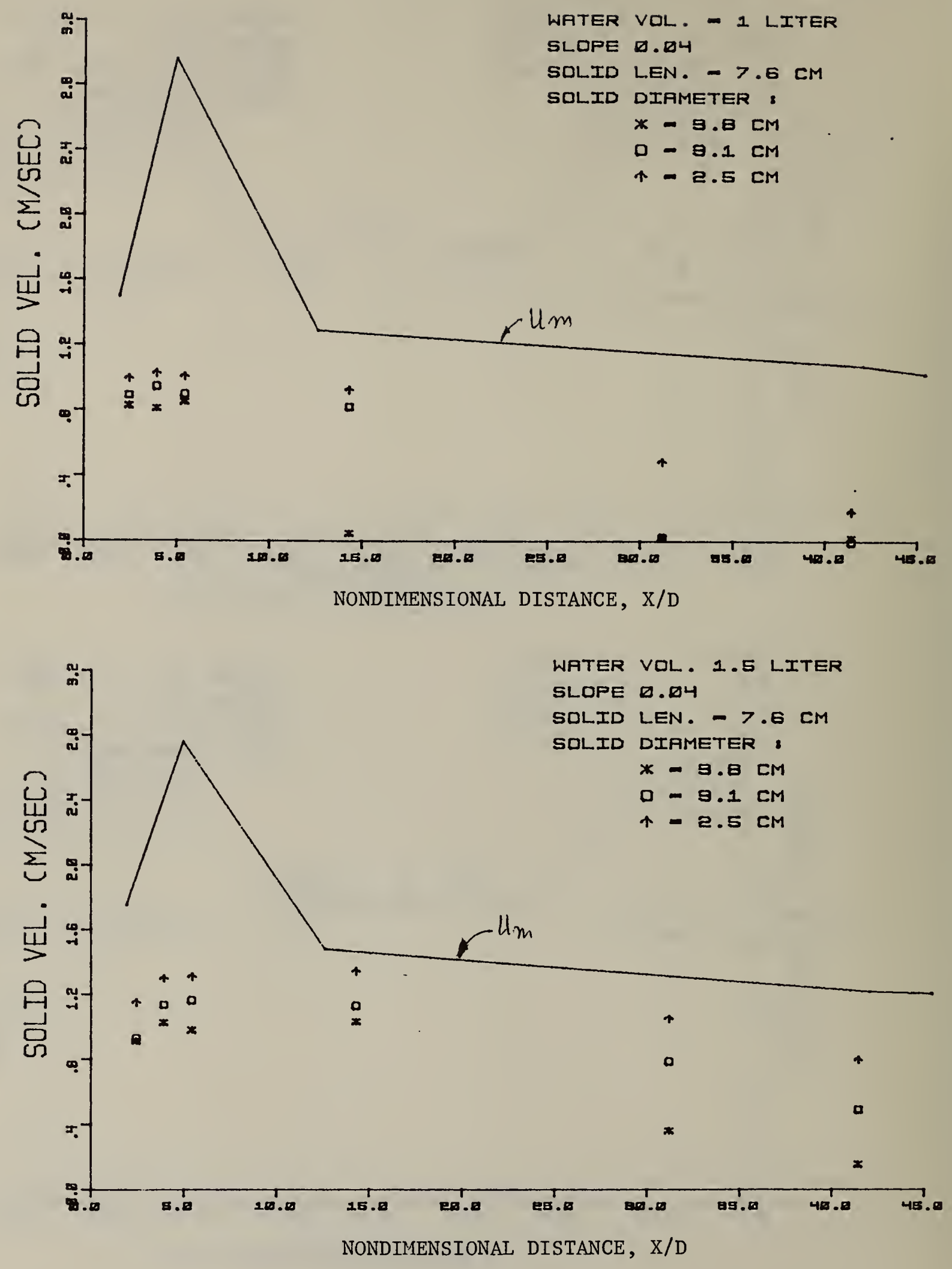

Figure 32. Solid velocity versus distance from the solid starting line for $7.6 \mathrm{~cm}$ long solids, and for $V_{W}=1.0$ and $1.5 \mathrm{~L}$, at a pipe slope of 0.04 

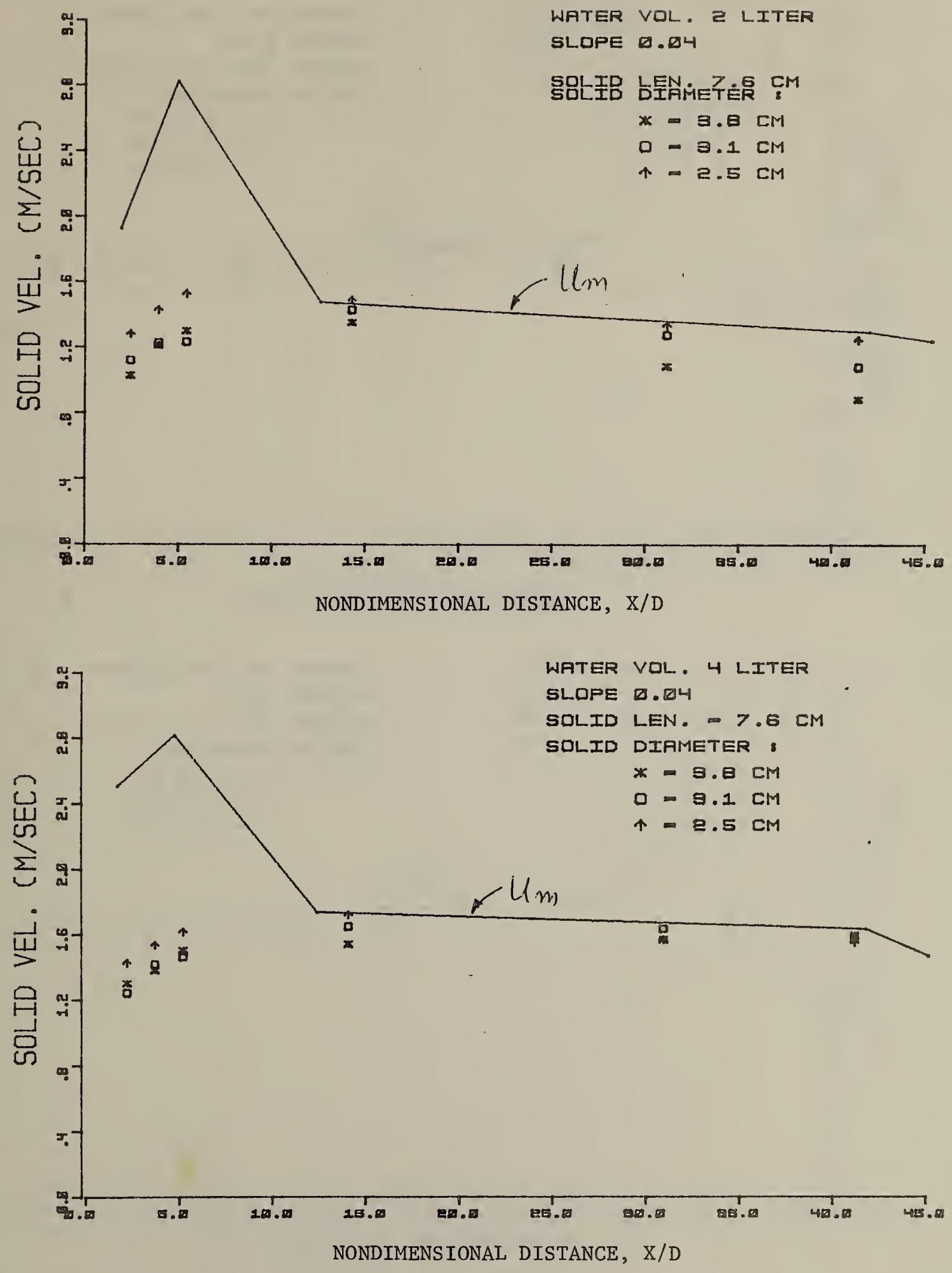

Figure 33. Solid velocity versus distance from the solid starting line for $7.6 \mathrm{~cm}$ long solids, and for $\mathrm{V}_{\mathrm{W}}=2.0$ and $4.0 \mathrm{~L}$, at a pipe slope of 0.04 


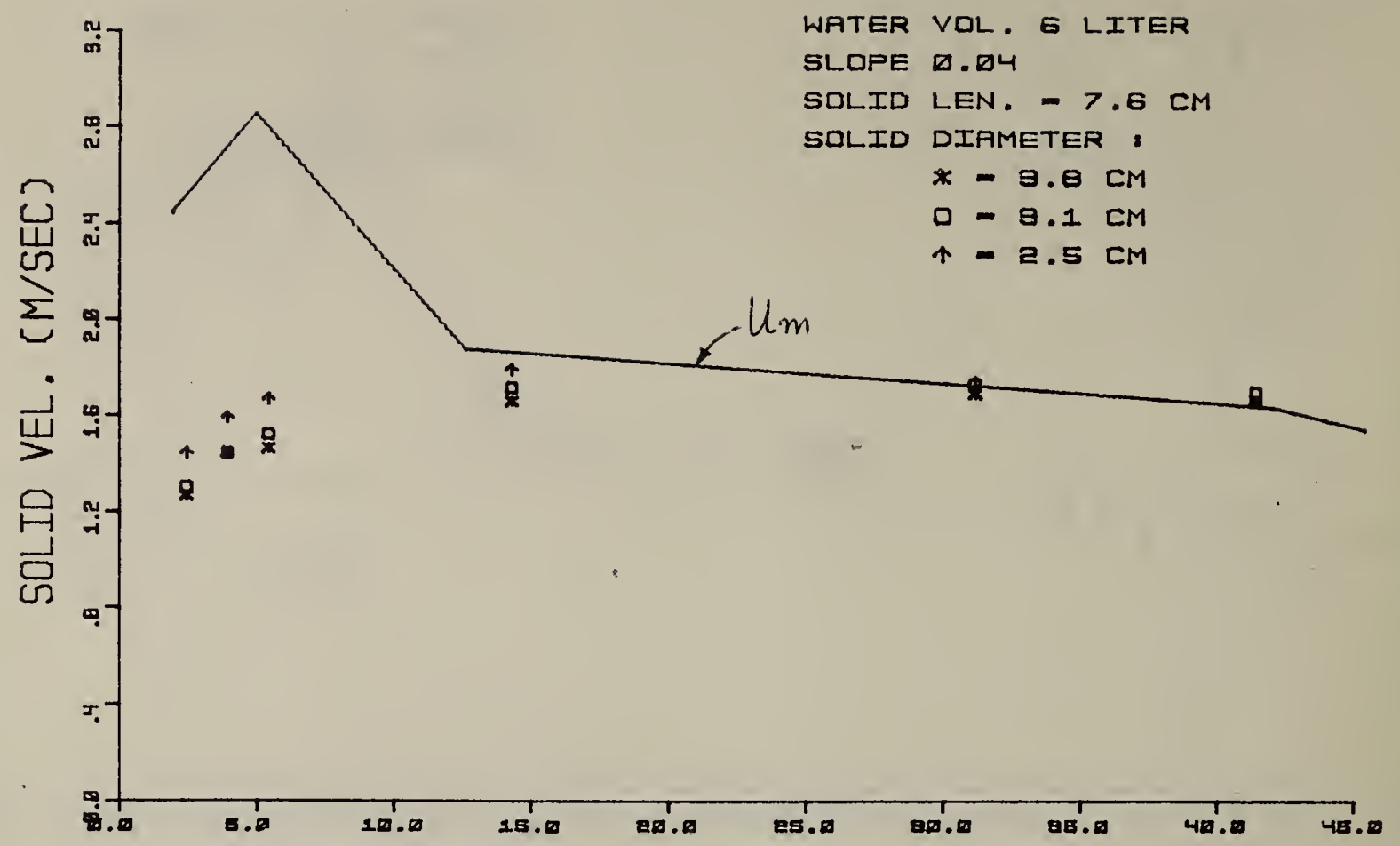

NONDIMENSIONAL DISTANCE, $\mathrm{X} / \mathrm{D}$

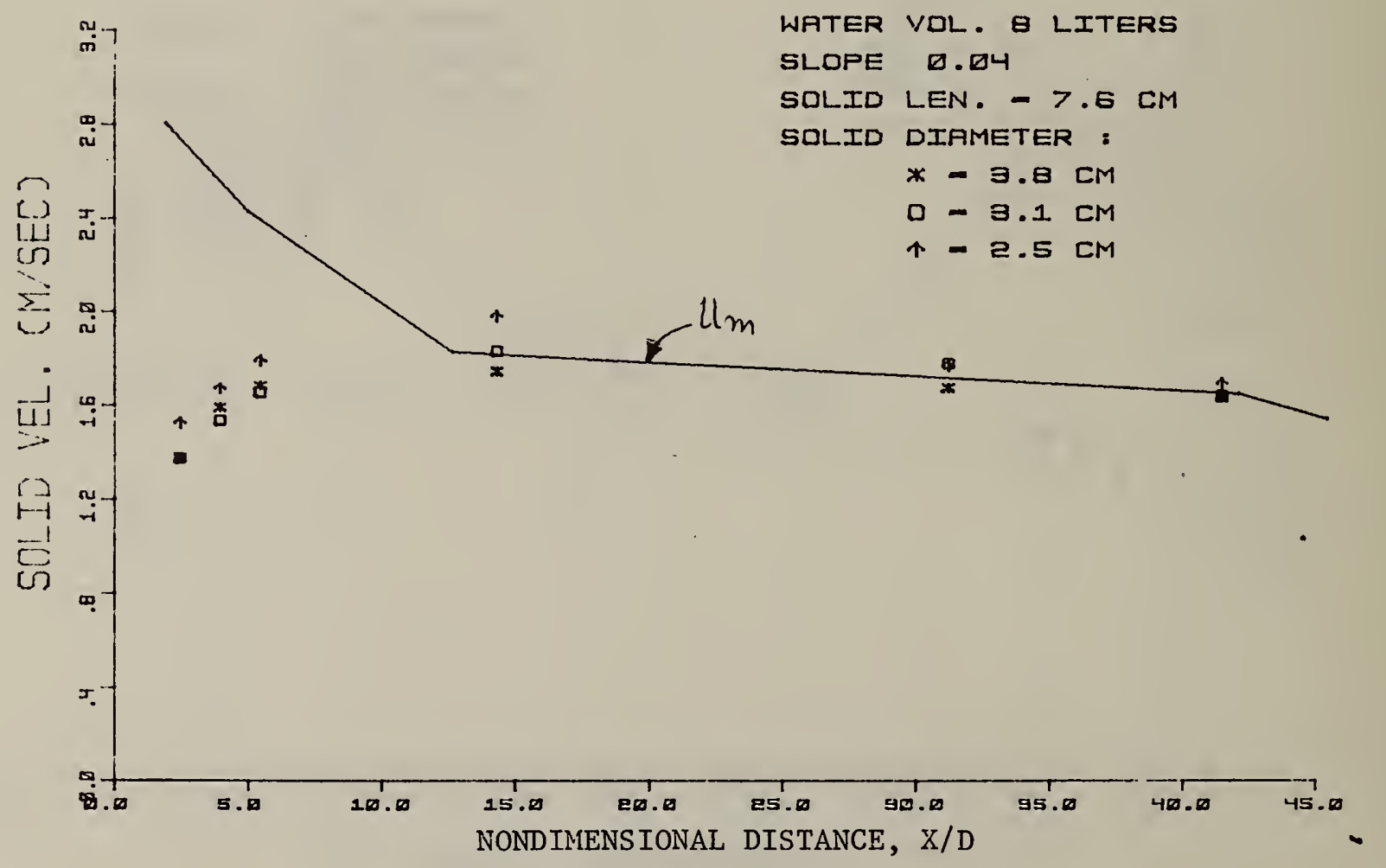

Figure 34. Solid velocity versus distance from the solid starting line for $7.6 \mathrm{~cm}$ long solids, and for $\mathrm{V}_{\mathrm{w}}=6.0$ and $8.0 \mathrm{~L}$, at a pipe slope of 0.04 

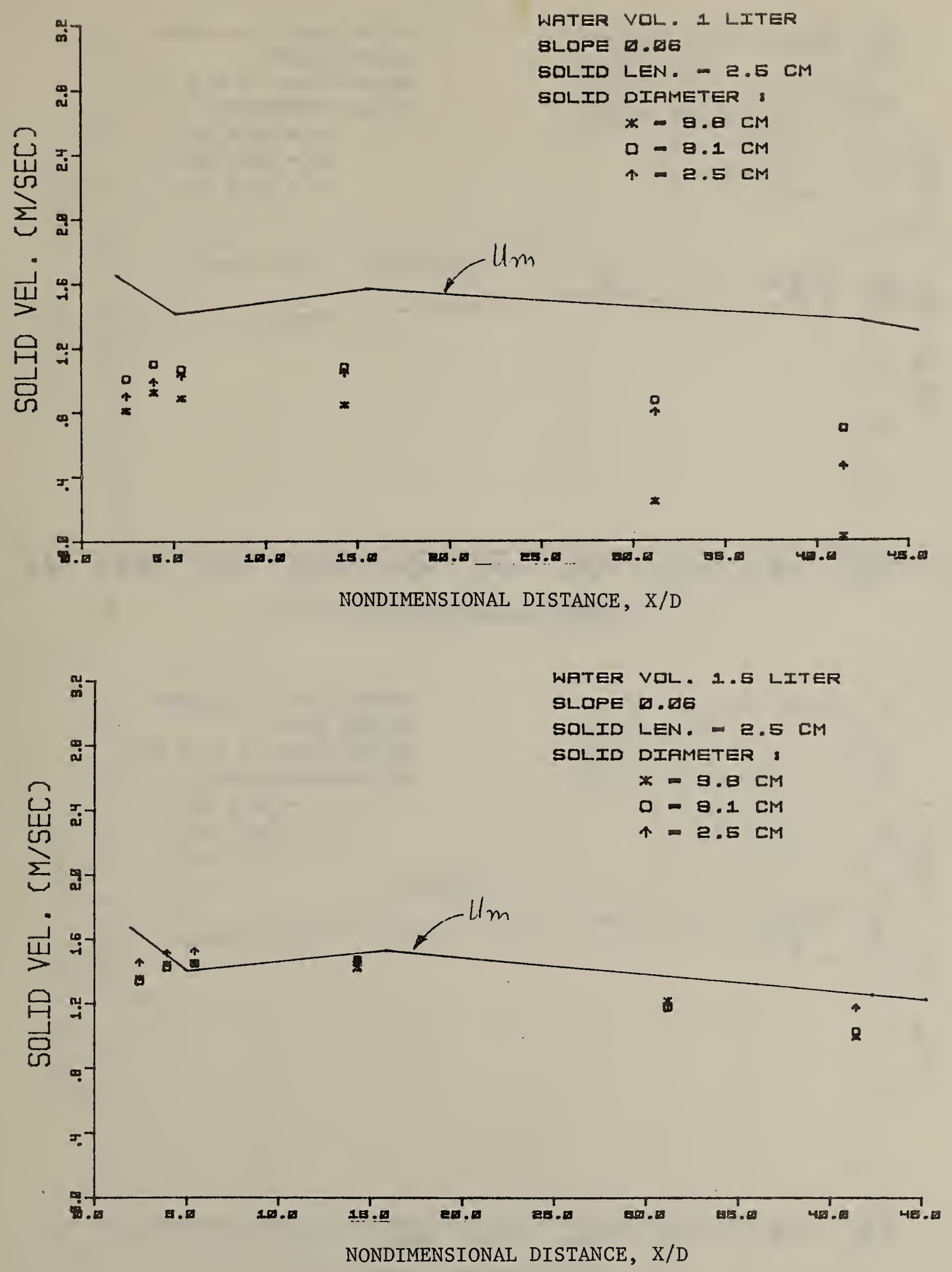

Figure 35. Solid velocity versus distance from the solid starting line for $2.5 \mathrm{~cm}$ long solids, and for $V_{W}=1.0$ and $1.5 \mathrm{~L}$, at a pipe slope of 0.06 

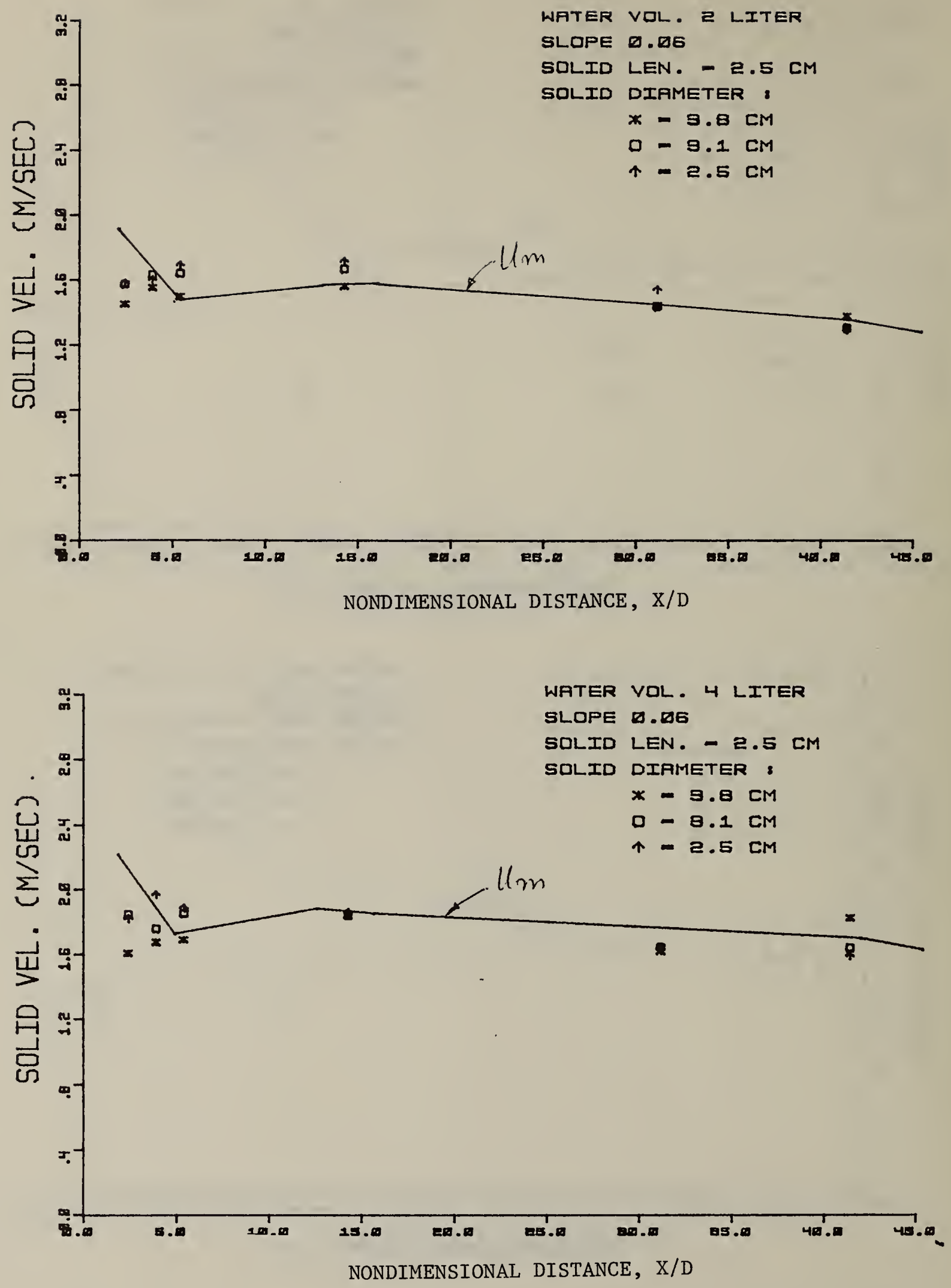

Figure 36. Solid velocity versus distance from the solid starting line for $2.5 \mathrm{~cm}$ long solids, and for $\mathrm{V}_{\mathrm{W}}=2.0$ and $4.0 \mathrm{~L}$, at a pipe slope of 0.06 

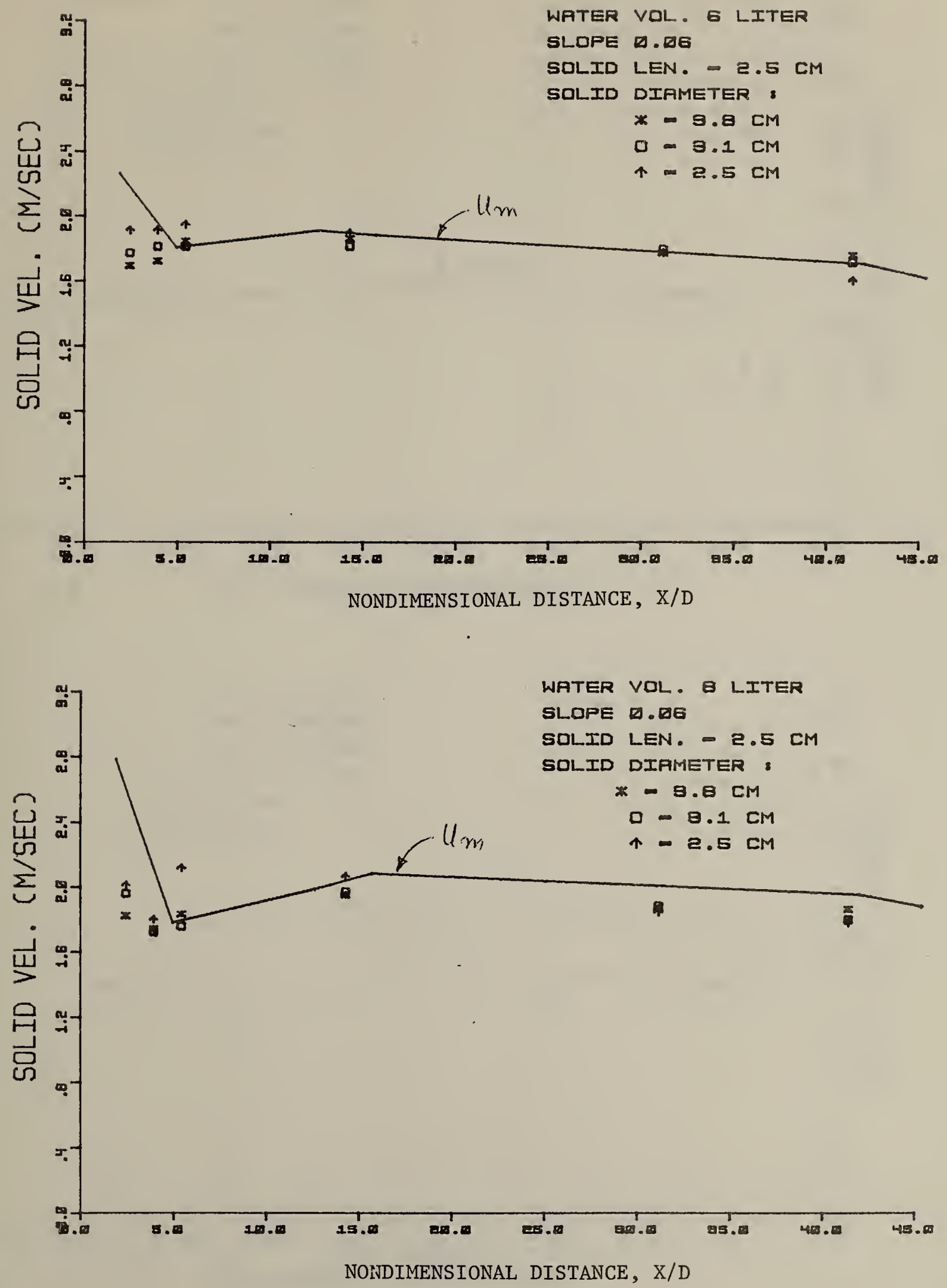

Figure 37. Solid velocity versus distance from the solid starting line for $2.5 \mathrm{~cm}$ long solids, and for $\mathrm{V}_{\mathrm{w}}=6.0$ and $8.0 \mathrm{~L}$, at a pipe slope of 0.06 

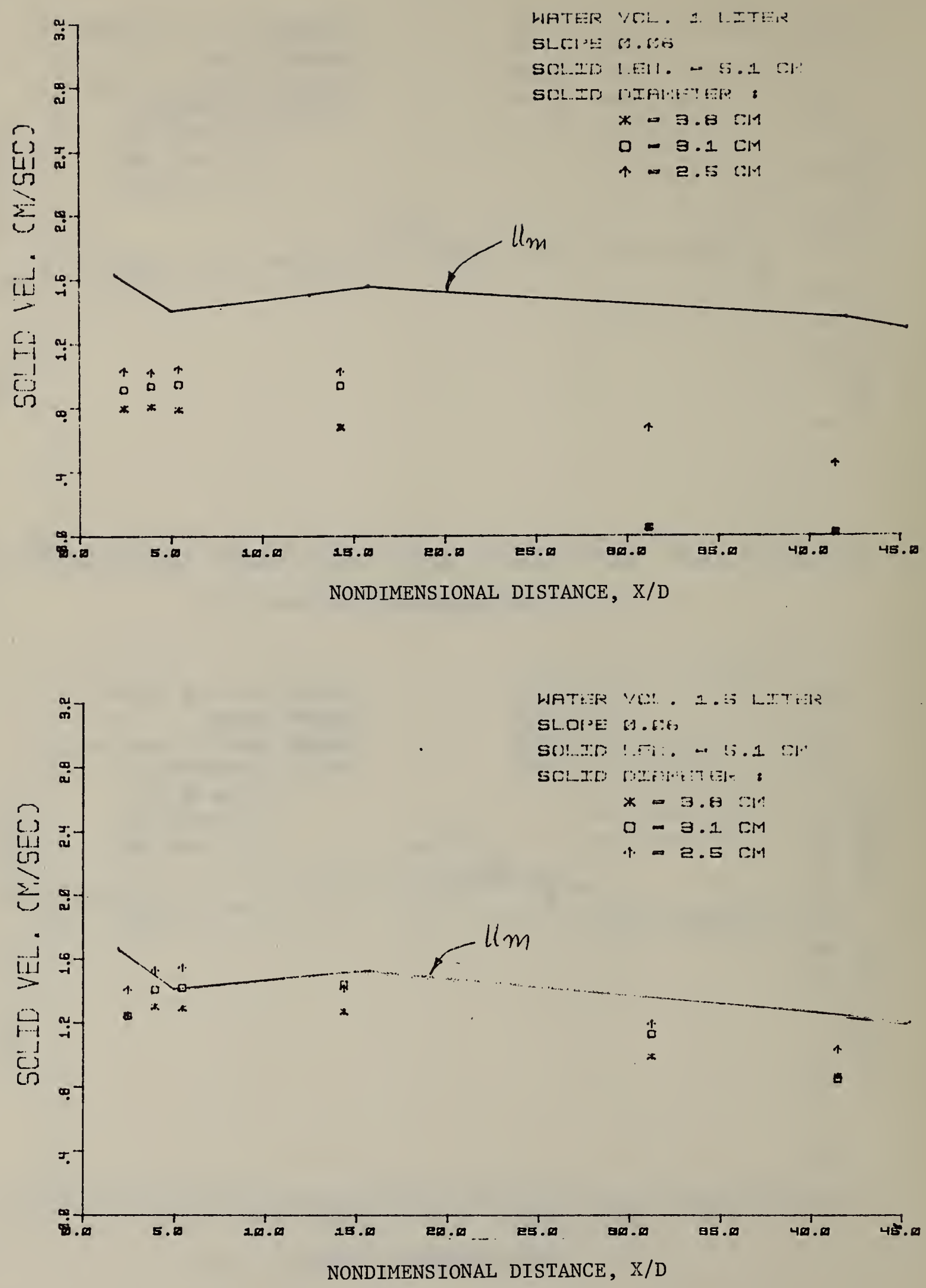

Figure 38. Solid velocity versus distance from the solid starting line for $5.1 \mathrm{~cm}$ long solid, and for $\mathrm{V}_{\mathrm{W}}=1.0$ and $1.5 \mathrm{~L}$, at a pipe slope of 0.06 

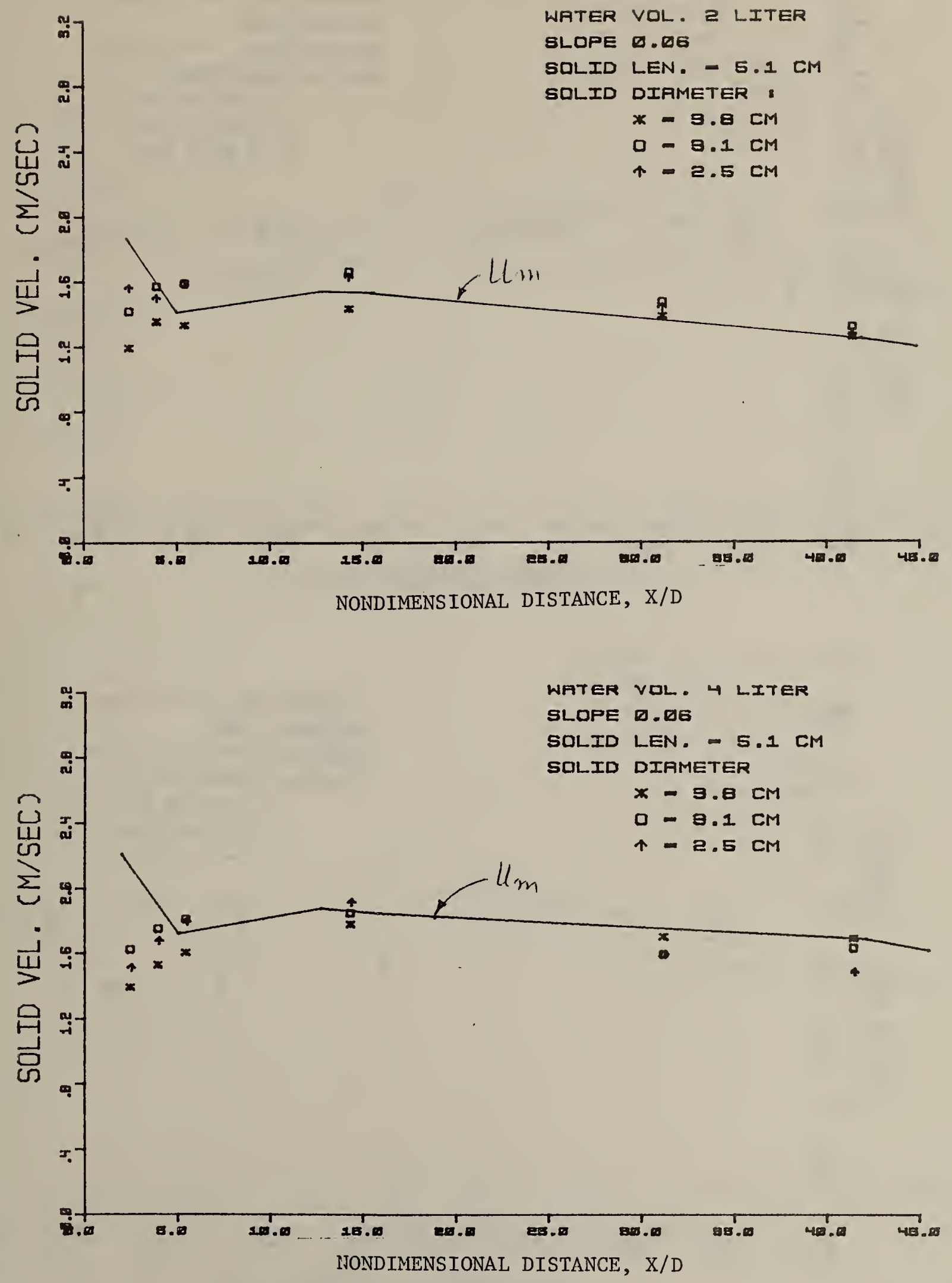

Figure 39. Solid velocity versus distance from the solid starting line for $5.1 \mathrm{~cm}$ long solid, and for $\mathrm{V}_{\mathrm{w}}=2.0$ and $4.0 \mathrm{~L}$, at a pipe slope of 0.06 

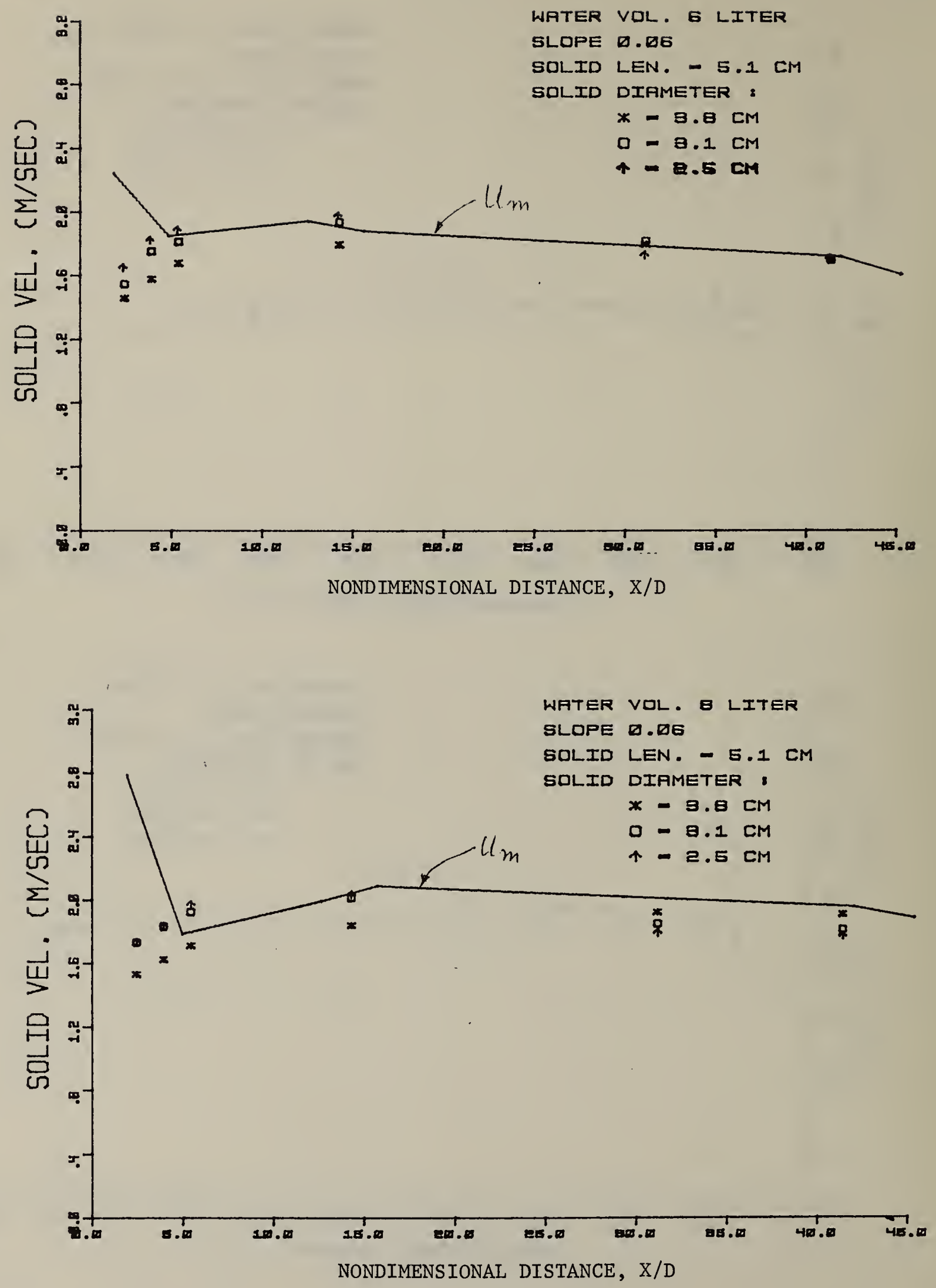

Figure 40. Solid velocity versus distance from the solid starting line for $5.1 \mathrm{~cm}$ long solid, and for $\mathrm{V}_{\mathrm{W}}=6.0$ and $8.0 \mathrm{~L}$, at a pipe slope of 0.06 

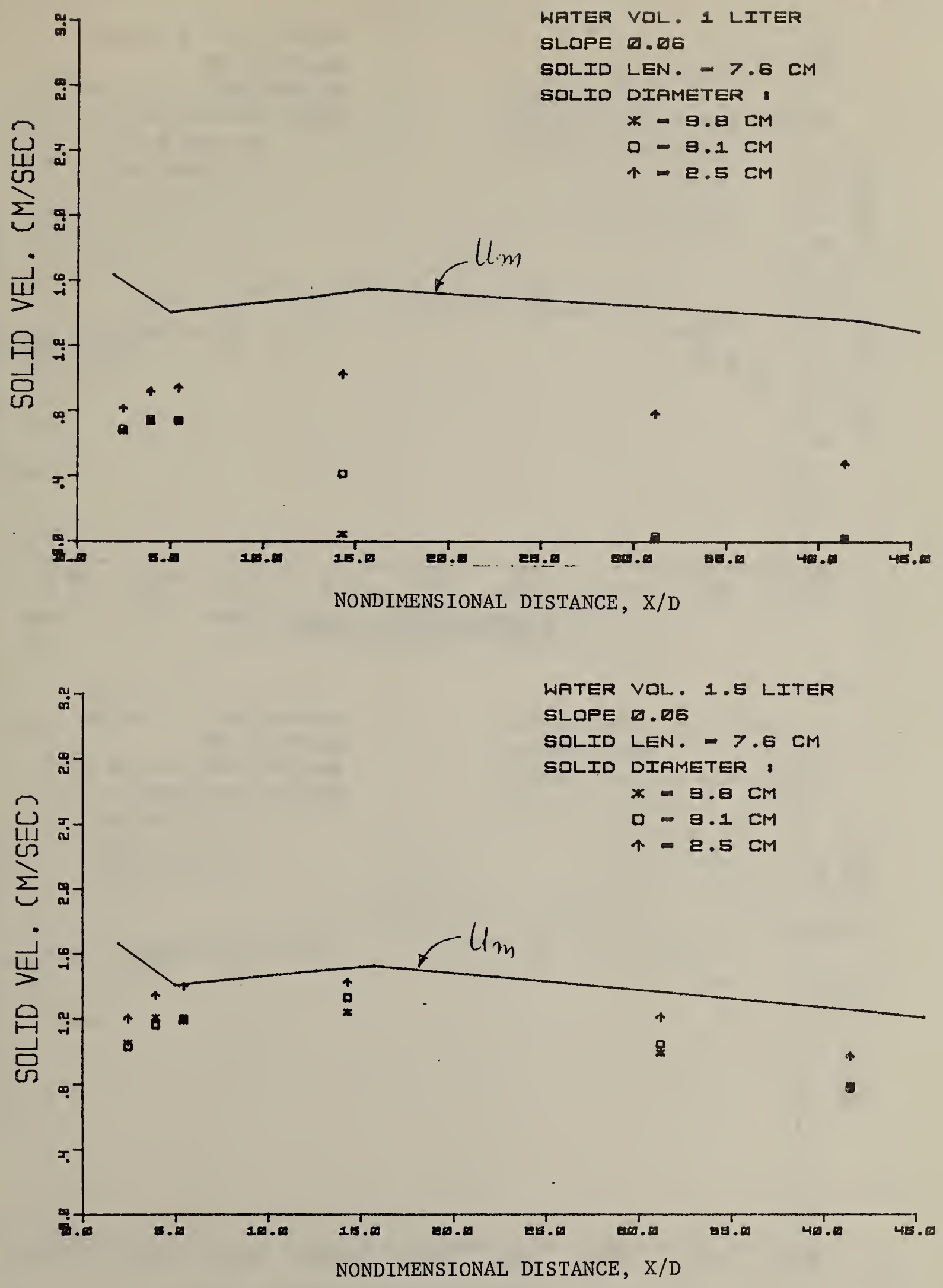

Figure 41. Soli.d velocity versus distance from the solid starting line for $7.6 \mathrm{~cm}$ long solids, and for $\mathrm{V}_{\mathrm{W}}=1.0$ and $1.5 \mathrm{~L}$, at a pipe : slope of 0.06 

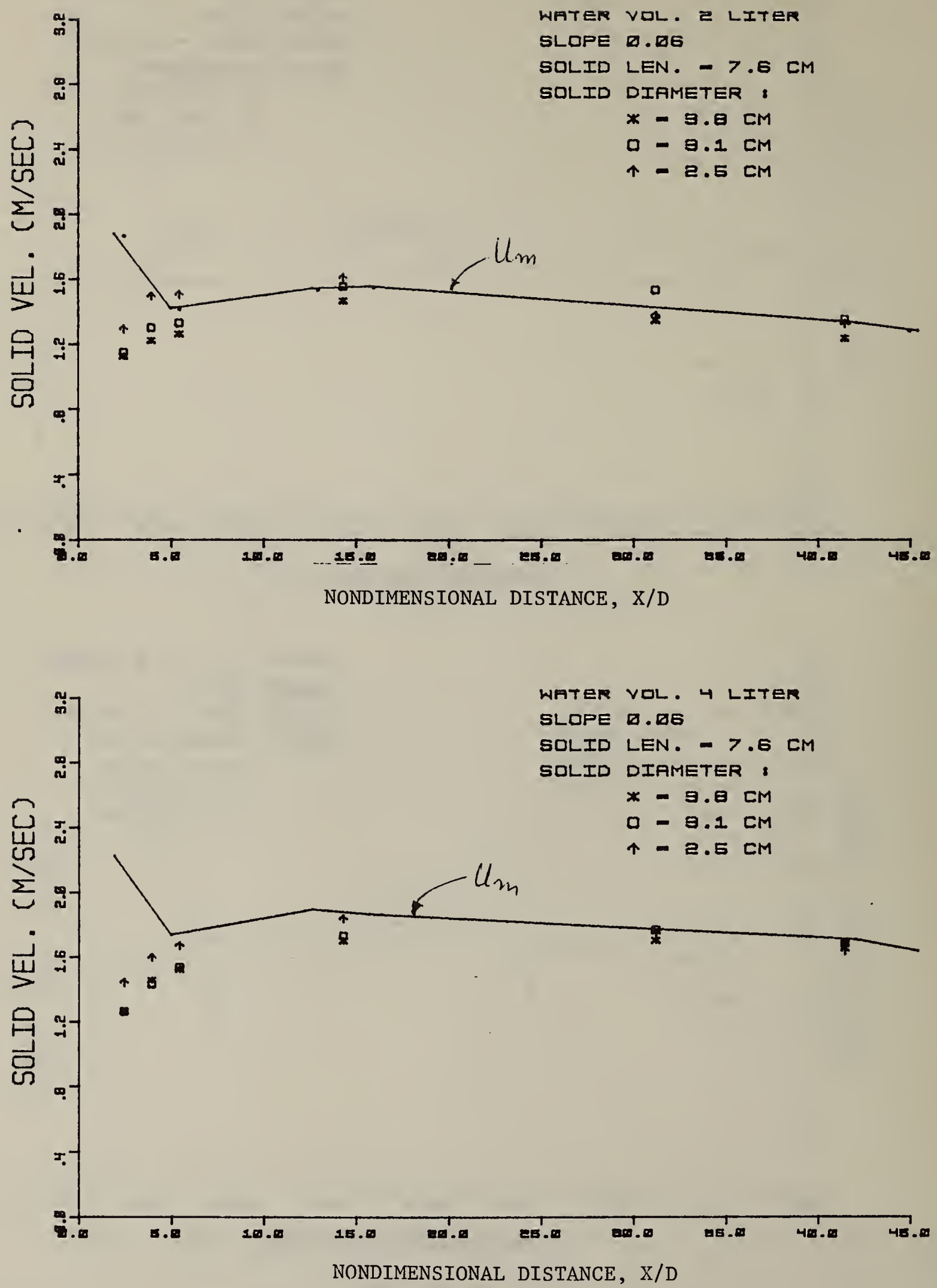

Figure 42. Solid velocity versus distance from the solid starting line for $7.6 \mathrm{~cm}$ long solids, and for $\mathrm{V}_{\mathrm{w}}=2.0$ and $4.0 \mathrm{~L}$, at a pipe slope of 0.06 

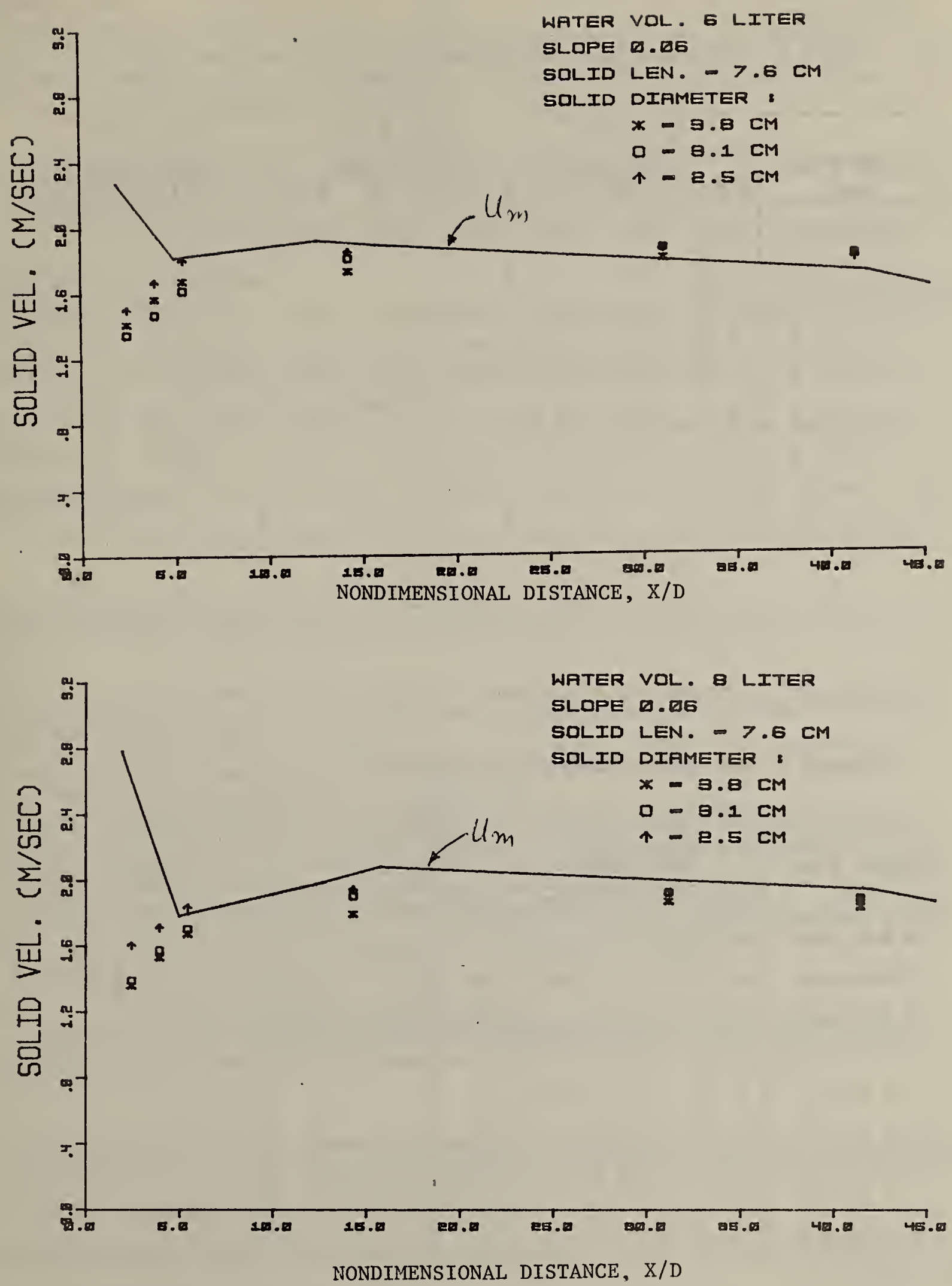

Figure 43. Solid velocity versus distance from the solid starting line for $7.6 \mathrm{~cm}$ long solids, and for $\mathrm{V}_{\mathrm{W}}=6.0$ and $8.0 \mathrm{~L}$, at a pipe slope of 0.06 
Table 1. Distance traversed by solids in $10.0 \mathrm{~cm}$ pipe (m)

\begin{tabular}{|c|c|c|c|c|c|c|c|c|c|}
\hline \multirow{3}{*}{$\begin{array}{l}\text { Solid Size } \\
(\mathrm{cm})\end{array}$} & \multicolumn{3}{|c|}{$\mathrm{V}_{\mathrm{w}}=1.0 \mathrm{~L}$} & \multicolumn{3}{|c|}{$\mathrm{V}_{\mathrm{w}}=1.5 \mathrm{~L}$} & \multicolumn{3}{|c|}{$\mathrm{V}_{\mathrm{W}}=2.0 \mathrm{~L}$} \\
\hline & \multicolumn{3}{|c|}{ Pipe Slope } & \multicolumn{3}{|c|}{ Pipe Slope } & \multicolumn{3}{|c|}{ Pipe Slope } \\
\hline & 0.02 & 0.04 & 0.06 & 0.02 & 0.04 & 0.06 & 0.02 & 0.04 & 0.06 \\
\hline 3.8 by 7.6 & 0.5 & 2.1 & 1.5 & $n^{1}$ & 4.0 & 3.6 & 3.0 & $c^{2}$ & c \\
\hline 3.8 by 5.1 & 1.2 & 3.0 & 3.0 & $\mathrm{n}$ & c & c & 4.2 & c & c \\
\hline 3.8 by 2.5 & 2.2 & 4.4 & 3.9 & $\mathrm{n}$ & c & c & c & c & c \\
\hline 3.1 by 7.6 & 1.2 & 3.3 & 3.1 & $\mathbf{n}$ & c & c & 4.2 & c & c \\
\hline 3.1 by 5.1 & 1.8 & 4.2 & 4.8 & $\mathrm{n}$ & c & c & c & c & c \\
\hline 3.1 by 2.5 & 2.2 & 4.6 & 4.0 & $\mathrm{n}$ & c & $c$ & c & c & c \\
\hline 2.5 by 7.6 & 1.8 & 4.2 & c & c & c & c & c & c & c \\
\hline 2.5 by 5.1 & 2.7 & c & c & c & c & c & c & c & c \\
\hline 2.5 by 2.5 & 2.7 & c & c & c & c & c & c & c & c \\
\hline
\end{tabular}

Table 2. Distance traversed by solids in $7.6 \mathrm{~cm}$ pipe

\begin{tabular}{|c|c|c|c|c|c|c|c|c|c|c|}
\hline \multirow{2}{*}{$\begin{array}{c}\text { Solid Size } \\
(\mathrm{cm})\end{array}$} & \multicolumn{3}{|c}{$\mathrm{V}_{\mathrm{w}}=1.15 \mathrm{~L}$} & \multicolumn{3}{c|}{$\mathrm{V}_{\mathrm{w}}=1.5 \mathrm{~L}$} & \multicolumn{3}{c|}{$\mathrm{V}_{\mathrm{w}}=1.9 \mathrm{~L}$} \\
\cline { 2 - 12 } & \multicolumn{3}{|c|}{ Pipe Slope } & \multicolumn{3}{c|}{ Pipe S1ope } & \multicolumn{4}{c|}{ Pipe S1ope } \\
\hline 3.8 by 7.6 & $\mathrm{n}$ & 2.1 & 4.4 & $\mathrm{n}$ & 4.6 & $\mathrm{c}$ & $\mathrm{c}$ & $\mathrm{c}$ & $\mathrm{c}$ \\
3.8 by 5.1 & $\mathrm{n}$ & 2.7 & 4.2 & $\mathrm{n}$ & $\mathrm{c}$ & $\mathrm{c}$ & $\mathrm{c}$ & $\mathrm{c}$ & $\mathrm{c}$ \\
3.8 by 2.5 & $\mathrm{n}$ & 4.8 & $\mathrm{c}$ & $\mathrm{n}$ & $\mathrm{c}$ & $\mathrm{c}$ & & & \\
\hline 3.1 by 7.6 & $\mathrm{n}$ & 2.1 & $\mathrm{c}$ & $\mathrm{n}$ & 4.5 & $\mathrm{c}$ & $\mathrm{c}$ & $\mathrm{c}$ & $\mathrm{c}$ \\
3.1 by 5.1 & $\mathrm{n}$ & 4.0 & 5.0 & $\mathrm{n}$ & $\mathrm{c}$ & $\mathrm{c}$ & $\mathrm{c}$ & $\mathrm{c}$ & $\mathrm{c}$ \\
3.1 by 2.5 & $\mathrm{n}$ & 4.8 & $\mathrm{c}$ & $\mathrm{n}$ & $\mathrm{c}$ & $\mathrm{c}$ & & & \\
\hline 2.5 by 7.6 & $\mathrm{n}$ & 3.3 & $\mathrm{c}$ & $\mathrm{n}$ & $\mathrm{c}$ & $\mathrm{c}$ & $\mathrm{c}$ & $\mathrm{c}$ & $\mathrm{c}$ \\
2.5 by 5.1 & $\mathrm{n}$ & $\mathrm{c}$ & $\mathrm{c}$ & $\mathrm{n}$ & $\mathrm{c}$ & $\mathrm{c}$ & $\mathrm{c}$ & $\mathrm{c}$ & $\mathrm{c}$ \\
2.5 by 2.5 & $\mathrm{n}$ & $\mathrm{c}$ & $\mathrm{c}$ & $\mathrm{n}$ & $\mathrm{c}$ & $\mathrm{c}$ & & & \\
\hline
\end{tabular}

1. n refers to no data

2. c refers to clear the pipe 
U.S. DEPT. OF COMM.

BIBLIOGRAPHIC DATA

SHEET (See instructions)

4. TITLE AND SUBTITLE
1. PUBLICATION OR REPORT NO. NBSIR $81-2450$
2. Performing Organ. Report No.

1
- Publication Date

Jaruary 1982

EXPERIMENTAL INVESTIGATION OF TRANSPORT OF DISCRETE SOLIDS WITH SURGE FLOWS IN

A 10.0 CM DIAMETER PARTIALLY FILLED PIPE

5. $\operatorname{AUTHOR}(S)$

Bal M. Mahajan

6. PERFORMING ORGANIZATION (If joint or other than NBS, see in structions)

NATIONAL BUREAU OF STANDARDS

DEPARTMENT OF COMMERCE

WASHINGTON, D.C. 20234

7. Contract/Grant No. $\mathrm{H}-48-78$

8. Type of Report \& Period Covered

9. SPCNSORING ORGANIZATION NAME AND COMPLETE ADDRESS (Street, City, Stote, ZIP)

Dept. of Housing and Urban Development

4517 th Street, SW

Washington, DC 20410

10. SUPPLEMENTARY NOTES

[Document describes a computer program; SF-185, FIPS Software Summary, is attached.

11. ABSTRACT (A 200-word or less factual summary of most significant information. If document includes a significant bibliography or literature survey. mention it here)

This report presents the results of a series of experiments on the transport of discrete solids with surge flows in a partially filled slightly pitched horizontal pipe. The experimental apparatus, instrumentation, and procedures are described.

The experiments were conducted using a cylindrical solid in a 10.0-cm (4-in) diameter pipe. The water surge flows were obtained by discharging different volumes of water into the pipe from a falling head open container which simulated a water closet.

For each experiment, flow induced solid velocities and stream depth histories at various locations along the length of the pipe were measured. The effects of water volume used, pipe slope, and size of the solid on the solid velocities were examined. Solid velocities were compared with the maximum water velocities estimated from the stream depth histories. Also, the distance traversed by the solids in the pipe were measured for those cases in which the solids did not clear the pipe.

The solid velocity increased with an increase in water volume used, a decrease in the size of the solid, and an increase in the pipe slope. The solid velocity in the initial reach of the pipe was less than the maximum water velocity; and the solid velocity approaches the maximum water velocity as the solid traveled downstream, except for some experiments with small water volumes.

The distance traversed by the solid increased with an increase in water volume, a decrease in the size of the solid, and an increase in the pipe slope.

The available data are too few to indicate any definitive conclusion; however, a comparison of data on solid transport in $7.6-\mathrm{cm}$ (reported in a prior publication) and $10.0-\mathrm{cm}$ pipe suggests that the 7.6-cm pipe may be slightly better for transport of solids with small water volumes than the 10.0-cm pipe.

12. KEY WORDS (Six to twelve entries; alphabetical order; capitalize only proper names; and separate key words by semicolons) equation; flow; horizontal; motion; partially-filled pipe; slope; solid; stream-depth; surge; transport; velocity; water

\section{AVAILABILITY}

区] Unlimited

For Official Distribution. Do Not Release to NTIS

Order From Superintendent of Documents, U.S. Government Printing Office, Washington, D.C. 20402.

区] Order From National Technical Information Service (NTIS), Springfield, VA. 2216I

14. NO. OF PRINTED PAGES

51

15. Price 


